
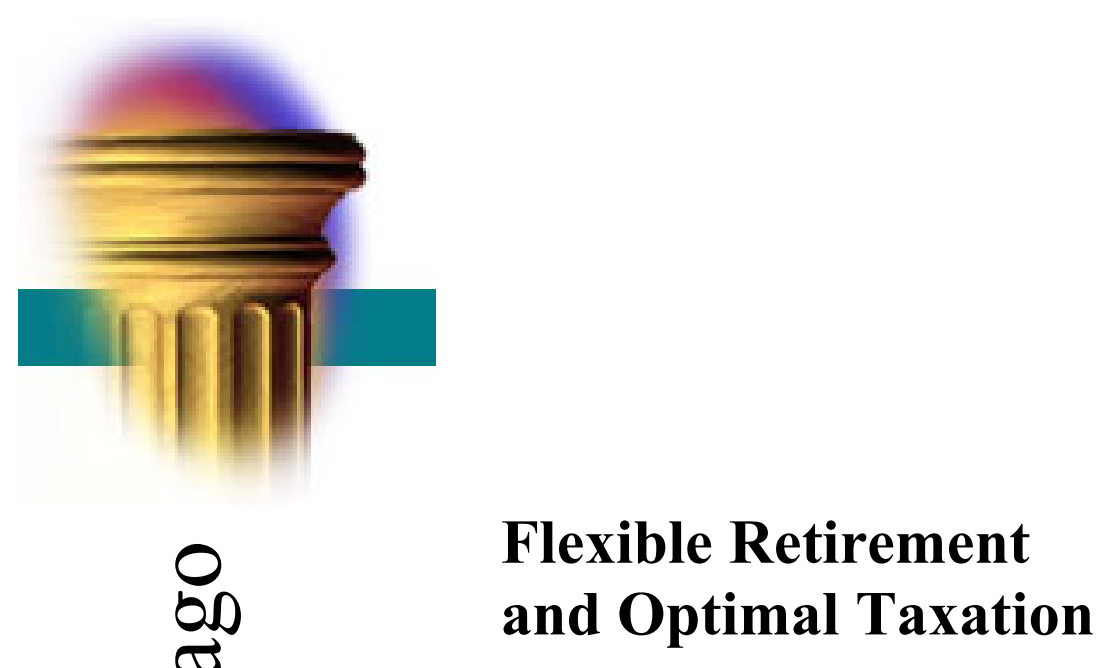

Abdoulaye Ndiaye

November 5, 2018

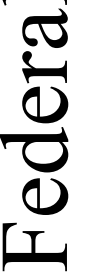

\author{
WP 2018-18 \\ https://doi.org/10.21033/wp-2018-18 \\ ${ }^{*}$ Working papers are not edited, and all opinions and errors are the \\ responsibility of the author(s). The views expressed do not necessarily \\ reflect the views of the Federal Reserve Bank of Chicago or the Federal \\ Reserve System.
}




\title{
Flexible Retirement and Optimal Taxation
}

\author{
Abdoulaye Ndiaye* \\ This version: November 5, 2018
}

First version: November 3, 2017

\begin{abstract}
This paper studies optimal insurance against private idiosyncratic shocks in a life-cycle model with intensive labor supply and endogenous retirement. In this environment, the optimal labor tax is hump-shaped in age: insurance benefits of taxation push for increasing-in-age taxes while rising labor supply elasticities and optimal late retirement of highly productive workers push for lowering taxes for old workers. In calibrated numerical simulations, the optimum achieves sizable welfare gains that age-dependent taxes do not deliver under the status quo U.S. Social Security. Nevertheless, an optimal combination of age-dependent linear taxes with increasing-in-age retirement benefits generates welfare gains close to optimal.
\end{abstract}

JEL classification: H21, H55, J26

Keywords: Retirement, Optimal Taxation, Social Security, ContinuousTime, Optimal Stopping

${ }^{*}$ NYU Stern and Chicago Fed. email: laaye.ndiaye@gmail.com. I am grateful to Guido Lorenzoni, Alessandro Pavan, Larry Christiano and Mariacristina de Nardi for their invaluable advice and guidance. I would like to thank Gadi Barlevy, Marco Bassetto, Gideon Bornstein, Gaby Cugat, Richard De Thorpe, Emmanuel Farhi, Mike Golosov, Narayana Kocherlakota, Jean-Baptiste Michau, Paul Mohnen, Jordan Norris, Giorgio Primiceri, Ali Shourideh, Stefanie Stantcheva, Bruno Strulovici, Yuta Takahashi, and Nicolas Werquin for numerous discussions. Finally, I would like to thank discussants and seminar participants at Northwestern, Illinois Economic Association Meetings, the National Tax Association Meetings, Chicago Fed, TSE, Sciences Po, Purdue, Michigan, Penn State, UCSB, UCLA, NYU Stern, Bocconi, Midwest Macro Meetings, SED, NBER Summer Institute, the Annual Congress of the EEA, CMU and Harvard. 
Planning for retirement and choosing when to retire are important decisions for most people. Workers pay payroll taxes on their labor income to be eligible for retirement benefits, save and invest in retirement pensions, and choose whether to retire early or delay retirement.

There is strong evidence that the tax and Social Security (SS henceforth) system affects retirement behavior. Labor income taxes affect labor supply, which adjusts both through the number of daily hours worked - an intensive margin - and through the timing of retirement - an extensive margin. Capital income taxes on retirement savings and the value of retirement pensions determine income after retirement. In turn, retirement behavior affects the income distribution and the duration of retirement, which are key inputs of the tax and retirement benefits system.

The goal of this paper is to investigate the consequences of flexible retirement for the optimal design of income taxes and retirement benefits over a person's life-cycle. Since Diamond and Mirrlees (1978), the vast majority of optimal tax theory assumes that retirement occurs at an exogenous date instead of being an endogenous decision. Recent literature analyzes the consequences of endogenous retirement for optimal tax and pension systems. Until now, the analysis has been restricted to economies in which agents experience a disability shock (cf. Golosov and Tsyvinski (2006)) or a permanent shock at birth in a static setting (cf. Michau (2014) and Shourideh and Troshkin (2015)). In realistic life-cycle settings where earnings risk is gradually resolved over time, the implications of flexible retirement for the pattern of optimal income taxes and retirement benefits are yet to be understood.

The main question my paper addresses is the following: How is the optimal tax and retirement benefits system altered when we acknowledge that people choose when to retire? I derive an analytical characterization of optimal historydependent policies and describe the economic forces that shape their patterns over the life-cycle. Finally, I calibrate the model to the U.S. economy and ask how the welfare gains can be achieved by simple policies. I study two such policy experiments: a reform of the tax system; and a joint reform of the tax and SS systems.

I jointly determine optimal tax and retirement benefits and the resulting retirement decisions in a dynamic life-cycle model in which workers adjust their labor supply through working hours and the timing of retirement. Individuals live for $T$ years, work, consume, and choose when to retire. During their working years, labor income is the product of intensive labor supply and productivity, 
which evolves as a persistent Markov process. A fixed utility cost of staying in the labor market creates a non-convexity in the disutility of labor. This fixed cost has important implications for the retirement decision. First, workers adjust their working hours continuously until they irreversibly exit the labor force, when their work hours discontinuously drop to zero. Second, when productivity is public information, low-productivity agents efficiently retire earlier than high-productivity agents. Third, there is an option value of waiting for higher earnings before retirement. As a consequence, at the retirement age, the marginal utility of staying in the labor market is lower than the marginal utility from not working. This option value decreases with age as the value of waiting for higher earnings vanishes at $T$.

The government chooses consumption, output and retirement age in order to maximize social welfare. As in the standard Mirrlees (1971) model, individual productivity and labor effort are privately observed by the workers. Therefore, the government's goal is to design a dynamic mechanism that is incentive compatible. I describe the distortions to the optimal retirement decision and analyze constrained efficient allocations by studying the wedges, or implicit marginal taxes, and consumption after retirement.

Methodologically, we cannot solve the government's problem using a direct approach because of the many incentive constraints. A First-Order Approach (FOA) provides analytic tractability in characterizing necessary conditions satisfied by optimal allocations. This approach relaxes the problem by imposing only a subset of incentive constraints. I follow the implementation of this approach by Farhi and Werning (2013) in the context of optimal taxation and ex-post numerically verify full incentive compatibility constraints. I formulate the model in continuous-time for a sharper characterization of the retirement decision.

In the analytical part of the paper, I determine how optimal policies evolve over time and I provide some intuition for the numerical results. Optimal policies imply a labor tax that is hump-shaped in age under flexible retirement, while it is increasing in age under exogenous retirement, for two reasons: First, despite the intensive Frisch elasticity of labor supply being constant, the total Frisch elasticity increases with age. This is because of the retirement margin and the decreasing option value of waiting for higher earnings before retirement. This elasticity effect implies that the optimal labor tax is flatter in age relative to the model without an extensive margin. Second, in the constrained optimum, agents with a history of high productivity shocks are provided with higher retirement consumption and are incentivized to retire later than agents with a history of low productivity shocks. Therefore, through selection, the labor force becomes increasingly more productive 
than the pool of all potential workers of the same age. When the forces of this composition effect are stronger than the increase of variance in productivity that occurs with age, the older labor force is also more equal in productivity than the general population. Setting a decreasing-in-age labor tax for old workers increases the efficiency of the intensive labor supply of these high-productivity workers. These two effects, balanced with the government's motive for increasing the level of insurance with age in the standard dynamic Mirrlees model, imply that the optimal labor tax is hump-shaped in age.

In the quantitative part of the paper, I exploit a recursive formulation of the FOA to numerically illustrate these effects. I calibrate the model to the U.S. economy with a rich representation of the status quo tax and SS systems. I find that the average implicit labor tax is hump-shaped in age under flexible retirement, while it is increasing with age under exogenous retirement. I compute the welfare gains from maintaining the status quo SS system and moving from the status quo U.S. tax code to the linear age-dependent labor and capital taxes that mimic optimal policies. I find that this reform brings modest welfare gains under flexible retirement, while it achieves the bulk of welfare gains when retirement is exogenous. The modest welfare gains are because the status quo SS system does not provide appropriate incentives for delayed retirement like the optimal system does. I find that this tax reform when coupled with a simple SS reform that makes retirement benefits steeper in claiming age, can generate sizeable welfare gains. For comparison, I do some counterfactual analysis and show that hump-shaped in age taxes perform better than optimal age-independent taxes and increasing-in-age taxes under an optimal SS reform. Because of the fixed cost incurred both by lowproductivity workers and high-productivity workers, most of the agents who delay retirement as a result of the SS reform are highly productive. The decreasing-inage labor tax for old workers increases the efficiency of the intensive labor supply of these high-productivity agents and delivers welfare gains from the age-dependent linear labor tax that is hump-shaped in age. These calibrations suggest that when one accounts for the endogeneity of retirement, introducing age-dependency into the tax code alone is not enough, and one needs to make SS benefits steeper in claiming age as well, in order to capture the bulk of welfare gains from optimal policies.

Related Literature A large empirical literature documents the relationship between retirement behavior and tax and SS systems around the world. Gruber and Wise (1998), Gruber and Wise (2002), and their accompanying volumes of com- 
parative studies document that over much of the second half of the 20th century, disincentives to continue working created a trend towards early retirement. This trend has shown signs of reversing in the mid-2000s because of longevity, gender composition, social norms, tax provision, SS reforms, and other factors.

This paper builds on the insights of the early non-linear income taxation literature. Mirrlees (1971) develops the theory and optimal tax formulas that Saez (2001) links to estimated elasticities. Albanesi and Sleet (2006) develop a dynamic Mirrleesian model and focus on the implementation of the optimal allocations with a restricted set of instruments. The subsequent literature develops the dynamic Mirrleesian model with persistent productivity shocks (Farhi and Werning (2013)) and focuses on the evolution of implicit labor taxes. Golosov et al. (2016) disentangle the motives of insurance and redistribution. Stantcheva (2017) incorporates endogenous human capital acquisition. Makris and Pavan (2017) investigate the effects of learning-by-doing on optimal taxes. A comprehensive survey of the dynamic Mirrleesian literature can be found in Golosov et al. (2006) and in Golosov and Tsyvinski (2015). All these papers assume an exogenous retirement age and find that, as inequality in hourly wages increases with age, the average labor tax should increase with age.

The model in this paper is similar to that of Farhi and Werning (2013), augmented with an endogenous retirement age. I find that accounting for an endogenous retirement age, the average labor tax should be hump-shaped in age. But introducing age-dependency into the tax code alone is not enough and delayed retirement needs to be incentivized through the SS system as well.

The first analysis of retirement and taxation comes from Diamond and Mirrlees (1978). In their framework, workers are subject to disability shocks (as subsequently in Golosov and Tsyvinski (2006)). All able workers choose the same retirement age and share the same productivity at any given age. Hence, their retirement decisions do not generate the composition effect, which is at the heart of my analysis. Also, Diamond and Mirrlees (1978) do not allow for an intensive margin of labor supply. Other papers study optimal taxation with an extensive margin of labor supply in a static framework (Saez (2002), Jacquet et al. (2013), Gomes et al. (2017), Rothschild and Scheuer (2013)).

Recent literature has analyzed optimal tax and retirement benefits and the timing of retirement. Michau (2014), Choné and Laroque (2014), Cremer et al. (2004) and Shourideh and Troshkin (2015) introduce the retirement margin in the analysis of optimal tax and retirement benefit systems. In these papers, a permanent shock deterministically pins down the whole history of productivity, as 
in a static setting. My paper analyzes a setting in which earnings risk is gradually resolved over time and is, therefore, able to describe the lifetime evolution of the optimal labor income tax.

This paper is also connected to the literature on age-dependent taxation. In the Ramsey tradition, Erosa and Gervais (2002) focus on linear taxes in an economy without uncertainty within a cohort and find that when the intensive elasticity of labor supply varies over an individual's lifetime, optimal tax rates are age-dependent. Conesa et al. (2009) postulate a specification of preferences that are isoelastic in leisure instead of labor. As a consequence, the elasticity of labor supply is high when labor is low. In their model, a low labor supply corresponds to the labor supply of older workers; therefore, they find decreasing the labor tax with age to be optimal. Assuming preferences that feature an increasing intensive elasticity parameter, Karabarbounis (2016) finds that the optimal labor tax, within the class of the Heathcote et al. (2014) tax function, is hump-shaped in age. The result of my paper does not rely on these particular specifications of preferences. I keep the intensive Frisch elasticity fixed so that the information structure and increasing inequality in earnings are responsible for the increasing labor tax profile at the beginning of work life, and the retirement margin and the selection of the labor force are responsible for their decreasing profile in old age. In a recent contribution, Heathcote et al. (2017) analyze the optimal degree of progressivity of age-dependent tax systems. Considering a productivity process that is on average increasing in age and has increasing variance in age, they find that the optimal degree of progressivity in the tax system is U-shaped in age. In the Mirrlees approach, Weinzierl (2011) justifies the rising age profile of wages as a reason to increase the labor tax with age but limits his sample to the ages 30 to 59. Farhi and Werning (2013) find that a rising variance of wages justifies increasing the linear labor tax with age and that such an age-dependent tax achieves nearly the entirety of welfare gains from the second-best. When one accounts for flexible retirement, the labor tax should be on average hump-shaped in age and age-dependent taxes alone do not achieve significant welfare gains unless they are complemented by SS reform.

As for the methodological approach, this paper builds on the dynamic mechanism design and optimal contracting literature. Pavan et al. (2014) develop the First Order Approach that simplifies the dynamic mechanism design problem. Bergemann and Strack (2015) adapt the theory to continuous-time. Strack and Kruse (2013) study pure stopping problems under private information. My paper analyzes the design of optimal mechanisms for optimal stopping problems with 
stochastic controls.

Outline The remainder of the paper is structured as follows. Section 1 sets up the framework of the model and defines the planning problem. Section 2 solves the first-best planning problem and highlights features of the retirement decision within the full information benchmark. Section 3 develops a recursive formulation of the second-best planning problem, solves for the optimal policies and retirement decision, and discusses the parameters and forces that shape them. Section 4 presents the numerical, welfare and counterfactual analyses. Section 5 concludes. In particular, Online Appendix A.7 presents three extensions of the model: (i) non-separable preferences in consumption and labor, (ii) workers with uncertain lifetimes, and (iii) productivity-dependent fixed costs of staying in the labor market.

\section{Model Setup}

In this section, I describe an economy in which workers are ex-ante heterogeneous in productivity, experience idiosyncratic productivity shocks over their lifetime, and adjust their labor supply through flexible working hours and the timing of their retirement.

Productivity, Technology, and Preferences Consider a continuous-time economy populated by a continuum of agents who live until age $T$. At each time $t$, each agent privately observes the realization of his ${ }^{1}$ current labor productivity $\theta_{t} \in(0,+\infty)$. Agents provide $l_{t} \geq 0$ units of labor at time $t$ at a wage rate equal to their productivity and earn gross income $y_{t}=\theta_{t} l_{t}$.

At time $t=0$, initial productivity $\theta_{0} \in(0,+\infty)$ is drawn from a distribution $F$ with density $f$. A standard Brownian Motion $B=\left\{B_{t}, \mathcal{F}_{t} ; 0 \leq t \leq T\right\}$ on $(\Omega, \mathcal{F}, \mathcal{P})$ drives the productivity shocks in future periods. A history of productivities $\left(\theta^{t}\right)=\left\{\theta_{s}\right\}_{s \in[0, t]}$ is a sequence of realizations of the productivity process that evolves according to the law of motion

$$
\frac{d \theta_{t}}{\theta_{t}}=\mu_{t} d t+\sigma_{t} d B_{t}
$$

By Ito's lemma, the real constants $\mu_{t}-\frac{1}{2} \sigma_{t}^{2}$ and $\sigma_{t}$ are, respectively, the drift and volatility of log-productivity. When the drift and volatility are independent of

\footnotetext{
${ }^{1}$ Throughout the text, I use the pronoun "he" for the agent and "she" for the planner.
} 
time, productivity is a Geometric Brownian Motion (GBM) and log-productivity is the continuous-time limit of a random walk.

Agents have time-separable preferences over consumption $\left\{c_{t}\right\}_{0 \leq t \leq T}$ and labor $\left\{l_{t}\right\}_{0 \leq t \leq T}$ processes that are progressively measurable with respect to the filtration $\mathcal{F}_{t} .{ }^{2}$ When an agent is working, $\left(l_{t}>0\right)$, he incurs a flow utility cost of staying in the labor market denoted by a deterministic function of age $\phi(t)$, and his current period utility is $u\left(c_{t}, l_{t}\right)-\phi(t)$, where $u$ is increasing in consumption, decreasing in labor, twice continuously differentiable, and concave.

Utility along the intensive margin is separable in consumption and labor and isoelastic in labor:

$$
u\left(c_{t}, l_{t}\right)=u\left(c_{t}\right)-\kappa \frac{l_{t}^{1+\frac{1}{\varepsilon}}}{1+\frac{1}{\varepsilon}}
$$

where $\varepsilon>0$ is the intensive Frisch elasticity of labor supply. In Appendix A.7, I extend the analysis to preferences that are non-separable in consumption and labor.

The fixed utility cost of staying in the labor market can be thought of as the utility cost of commuting time, work-related consumption costs, or taste for leisure. I write it in units of utils for tractability. This fixed cost creates a nonconvexity in the disutility of work as agents prefer no work to a few hours of work. As in French (2005) and Rogerson and Wallenius (2013), these non-convexities trigger retirement at some point in the worker's life. In Appendix A.7, I extend the analysis to fixed utility costs that depend both on age and current productivity $\phi_{t}\left(\theta_{t}\right)$.

Retirement, $l_{t}=0$, is an irreversible decision. Define a stopping time $\mathscr{T}_{R} \in \mathcal{T}^{3}$ after which a retired agent provides zero labor effort and does not incur the fixed utility cost. After retirement, an agent's utility in each period is $u\left(c_{t}, 0\right)$. I define the retirement age as the age at which an individual chooses to exit the labor force forever ${ }^{4}$ - which the model allows to differ from the age at which an individual

\footnotetext{
${ }^{2}$ Consumption $c_{t}\left(\theta^{t}\right)$ and labor $l_{t}\left(\theta^{t}\right)$ depend on the whole history of productivities until time $t$. In the text, I drop the realisations $\theta^{t}$ when referring to $\mathcal{F}_{t}$--measurable processes $\left\{c_{t}, y_{t}\right\}$ to simplify the notation.

${ }^{3}$ A random variable $\mathscr{T}_{R}$ is a stopping time if $\left\{\mathscr{T}_{R} \leq t\right\} \in \mathcal{F}_{t}, \forall t \geq 0$. Intuitively, this definition means that at any time $t$, one must know whether retirement has occurred or not.

${ }^{4}$ The irreversible retirement assumption is motivated by empirical and theoretical reasons. Rogerson and Wallenius (2013) find empirical evidence in the Current Population Survey data that retirement occurs as abrupt transitions from full-time to little or no work in the U.S.. By age 70, the age by which individuals should start claiming SS benefits, $75 \%$ of men report working zero hours. In addition, this assumption can actually be easily relaxed. The main predictions of the model remain unchanged if this paper allows for retirees to return to the labor market at a lower wage. A more involved theoretical reason is in Grochulski and Zhang (2016). In a setting
} 
chooses to start claiming Old-Age, Survivors and Disability Insurance (OASDI) benefits. $^{5}$

Planning Problem Preferences over consumption and labor $\left\{c_{t}, l_{t}\right\}$ and retirement decisions $\left\{\mathscr{T}_{R}\right\}$ are summarized by an agent's indirect utility at time zero:

$$
v\left(\theta_{0}\right) \equiv \mathrm{E}\left\{\int_{0}^{\mathscr{T}_{R}} e^{-\rho t}\left[u\left(c_{t}, l_{t}\right)-\phi(t)\right] d t+\int_{\mathscr{T}_{R}}^{T} e^{-\rho t} u\left(c_{t}, 0\right) d t \mid \theta_{0}\right\}
$$

in which $\rho$ is the rate of time preference. A utilitarian planner chooses incentive compatible (IC) allocations to maximize social welfare:

$$
\max _{\left\{c_{t}, l_{t}, v\left(\theta_{0}\right), \mathscr{T}_{R}\right\}} \int_{0}^{\infty} v\left(\theta_{0}\right) d F\left(\theta_{0}\right)
$$

subject to the law of motion of productivity (1), the definition of indirect utility (2) and an intertemporal resource constraint. For simplicity, I work in partial equilibrium and the planner can save aggregate resources in a small open economy and borrow at a net rate of return $r$. I study the planner's problem for a single cohort in isolation and abstract from intergenerational redistribution issues. ${ }^{6}$ The planner's resource constraint is therefore:

$$
\mathrm{E}\left\{\int_{0}^{T} e^{-r t} c_{t} d t\right\}+G \leq \mathrm{E}\left\{\int_{0}^{\mathscr{T}_{R}} e^{-r t} \theta_{t} l_{t} d t\right\} .
$$

The left-hand side includes exogenous government spending $G^{7}$ and the cost of providing lifetime consumption to agents. The right-hand side is the sum of the net present value of income $y_{t}$ generated by workers until they retire. Because of the law of large numbers, the aggregate resource constraint is the expectation over the histories of productivities $\left(\theta^{t}\right)$.

similar to Sannikov (2008) that allows for agents to put in zero labor effort temporarily, they find that when the utility of consumption is unbounded below, workers almost surely provide positive labor efforts as the planner can threaten to provide arbitrarily low utility to shirking agents with zero consumption. I use a logarithmic utility of consumption in most of my analysis and it satisfies these assumptions. In my setting, the fixed cost of staying in the labor market has to be paid even if labor effort was allowed to be suspended temporarily; therefore, retirement would be triggered. This utility function, coupled with the fixed cost, is another justification for an interior labor effort $l_{t}>0$ before irreversible retirement.

${ }^{5}$ In a decentralized economy, workers can actually claim SS benefits whenever they want, and their optimal retirement benefits system are computed according to the history of their earnings. Because I work with allocations directly in this primal approach, the SS benefits are implicit in the model.

${ }^{6}$ Given that I study insurance and redistribution across one cohort, time is equivalent to age for my cohort.

${ }^{7} G$ can capture many sources of exogenous government revenues and expenses as well as intergenerational transfers to or from another cohort etc. 


\section{The First-Best Planning Problem}

This section solves the planning problem with full information. I highlight features of the optimal retirement decision that are absent in existing models with no endogenous retirement choice but have important implications for optimal policy.

Let the rate of time preference equal the rate of return of government savings, $\rho=r$. From the intertemporal Euler equation, there is perfect insurance against productivity shocks and consumption is the same across all histories: $u^{\prime}\left(c_{t}\left(\theta^{t}\right)\right)=\lambda$, with $\lambda$ the multiplier on the planner's resource constraint (4). When it is optimal to work, the marginal rate of transformation of labor into consumption is the wage rate $\theta_{t}$. Therefore labor supply satisfies $\kappa l_{t}^{\frac{1}{\varepsilon}}=\lambda \theta_{t}$. With full information, consumption is smoothed and more productive agents work more hours and produce more output. To maximize social welfare, the planner maximizes total resources available in the economy and makes high-productivity workers retire later than low-productivity workers, as long as the fixed cost of staying in the labor market for high-productivity workers is not too high compared to that of low-productivity workers. The following proposition confirms that it is indeed the case.

Proposition 1. (First-best retirement decision) There exists a time-dependent deterministic productivity threshold $\theta_{R}^{f b}(t)$ such that retirement occurs if and only if productivity falls below it: $\mathscr{T}_{R}^{f b}=\inf \left\{t ; \theta_{t} \leq \theta_{R}^{f b}(t)\right\}$.

The proof is in Appendix A. This proposition means that the planner balances the need to induce the highly productive (high earning) agents to continue working with the need to avoid the fixed utility cost for less productive (low earning) workers. In the first-best case, it is therefore, optimal to set productivity cutoffs below which retirement occurs. To understand the determinants and lifetime evolution of these cut-offs, I consider the case in which agents are risk neutral.

The Risk-Neutral Case To qualify results further, I now consider agents who are risk neutral in consumption, so that $u\left(c_{t}\right)=c_{t}$. Consumption is not pinned down by the Euler equation. I eliminate consumption from the planner's problem by replacing the resource constraint into the planner's social welfare function:

$$
w \equiv \max _{\mathscr{T}_{R}} \mathrm{E}\left\{\int_{0}^{\mathscr{T}_{\mathscr{R}}} e^{-\rho t}\left[\theta_{t} l_{t}^{f b}-\kappa \frac{\left(l_{t}^{f b}\right)^{1+\frac{1}{\varepsilon}}}{1+\frac{1}{\varepsilon}}-\phi(t)\right] d t\right\}-G
$$

subject to the law of motion of productivity (1). Normalizing government spending to zero, $G=0$, and replacing the first-best labor allocations using the optimality 
condition $\kappa\left(l_{t}^{f b}\right)^{\frac{1}{\varepsilon}}=\theta_{t}$, the social welfare function $w\left(\theta_{t}, t\right)$ satisfies the following Hamilton-Jacobi-Bellman (HJB) equation:

$0=\max \left\{-w(\theta, t),-\rho w(\theta, t)+\frac{\theta^{1+\varepsilon}}{\kappa^{\varepsilon}(1+\varepsilon)}-\phi(t)+\left(\mu_{t} \theta\right) \partial_{\theta} w(\theta, t)+\frac{\sigma_{t}^{2} \theta^{2}}{2} \partial_{\theta \theta} w(\theta, t)+\partial_{t} w(\theta, t)\right\}$.

The terms to the right of $-\rho w(\theta, t)$ consist of the marginal social value of labor minus the fixed cost and derivatives of social welfare with respect to time and productivity.

Now consider the case of productivity that evolves according to a GBM, i.e., $\mu_{t}$ and $\sigma_{t}$ are, respectively, constants $\mu$ and $\sigma$. I show that even when the fixed cost is a constant $\phi(t)=\phi$, there is an option value of waiting for higher productivity shocks before retirement. In addition, this option value decreases over time. Therefore, even when the fixed cost is constant over time, the elasticity over the retirement margin increases over time. Hence, the total Frisch elasticity increases over time, despite the intensive Frisch elasticity and the fixed cost being constant. The following corollary summarizes this result in terms of the retirement thresholds $\theta_{R}^{f b}(t)$.

Corollary 1. (Option value of continued work vs. retirement)

1. Suppose $\phi$ is constant and productivity is a GBM. Denote $\theta^{*}$ the unique level of productivity below which the marginal value of labor is less than the fixed utility cost of work, that is, $\theta^{*} l^{f b}\left(\theta^{*}\right)-\kappa \frac{\left(l^{f b}\left(\theta^{*}\right)\right)^{1+\frac{1}{\varepsilon}}}{1+\frac{1}{\varepsilon}}=\phi$. Then for all $t<T$, $\theta_{R}^{f b}(t) \leq \theta^{*}$ and the marginal social value of continued work is negative, i.e, $\theta_{R}^{f b}(t) l^{f b}\left(\theta_{R}^{f b}(t)\right)-\kappa \frac{\left(l^{f b}\left(\theta_{R}^{f b}(t)\right)\right)^{1+\frac{1}{\varepsilon}}}{1+\frac{1}{\varepsilon}}-\phi \leq 0$.

2. The retirement threshold function $\theta_{R}^{f b}(t)$ is increasing in $t$. In addition, $\lim _{t \rightarrow T} \theta_{R}^{f b}(t)=\theta^{*}$.

Point 1 of the corollary states that retirement occurs below a productivity level at which it would be efficient not to work in a static environment. This creates an option value of waiting for higher productivity shocks and higher earnings before retirement that is not present in models with permanent productivity shocks like Michau (2014) or Shourideh and Troshkin (2015). Working today instead of retiring preserves the option of retiring later at a higher wage, hence the term "option value" of work. Indeed, when there is no uncertainty on future earnings, the marginal value of labor is equal to the fixed utility cost of work at retirement, and the option value is zero. In practice, this option value is negative at retirement. 
Rust (1989), Lazear and Moore (1988) and Stock and Wise (1988) estimate structural models of retirement with uncertain earnings and find that people continue to work at any age, as long as the expected present utility value of continuing work is greater or equal to the expected present value of immediate retirement.

Point 2 of the corollary states that the option value of continued work decreases over time as the horizon shortens. Therefore, the total Frisch elasticity increases over time, despite the intensive Frisch elasticity and the fixed cost being constant. The option value of continued work vanishes at the end of the horizon and only then is the irreversible retirement decision similar to a static participation decision and the marginal value of labor equal to the fixed utility cost of work.

To develop some intuition, let us consider the infinite horizon limit $T \rightarrow \infty$. In this case, the HJB equation is time-homogeneous and the retirement threshold is independent of time, $\theta_{R}^{f b}$. The proof in Appendix A proceeds similarly to Leland (1994) by decomposing the value of social welfare into

$$
w(\theta)=\underbrace{A \theta^{1+\varepsilon}-\frac{\phi}{\rho}}_{\text {social value of working forever (SVWF) }}-\overbrace{\left(\frac{\theta_{R}^{f b}}{\theta}\right)^{x}}^{\text {discounting at retirement } \mathrm{E}\left[e^{\left.-\rho \mathscr{T}_{R}^{f b} \mid \theta\right]}\right.} \underbrace{\left[A\left(\theta_{R}^{f b}\right)^{1+\varepsilon}-\frac{\phi}{\rho}\right]}_{\text {SVWF starting at retirement threshold }}
$$

where

$$
A=\frac{1}{\kappa^{\varepsilon}(1+\varepsilon)\left[\rho-(1+\varepsilon)\left(\mu+\frac{\sigma^{2}}{2} \varepsilon\right)\right]}
$$

and $x(\rho, \mu, \sigma)$ is a positive constant defined in the Appendix A. The value of social welfare $w(\theta)$ is the value of lifetime utility of output if the agent were to work forever, minus the value of lifetime utility of output if he were to work forever at the optimal retirement threshold, discounted by the expected value of the discount factor at retirement. This value is zero at retirement. From a smooth pasting argument as in Dixit (1993), the value of its derivative is also zero at retirement. This gives an explicit value of the threshold:

$$
\theta_{R}^{f b}=\left(\frac{\phi}{\rho} \frac{x}{A(1+\varepsilon+x)}\right)^{\frac{1}{\varepsilon}} .
$$

Now, $\theta_{R}^{f b}$ is increasing in the fixed cost $\phi .^{8}$ Agents retire earlier when their fixed cost is large. In addition, $\theta^{*}=\left(\phi \kappa^{\varepsilon}(1+\varepsilon)\right)^{\frac{1}{\varepsilon}}$. It can be deduced that $\theta_{R}^{f b}<\theta^{*}$ since $\frac{\rho-(1+\varepsilon)\left(\mu+\frac{\sigma^{2}}{2} \varepsilon\right)}{\rho}<1$ and $\frac{(x)}{(1+\varepsilon+x)}<1$. Thus, the marginal social value of continued

\footnotetext{
${ }^{8}$ For convergence of net present values, I assume that $\rho>\mu>\sigma^{2} \varepsilon / 2$ in the proof in the Appendix A.
} 
work is negative at retirement.

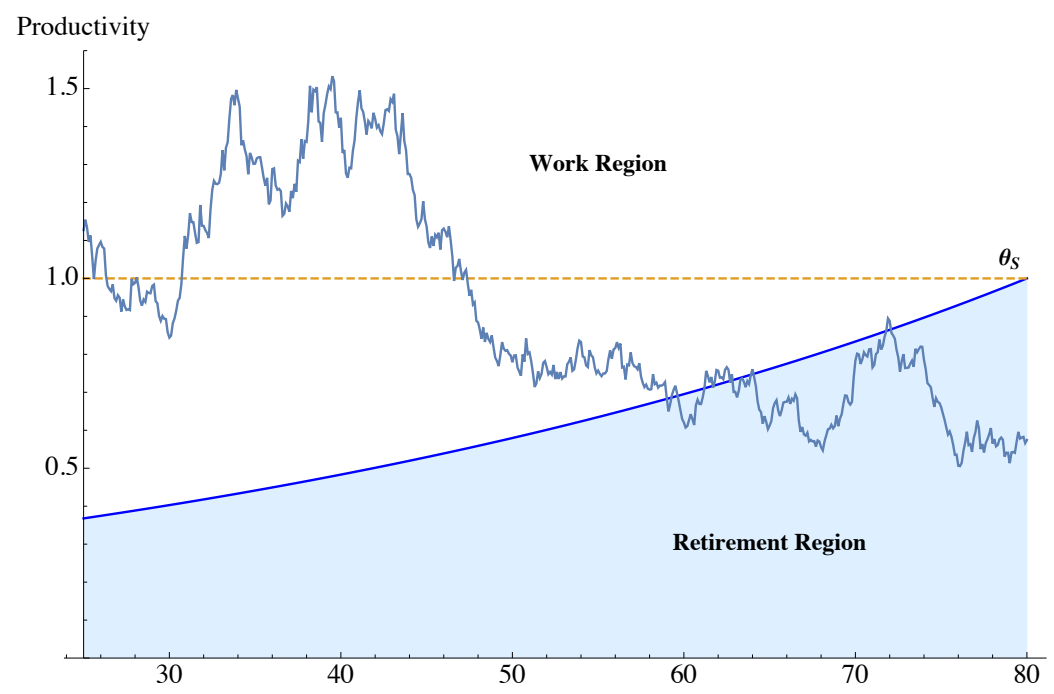

Figure 1: First-Best Retirement Rule

Note: Example of productivity history. Horizontal axis $t$, vertical axis $\theta_{t}$. Retirement region shaded. $\theta_{s}$ : static participation cut-off. The retirement region expands with age.

In summary, the solution of the first-best planning problem generates the following insights about the implications of optimal retirement: First, low-productivity agents retire earlier than high-productivity agents. Second, there is an option value of waiting for higher earnings before retiring. Third, the total Frisch elasticity increases over time, despite the intensive Frisch elasticity and the fixed cost being constant.

When the planner cannot observe productivity, first-best allocations with constant consumption are not achievable as any agent would be better off retiring immediately. Nevertheless, history-dependent versions of these intuitions carry through in the second-best as the planner tries to mimic the first-best.

\section{The Second-Best Planning Problem}

This section studies the second-best problem in which productivity and its evolution is private information to the planner. I start by setting up the planning problem with full IC constraints. Then, I relax the incentive problem using the First Order Approach (FOA) procedure developed in Farhi and Werning (2013), and I incorporate the retirement decision. Finally, through a redefinition of the state space, I write a recursive formulation of the FOA. 


\subsection{Incentive Compatibility}

In the second-best problem, both the agents and the planner observe consumption $\left\{c_{t}\right\}$, retirement status $\mathscr{T}_{R}$ and income from work $\left\{y_{t}\right\}$. However, the planner does not observe $\left\{\theta_{t}\right\}$, and therefore does not observe labor $\left\{l_{t}=y_{t} / \theta_{t}\right\}$ either. As a result, the planner needs to incentivize the agents with dynamic contracts.

A contract is a consumption process $\left\{c_{t}\right\}$ and a stochastic retirement time $\mathscr{T}_{R}$ adapted to the filtration generated by $\left\{y_{t}\right\} .{ }^{9}$ By the revelation principle, a contract is a mapping from any reported process of productivities $\left\{\tilde{\theta}_{t}\right\}$ to a triplet $\left\{\tilde{c}_{t}, \tilde{y}_{t}, \tilde{\mathscr{T}}_{R}\right\}$ of processes adapted to the filtration generated by $\left\{\tilde{\theta}_{t}\right\}$. It specifies the consumption, output, and retirement status at any time. An allocation is IC if it is the outcome of a contract in which it is optimal for the agent to truthfully reveal his true productivity process $\left\{\theta_{t}\right\}$. In other words, for any reporting strategy $\left\{\sigma_{t}\left\{\theta_{s}\right\}_{s \in[0, t]}\right\}, \quad \mathrm{E}\left\{v\left(\theta_{0}\right)\right\} \geq \mathrm{E}^{\sigma}\left\{v\left(\sigma\left(\theta_{0}\right)\right)\right\}$, where $\mathrm{E}^{\sigma}$ is the expectation over the paths generated by reports. The planner commits to a non-renegotiable contract at time zero.

After retirement, the incentive problem stops since the agent does not need to be incentivized to work. Therefore, the planner does not need to distort consumption decisions after retirement.

Lemma 1. Suppose $r=\rho$ and $u$ is strictly concave in consumption. For any allocation that solves the planner's second-best problem, consumption is constant after retirement.

The result is intuitive: Since output is zero after retirement, there is no information for the planner to learn about the agent's real productivity after retirement. Since there is no incentive constraint after retirement, the problem is one of full insurance. The Euler equation holds intertemporally, and the marginal utility of consumption at $l=0$ is equalized cross-sectionally. Since $u_{c}$ is strictly decreasing, it follows that consumption is constant after retirement.

This lemma implies that consumption after retirement only depends on the history of productivities until retirement. However, it also allows for a jump in consumption "at" retirement. Because of this possibility, I denote by " $c_{\mathscr{T}_{R}^{+}}$" consumption after retirement. ${ }^{10}$

\footnotetext{
${ }^{9}$ The planner's objective is concave and the optimal contract cannot be strictly improved by randomization over allocations and stopping times.

${ }^{10}$ The fact that consumption is constant after retirement in this setting is linked to different forces than those in Sannikov (2014). In that model, agents have their consumption distorted and compensations optimally delayed after retirement. The planner continues to observe positive post-termination output, which itself depends on the persistent labor effort of the agent; in my model, output is zero after retirement.
} 
Following this lemma, allocations before retirement and the retirement decision pin down retirement consumption through the resource constraint. In order to characterize allocations before retirement, I now relax the planner's incentive constraints.

\subsection{Recursive Formulation of the Planning Problem}

Given constant consumption after retirement, an agent's ex-ante indirect utility, or promised utility, given consumption, labor $\left\{c_{t}, l_{t}=y_{t} / \theta_{t}\right\}$, and retirement time $\left\{\mathscr{T}_{R}\right\}$ is

$$
v_{0}=\mathrm{E}\left\{\int_{0}^{\mathscr{T}_{R}} e^{-\rho t}\left[u\left(c_{t}, \frac{y_{t}}{\theta_{t}}\right)-\phi(t)\right] d t+\int_{\mathscr{T}_{R}}^{T} e^{-\rho t} u\left(c_{\mathscr{T}_{R}^{+}}, 0\right) d t\right\} .
$$

Denote $g(t) \equiv \int_{t}^{T} e^{-\rho(s-t)} d s=\frac{1}{\rho}\left(1-e^{-\rho(T-t)}\right)$ a shorthand that represents by how much the utility of constant consumption is discounted from time $t$ until retirement. Promised utility at time $t$ before retirement is then

$$
v_{t}=\mathrm{E}\left\{\int_{t}^{\mathscr{T}_{R}} e^{-\rho(s-t)}\left[u\left(c_{s}, \frac{y_{s}}{\theta_{s}}\right)-\phi(s)\right] d s+e^{-\rho\left(\mathscr{T}_{R}-t\right)} u\left(c_{\mathscr{T}_{R}^{+}}, 0\right) g\left(\mathscr{T}_{R}\right) \mid \mathcal{F}_{t}\right\}
$$

and the feasibility constraint is

$$
\mathrm{E}\left\{\int_{0}^{\mathscr{T}_{R}} e^{-r t} c_{t} d t+e^{-\rho \mathscr{T}_{R}} c_{\mathscr{T}_{R}^{+}} g\left(\mathscr{T}_{R}\right)\right\} \leq \mathrm{E}\left\{\int_{0}^{\mathscr{T}_{R}} e^{-r t} y_{t} d t\right\}
$$

By duality, it is equivalent for the planner to maximize ex-ante promised utility (10) or to minimize the cost of providing allocations:

$$
K_{0}(v)=\min _{\left\{c, y, \mathscr{T}_{R}\right\}} \mathrm{E}\left\{\int_{0}^{\mathscr{T}_{R}} e^{-\rho t}\left(c_{t}-y_{t}\right) d t+e^{-\rho \mathscr{T}_{R}} c_{\mathscr{T}_{R}^{+}} g\left(\mathscr{T}_{R}\right)\right\}
$$

subject to a minimum promised utility $v_{0} \geq v$, full incentive compatibility and the law of motion of productivity (1).

The First Order Approach (FOA) relaxes the IC constraints by restricting attention to local deviations. An IC mechanism must be immune to such deviations. As a result, the sensitivity of promised utility with respect to reports, denoted by $\Delta_{t} \equiv \partial_{\theta} v_{t}$, satisfies an envelope condition on the agent's optimal reporting problem. I discuss the optimal reporting problem in detail in Appendix A.

Kapička (2013), Farhi and Werning (2013), and Golosov et al. (2016) implement the FOA in the context of optimal taxation while Williams (2011) and Sannikov (2014) do so in the context of optimal contracting in continuous-time. It is a necessary but not generally sufficient condition for an allocation to be 
IC. ${ }^{11}$ In the numerical analysis, I verify ex-post that the allocations obtained from the FOA satisfy full incentive compatibility using a method developed by Farhi and Werning (2013) that does not require solving for the full incentive compatible mechanism. I continue the recursive formulation of the problem and reparametrize the state space in a simpler form. The lemma below derives the law of motion of promised utility and its sensitivity and allows me to solve the problem recursively.

Lemma 2. (Law of motion of promised utility and the sensitivity process)

1. The law of motion of promised utility is

$$
d v_{t}=\left(\rho v_{t}-u\left(c_{t}, \frac{y_{t}}{\theta_{t}}\right)+\phi(t)\right) d t+\theta_{t} \Delta_{t} \sigma_{t} d B_{t}
$$

with the boundary condition

$$
v_{o}=v
$$

2. (FOA) The law of motion of the sensitivity process $\Delta_{t} \equiv \partial_{\theta} v_{t}$ is

$$
d \Delta_{t}=\left[\left(\rho-\mu_{t}\right) \Delta_{t}-u_{\theta}\left(c_{t}, \frac{y_{t}}{\theta_{t}}\right)-\sigma_{\Delta, t} \sigma_{t}\right] d t+\sigma_{\Delta, t} \sigma_{t} d B_{t}
$$

with the boundary condition

$$
\Delta_{0}=\arg \min _{\Delta} K_{0}(v, \Delta)
$$

Point 1 of this lemma states that the drift of promised utility is the discounted flow utility. More importantly, it highlights that the volatility of promised utility is controlled by the sensitivity process. The boundary condition is the promisekeeping constraint. Point 2 of the lemma characterizes how the sensitivity with respect to reports is linked to allocations in an incentive compatible mechanism, i.e., the evolution of informational rents. ${ }^{12}$ The term $u_{\theta}$ constitutes the rent in the static Mirrlees model, while the term $\sigma_{\Delta, s} \sigma_{t}$ is a dynamic rent that summarizes an agent's advance information about his future productivity profile. The term $\mu \Delta_{s}$ captures how a misreport today affects the planner's perceived distribution of productivities in the future. The boundary condition ensures that the initial sensitivity is chosen to minimize the ex-ante cost of providing promised utility $v$. The proof is in Appendix A.

These recursive formulations allow me to analyze the relaxed planning problem. Promised utility $v_{t}$, and its sensitivity with respect to reports $\Delta_{t}$, time $t$, and

\footnotetext{
${ }^{11}$ Nevertheless, it gives a lower bound on the cost of providing a given promised utility to the agents.

${ }^{12}$ Informational rents are rents the high-productivity agents derive from having information on their types that is not available to the planner.
} 
current productivity $\theta_{t}$ can be used as state variables of the recursive formulation. At retirement, promised utility $v_{\mathscr{T}_{R}}$ is provided with a constant consumption $c_{\mathscr{T}_{R}^{+}}$, so $v_{\mathscr{T}_{R}}=g\left(\mathscr{T}_{R}\right) u\left(c_{\mathscr{T}_{R}^{+}}, 0\right)$ and $c_{\mathscr{T}_{R}^{+}}=u_{l=0}^{-1}\left(\frac{v_{\mathscr{T}_{R}}}{g\left(\mathscr{T}_{R}\right)}\right)$ in which $u_{l=0}^{-1}$ is the inverse function of $u(c, 0)$. At each time $t$, the planner's problem is to minimize the cost:

$K(v, \Delta, \theta, t)=\min _{\{c\},\{y\}, \sigma_{\Delta}, \mathscr{T}_{R}} \mathrm{E}\left\{\int_{t}^{\mathscr{T}_{R}} e^{-\rho(s-t)}\left(c_{s}-y_{s}\right) d s+e^{-\rho\left(\mathscr{T}_{R}-t\right)} g\left(\mathscr{T}_{R}\right) u_{l=0}^{-1}\left(\frac{v_{\mathscr{T}_{R}}}{g\left(\mathscr{T}_{R}\right)}\right)\right\}$

subject to the law of motion of productivity (1), the law of motion of promised utility (14), and the law of motion of the sensitivity process (15).

In what follows, I work for tractability with dual variables of $\left(v_{t}, \Delta_{t}\right)$ that are derivatives of the cost function with respect to these state variables. I introduce the co-states $\lambda_{t}=K_{v}$ and $\gamma_{t}=K_{\Delta}$. The economic intuition behind these variables is that they represent the marginal change in the cost of providing allocations when promised utility $v_{t}$ or, respectively, its sensitivity $\Delta_{t}$ is marginally increased. ${ }^{13}$

\subsection{Optimal Policies}

\subsubsection{Wedges, Retirement Consumption, and Distortions of The Re- tirement Decision}

The approach to solving the planner's problem by finding the allocations that maximize her objective is called the primal approach. ${ }^{14}$ To characterize the planner's optimum, it is useful to define some wedges that capture distortions in the constrained optimal allocation relative to the first-best.

Definition 1. The labor wedge (or intratemporal wedge) $\tau^{L}$ on workers is the gap between the marginal rate of substitution and the marginal rate of transformation between consumption and labor before retirement.

$$
\tau_{t}^{L} \equiv 1+\frac{\frac{1}{\theta_{t}} u_{l}\left(c_{t}, \frac{y_{t}}{\theta_{t}}\right)}{u_{c}\left(c_{t}, \frac{y_{t}}{\theta_{t}}\right)}
$$

The capital wedge (or intertemporal wedge) at time $t$ and horizon $s$ is the difference between the expected marginal rate of intertemporal substitution between time $t$

\footnotetext{
${ }^{13}$ Because of the Pontryagin Maximum Principle, (see Bismut (1973)) this method of working directly with the Lagrangians of the problem makes the problem tractable.

${ }^{14}$ As is well known, there can be several policies that implement the planner's optimal allocations.
} 
and time $t+s$ and the return on savings.

$$
\tau_{t, s}^{K} \equiv 1-e^{-(\rho-r) s} \frac{u_{c}\left(c_{t}, \frac{y_{t}}{\theta_{t}}\right)}{\mathrm{E}_{\mathrm{t}}\left\{u_{c}\left(c_{t+s}, \frac{y_{t+s}}{\theta_{t+s}}\right) \mid \mathcal{F}_{t}\right\}}
$$

The intertemporal wedge at time $t$ is the marginal intertemporal wedge between $t$ and $t+d t$, i.e., $\tau_{t}^{K}=\left.\frac{d \tau_{t, s}^{K}}{d s}\right|_{s=0}$.

A positive wedge on labor means that labor is distorted downwards. The capital wedge represents the deviation from the Euler equation. These wedges have been the focus of the dynamic taxation literature. In addition to these wedges, I am interested in consumption after retirement and its net present value:

$$
\left\{c_{t}\right\}_{\left\{\mathscr{T}_{R}<t \leq T\right\}} \quad \mathrm{E}\left\{\int_{\mathscr{T}_{R}}^{T} e^{-r\left(t-\mathscr{T}_{R}\right)} c_{t} d t \mid \mathcal{F}_{\mathscr{T}_{R}}\right\}
$$

and the percentage change, if any, in consumption before and after retirement, which I denote $\frac{\Delta c_{\mathscr{T}_{R}^{+}}}{c_{\mathscr{T}_{R}^{-}}}$with an abuse of notation. Finally, to analyze the distortions to the retirement decision, I compare the second-best retirement rule $\mathscr{T}_{R}^{s b}$ to the first-best retirement rule $\mathscr{T}_{R}^{f b}$, which is summarized by the threshold function $\theta_{R}^{f b}(t)$ in the separable utility case. ${ }^{15}$

\subsubsection{Optimal Retirement Policy}

Since after retirement consumption is constant and labor effort is zero, promised utility is not sensitive to the reports after retirement. The endogenous retirement boundary is therefore $\mathscr{T}_{R}^{s b}=\inf \left\{t ; \Delta\left(\theta^{t}\right)=0\right\}$. For incentive compatibility, given the same past history of productivity, promised utility is higher for higher reports, so $\partial_{\theta} v=\Delta \geq 0$. The sensitivity process starts at a positive value defined by $\Delta_{0}=\arg \min _{\Delta} K_{0}(v, \Delta)$, and follows the law of motion (15) until it hits zero, at which point retirement is triggered.

\footnotetext{
${ }^{15}$ At each age, the planner compares the expected value of continued work against the expected value of retiring today taking incentives into account. Corollary 1 implies that there is no simple "marginal benefit = marginal cost" equation that holds in the first-best and defines a retirement wedge because of the option value of continued work. This is unlike in Michau (2014) or Shourideh and Troshkin (2015) who define the retirement margin as the deviation from the retirement age that equalizes the marginal value of labor with the fixed utility cost of work. In my setting, the marginal value of labor is optimally lower than the fixed utility cost of work at retirement in the first-best. One can define a retirement margin using equation (7) and the value matching and smooth pasting conditions that define the retirement thresholds. However one needs to assume first that the optimal retirement rule is a cut-off rule at the second-best, which in general is not the case. Even if so, the resulting expression does not provide more intuition than directly comparing the optimal retirement rules.
} 
The second-best retirement decision is more complex than the first-best one and depends on the whole history of productivities through the endogenous variable $\Delta\left(\theta^{t}\right) \cdot{ }^{16}$ In Appendix A.7, I show that in a risk-neutral case with a progressive redistributive motive for the government, the second-best retirement rule is determined by thresholds as in the first-best. In that case, low-productivity agents retire earlier than high-productivity agents.

To build intuition on why agents with a history of low productivity shocks retire earlier than agents with a history of high productivity shocks in the riskaverse case, consider first-order conditions for consumption $c_{t}$, output $y_{t}$, and the variance of sensitivity $\sigma_{\Delta, t}$ in the planner's problem:

$\left[c_{t}\right]: \lambda_{t}=\frac{1}{u^{\prime}\left(c_{t}\right)}, \quad\left[y_{t}\right]: \frac{\tau_{t}^{L}}{1-\tau_{t}^{L}}=-\left(1+\frac{1}{\varepsilon}\right) \frac{\gamma_{t}}{\lambda_{t}} \frac{1}{\theta_{t}}$, and $\left[\sigma_{\Delta, t}\right]: \sigma_{\Delta, t}=\frac{\gamma_{t} \sigma^{-1}-K_{v \Delta} \theta_{t} \Delta_{t}-K_{\Delta \theta} \theta_{t}}{K_{\Delta \Delta}}$.

These first order conditions determine consumption, output, and wedges as a function of the Lagrangians $\lambda_{t}, \gamma_{t}$. In particular, $\lambda_{t}$ is the inverse of marginal utility of consumption and $\gamma_{t}$ links the marginal utility of consumption to the labor wedge, the intensive Frisch elasticity, and current productivity. By definition, $\gamma_{t}$ is the marginal change in the planner's cost of providing allocations with respect to the sensitivity $\Delta$. When $\Delta$ is larger, it hits the retirement boundary $\{\Delta=0\}$ later, and the expected retirement age is delayed. Agents work longer and the cost of providing allocations for a given promised utility is lower. This means that $\gamma$ starts at zero $\left(\gamma_{0}=0\right)$ and takes negative values for all $t>0, \gamma_{t} \leq 0$. The process $\gamma\left(v_{t}, \Delta_{t}, \theta_{t}, t\right)$ is defined for $\Delta_{t}$ non-zero. Denote by the same symbol $\gamma_{t}$, the extension of the process to the whole space of productivity histories. Since labor effort jumps discontinuously from a positive value to zero at retirement because of the fixed cost $\phi_{t}, \gamma_{t}$ jumps from a negative value to zero at retirement. In other words, because of the fixed cost, the super contact condition ${ }^{17}$ does not hold at the retirement boundary.

Replacing the first order condition on $c_{t}$ in the law of motion of $\Delta$ yields

$$
d \Delta_{t}=\left[\left(\rho-\mu_{t}\right) \Delta_{t}-\left(\frac{1-\tau_{t}^{L}}{\lambda_{t}}\right)^{1+\varepsilon}\left(\frac{\theta_{t}}{\kappa}\right)^{\varepsilon}-\sigma_{\Delta, t} \sigma_{t}\right] d t+\sigma_{\Delta, t} \sigma_{t} d B_{t} .
$$

Consider two agents with histories $\left\{\hat{\theta}^{t}\right\} \neq\left\{\theta^{t}\right\}$ such that $\hat{\theta}_{t}=\theta_{t}$ and $\hat{\tau}_{t}^{L}=$ $\tau_{t}^{L}$. From the first-order condition for $y_{t}$, these states are those for which the corresponding $(\gamma, \lambda)$ are on a given line at time $t, \gamma_{t}=\alpha \lambda_{t}$. Assuming the volatility of the sensitivity $\sigma_{\Delta}$ is small, from (20) one can see that the agent for whom $\lambda_{t}$

\footnotetext{
${ }^{16}$ The retirement boundary is the optimal exercise boundary of an exotic American option with stochastic dividends. Its derivation in the space of states $\left(\theta^{t}\right)$ is non-trivial.

${ }^{17}$ The super contact condition means that the value function is twice differentiable.
} 
is lower has a more negative drift for $\Delta_{t}$, and therefore has an earlier expected retirement age. Equivalently, this is the agent with lower consumption today as a consequence of the FOC on $c_{t}$. Respectively, the agent with lower $\gamma_{t}$ has an earlier expected retirement age. This is reminescent of the retirement rule in the firstbest in Proposition 1 but in a setting in which past history matters through the level of promised marginal utility of consumption. Agents who have a history of low productivity shocks, and who have lower consumption, retire earlier than the agents who have a history of high productivity shocks. Thus, in the second-best, the whole history as summarized by the endogenous state variables $\left(\lambda_{t}, \gamma_{t}, \theta_{t}, t\right)$, rather than current productivity alone, determines the retirement decision. ${ }^{18}$

\subsubsection{Optimal Capital Wedge}

Under separable utility, a standard Inverse Euler Equation of optimal contracting and dynamic moral hazard models holds.

Proposition 2. (Capital wedge)

1. There exists a process $\sigma_{c, t}$ such that

$$
d\left(\frac{1}{u^{\prime}\left(c_{t}\right)}\right)=\frac{1}{u^{\prime}\left(c_{t}\right)} \sigma_{c, t} \sigma_{t} d B_{t} \quad \text { (Inverse Euler Equation) }
$$

2. The intertemporal wedge between $t$ and $t+s$ is positive and satisfies

$$
\tau_{t, s}^{K}=\int_{t}^{t+s} \sigma_{c, t^{\prime}}^{2} \sigma_{t}^{2} d t^{\prime}
$$

and the intertemporal wedge at time $t$ is $\tau_{t}^{K}=\sigma_{c, t}^{2} \sigma_{t}^{2}$.

The proof is in Appendix A. Point 1 states that the standard Inverse Euler Equation extends to the case with endogenous retirement. The inverse of marginal utility of consumption is a martingale. A direct consequence of this is that the intertemporal wedge is positive, since Jensen's inequality applies to the inverse function that is concave.

Point 2 highlights that the intertemporal wedge $\tau_{t}^{K}$ is linked to the volatility of the inverse of the marginal utility of consumption. This volatility is a control

${ }^{18}$ Further, replacing the first order condition on $y_{t}$ in the law of motion (20) yields

$$
d \Delta_{t}=\left[\left(\rho-\mu_{t}\right) \Delta_{t}-\left(\frac{\theta_{t} \tau_{t}^{L}}{\left(-\gamma_{t}\right)(1+1 / \varepsilon)}\right)^{1+\varepsilon}\left(\frac{\theta_{t}}{\kappa}\right)^{\varepsilon}-\sigma_{\Delta, t} \sigma_{t}\right] d t+\sigma_{\Delta, t} \sigma_{t} d B_{t} .
$$

Labor effort is continuous before retirement. At retirement, the labor effort jumps to zero and $\gamma_{t}$ jumps to zero. Therefore, from (21), at retirement $\Delta=0$, the drift of $\Delta_{t}$ jumps to $-\infty$ and the volatility $\sigma_{\Delta, t}$ jumps to zero. 
for how much the changes in productivity translate into changes in consumption. It is, therefore, a measure of risk exposure. A high volatility of the inverse of marginal utility of consumption implies that the planner exposes the agents to risk to provide incentives at the expense of insurance. This risk exposure stops at retirement and the volatility $\sigma_{c, t}$ goes to zero. ${ }^{19}$

\subsubsection{Optimal Labor Wedge}

The evolution of the labor wedge is obtained from the evolution of $\gamma_{t}$ :

Proposition 3. (Labor wedge)

The law of motion of $\gamma_{t}$, is

$$
d \gamma_{t}=\left[-\theta_{t} \lambda_{t} \sigma_{c, t} \sigma_{t}^{2}+\mu_{t} \gamma_{t}\right] d t+\gamma_{t} \sigma_{t} d B_{t}, \quad \gamma_{0}=0
$$

In addition, the labor wedge satisfies

$$
d\left(\frac{\tau_{t}^{L}}{1-\tau_{t}^{L}}\right)=\left[\left(1+\frac{1}{\varepsilon}\right) \sigma_{c, t}+\frac{\tau_{t}^{L}}{1-\tau_{t}^{L}} \sigma_{c, t}^{2}\right] \sigma_{t}^{2} d t-\frac{\tau_{t}^{L}}{1-\tau_{t}^{L}} \sigma_{c, t} \sigma_{t} d B_{t}
$$

The proof is in Appendix A. The first order condition on $y_{t}$, coupled with the law of motion of $\gamma_{t}$, implies:

$$
d\left(\lambda_{t} \frac{\tau_{t}^{L}}{1-\tau_{t}^{L}}\right)=\left[\left(1+\frac{1}{\varepsilon}\right) \lambda_{t} \sigma_{c, t} \sigma_{t}^{2}\right] d t
$$

This expression states that the process $\lambda_{t} \frac{\tau_{t}^{L}}{1-\tau_{t}^{L}}$ has zero instantaneous volatility. This means that its paths are less dispersed than the paths of productivity for insurance purposes. Applying Ito's lemma to (23) yields:

$$
d\left(\frac{\tau_{t}^{L}}{1-\tau_{t}^{L}}\right)=\left[\left(1+\frac{1}{\varepsilon}\right) \sigma_{c, t}\right] \sigma_{t}^{2} d t+\frac{\tau_{t}^{L}}{1-\tau_{t}^{L}} \lambda_{t} d\left(u^{\prime}\left(c_{t}\right)\right) .
$$

Exogenous Retirement The labor wedge formula (24) applies to all productivity histories for which agents work. Consider the time periods for which all agents work. On one hand, the first term of (24) is the instantaneous covariance between log-productivity and the inverse of marginal utility of consumption scaled by the inverse of the intensive Frisch elasticity of labor supply. When the instantaneous variance of log-productivity is non-zero, this drift is positive and gives a positive slope to the labor wedge. The covariance of consumption growth and

\footnotetext{
${ }^{19}$ In Sannikov (2014), risk exposure does not go to zero at retirement. Instead, it builds up to target, starts falling at an age before retirement, and goes to zero at the end of the horizon. The difference is because, in my setting, there is no output after retirement, and therefore there is no need for the agent to be exposed to risk after retirement.
} 
log-productivity captures the benefits of added insurance since it depends on the variability of consumption and the degree of risk aversion. But, insurance comes at the cost of decreased incentives for work; the more elastic the labor supply, the stronger the effect, explaining the role of the intensive Frisch elasticity. In addition, the second term is autoregressive and is scaled by the change in the marginal utility of consumption. Since the inverse of the marginal utility of consumption is a martingale, the marginal utility of consumption is a submartingale and its paths trend upwards. Therefore, the labor wedge is increasing at a young age when all agents are working. These are the standard forces in the model with a fixed retirement age in Farhi and Werning (2013).

Despite the fact that $\mu(t)$ can capture a hump-shaped profile of productivities, this does not lead to a decreasing labor wedge if retirement is exogenous in the model. Figure 11 in Appendix B shows that when retirement occurs exogenously at a fixed age, the labor wedge is everywhere increasing-in-age, despite average productivities decreasing in old age. The drift term of productivity does not enter into the labor wedge formula. ${ }^{20}$ The planner provides insurance against nonpredictable shocks to productivity through the labor wedge and the predictable shocks through the capital wedge.

The law of motion of the labor wedge also captures two effects that are present once one accounts for a flexible retirement age.

The Elasticity Effect For simplicity, suppose that the government wants to set taxes such that $\tau_{t}^{L}\left(\left\{\theta^{t}\right\}\right)=\tau_{0}^{L}\left(\theta_{0}\right)$. From equation (24), this is actually optimal in the case of quasilinear utility in consumption and GBM productivity. The innovations to the labor wedge are zero and with a redistributive motive at time zero, ${ }^{21}$ the labor wedge is constant, equal to the time zero labor wedge $\tau_{t}^{L}=\tau\left(\theta_{0}\right)$. The added insurance motive from new shocks is absent since the average wedge would be constant if no agent retired. From Appendix A.7, output is scaled down by the wedge, $y^{s b}=\left(1-\tau\left(\theta_{0}\right)\right)^{\varepsilon} y^{f b}$ and therefore the retirement productivity cut-offs are $\theta_{R}^{s b}\left(\theta_{0}, t\right)=\frac{\theta_{R}^{f b}(t)}{1-\tau\left(\theta_{0}\right)}$. Therefore, when setting $\tau_{t}^{L}=\tau^{L}\left(\theta_{0}\right)$, the government takes into account distortion of extensive margin: An increase in $\tau^{L}$ leads to an increase in $\theta_{R}^{s b}\left(\theta_{0}, t\right)$ and leads to a decrease in expected retirement age $\mathscr{T}_{R}$, which reduces government revenues. Similarly, with risk-averse utility in consumption, concavity

\footnotetext{
${ }^{20}$ This result is true as long as the drift of $\log$-productivity, generally $\mu_{t}-\frac{\sigma_{t}^{2}}{2}$, is independent of productivity.

${ }^{21}$ Appendix A.7 presents the case of the second-best with quasilinear utility in consumption and a government that puts Pareto weights at time zero $\alpha\left(\theta_{0}\right)$ that are decreasing in $\theta_{0}$.
} 
of $u(c)$ is the analogue of the redistributive motive for quasilinear utility in consumption. Therefore, when setting optimal history dependent wedges $\tau_{t}^{L}\left(\left\{\theta^{t}\right\}\right)$, the government takes into account the distortions to current period output $y_{t}^{s b}$ and future distortions of the retirement boundary.

The Composition Effect The second term in the labor wedge formula (24) is autoregressive and shows that innovations in the labor wedge must follow innovations in the marginal utility of consumption. When productivity increases, consumption increases and the marginal utility of consumption decreases. Therefore, over short horizons, the labor wedge must decrease when productivity increases, which Farhi and Werning (2013) call a form of "short-run regressivity". Here I highlight the implications of the negative covariance between consumption and the labor wedge when retirement is endogenous, compared with when retirement is exogenous. When $t$ is closer to retirement, Section 3.3.2 shows that retirement occurs earlier for agents with a history of low productivity shocks compared with agents with a history of high productivity shocks. Therefore, by selection, the labor force becomes more productive than the general population in old age, while such selection does not occur with exogenous retirement. In the short run, this calls for lower labor wedges for this more productive sub-population. This is the novel composition effect. To draw out implications more clearly, apply Ito's lemma to the Inverse Euler equation and replace $d\left(u^{\prime}\left(c_{t}\right)\right)=u^{\prime}\left(c_{t}\right) \sigma_{c, t}^{2} \sigma_{t}^{2} d t-u^{\prime}\left(c_{t}\right) \sigma_{c, t} \sigma_{t} d B_{t}$ in (24) to obtain the formula of the labor wedge in the proposition:

$$
d\left(\frac{\tau_{t}^{L}}{1-\tau_{t}^{L}}\right)=\left[\left(1+\frac{1}{\varepsilon}\right) \sigma_{c, t}+\frac{\tau_{t}^{L}}{1-\tau_{t}^{L}} \sigma_{c, t}^{2}\right] \sigma_{t}^{2} d t-\frac{\tau_{t}^{L}}{1-\tau_{t}^{L}} \sigma_{c, t} \sigma_{t} d B_{t}
$$

The full composition effect is captured by the last two terms on the right. As the labor force becomes increasingly productive when agents retire, over infinitesimal periods the remaining workforce has on average positive productivity shocks, $\sigma_{t} \theta_{t} d B_{t}>0$. The last term on the right-hand side of the equation above $-\frac{\tau_{t}^{L}}{1-\tau_{t}^{L}} \sigma_{c, t} \sigma_{t} d B_{t}<$ 0 captures that the labor force in old age becomes more productive and must have lower labor wedges in the short-run. However, the term $\frac{\tau_{t}^{L}}{1-\tau_{t}^{L}} \sigma_{c, t}^{2} \sigma_{t}^{2} d t$ captures the volatility of consumption growth, and the increase in volatility of log-productivity over a longer horizon $d t$ and calls for higher labor distortions. Therefore, there is a race between selection and rising inequality in productivity and consumption. If the force of selection into a more productive labor force is stronger than the increase in volatility of log-productivity, the composition effect yields a decreasingin-age average labor wedge for old workers.

For simplicity, let's consider again the case of risk-neutral utility in con- 
sumption with a redistributive motive at time zero. The average labor wedge over the cross-section of workers is $\mathrm{E}\left[\tau_{t}^{L} \mid\right.$ work $]=\mathrm{E}\left[\tau_{t}^{L}\left(\left\{\theta^{t}\right\}\right) \mid t>\inf _{s \leq t}\left\{s ; \theta_{s} \leq\right.\right.$ $\left.\left.\theta_{R}^{s b}\left(\theta_{0}, s\right)\right\}\right]$. Let's consider the average of these, over the initial types $\theta_{0}$ that I denote $\theta_{R}^{s b}(t) \equiv \mathrm{E}_{\theta_{0}}\left[\theta_{R}^{s b}\left(\theta_{0}, t\right)\right]$. Then the average labor wedge is approximately $\mathrm{E}\left[\tau_{t}^{L} \mid\right.$ work $] \simeq \mathrm{E}\left[\tau_{t}^{L}\left(\left\{\theta^{t}\right\}\right) \mid t>\inf _{s \leq t}\left\{s ; \theta_{s} \leq \theta_{R}^{s b}(s)\right\}\right]$. From Golosov et al. (2016), with log-normal initial productivity, the optimal tax function is hump-shaped over the cross-section; also, at top productivities, it behaves as $\tau\left(\theta_{0}\right) \sim_{\theta_{0} \rightarrow \infty} \frac{1}{(1+\varepsilon) \ln \left(\theta_{0}\right)}$, which is decreasing. Therefore, initially before agents retire the average tax is taken accross the whole population and is constant. Then when agents start retiring, the average is across more productive workers. Since $\tau\left(\theta_{0}\right)$ is inverse humpshaped in $\theta_{0}$, the average tax over the population of remaining workers increases, then decreases all the way to zero.

\subsubsection{Optimal Retirement Consumption}

Proposition 4. Consumption after retirement is constant. In addition, consumption after retirement is equal to the final period consumption: $c_{\mathscr{T}_{R}^{+}}=c_{\mathscr{T}_{R}^{-}}$.

The fact that consumption after retirement is equal to consumption at retirement is a consequence of the smooth pasting condition of optimal stopping. It implies that the marginal change in the cost of providing an infinitesimal promised utility before and after retirement are equal. In the separable utility case, it implies that there is no jump in consumption at retirement, i.e $\frac{1}{u^{\prime}\left(c_{\mathscr{T}_{R}^{-}}\right)}=K_{v}^{-}=$ $K_{v}^{+}=\frac{1}{u^{\prime}\left(\frac{v \mathscr{T}_{R}}{g\left(\mathscr{T}_{R}\right)}\right)}=\frac{1}{u^{\prime}\left(c_{\mathscr{T}_{R}^{+}}\right)}$.

To minimize distortions, agents are given their last period consumption at retirement in the separable utility case. Agents with a history of high productivity shocks are offered correspondingly higher retirement consumption than agents with a history of low productivity shocks, in order to induce them to retire later. In addition, the net present value of retirement consumption only needs to depend on their remaining life expectancy $T-\mathscr{T}_{R}$ and last-period consumption (which in turn depends on the whole history until retirement).

\section{Numerical Analysis}

This section highlights the quantitative implications of the model for the evolution of optimal wedges over the life-cycle and the welfare gains from optimal policies and simple tax and SS reforms. Subsection 4.1 calibrates the model parameters in 
a baseline U.S. economy. Then, Subsection 4.2 presents optimal policies for those calibrated parameters. Subsection 4.3 quantifies welfare gains from optimal policies and those from simple tax and SS reforms. Finally, subsection 4.4 compares those welfare gain with those from counterfactual policies.

\subsection{Calibration}

To provide context, I start by discussing the empirical evidence on the fixed cost of staying in the labor market, a crucial parameter in the model.

Estimates of the Fixed Cost in Dynamic Models French (2005), Rogerson and Wallenius (2013), Prescott et al. (2009), and Chang et al. (2014) estimate life-cycle models with endogenous retirement. They consider non-convexities in the labor supply decision due to fixed time costs that match the hours worked and labor force participation of old workers. They find that one needs large fixed time costs, around 5 to 6 hours a day, to match the retirement data. In their estimations of extensive margin elasticities, Chetty et al. (2012) find, in a model similar to Rogerson and Wallenius (2013), that extensive margin labor supply responses ought to be very large to explain the gap between the micro and macro Frisch elasticities. In addition, Banks et al. (1998) and Aguila et al. (2011) posit that there are sizable fixed consumption costs related to work. In my analysis, I calibrate the fixed utility cost of staying in the labor market and compare its time value and consumption value with the time costs and consumption costs estimated in the literature.

Exogenously calibrated parameters I perform the numerical simulation in a discrete time version of the model, in which agents live for $T=55$ periods, with each period corresponding to 1 year from age 25 to 79 . I set the discount factor and the interest rate equal to $\rho=r=0.05 .{ }^{22}$ Since Deaton and Paxson (1994), there is evidence that inequality in consumption and income increases with age within a cohort. Consistent with these findings, I assume that productivity is a

\footnotetext{
${ }^{22}$ The theoretical analysis performed in continuous-time allowed for a simple representation of forces shaping the dynamics of the wedges. Additionally, the continuous-time analysis allowed for explicit analytic results in special cases that are not available in discrete time. I choose to perform a numerical simulation of the discrete time model presented in Appendix B rather than solving the HJB equation, using the Markov Chain Approximation Method as in Kushner and Dupuis (2013), which is known to be convenient in two-dimensional problems but not in higher dimensions. By using balanced growth preferences, I reduce the dimensionality of the problem in discrete time with one less state variable.
} 
geometric random walk with an age-dependent drift that captures a hump-shaped productivity profile: ${ }^{23}$

$$
\log \left(\theta_{t}\right)=\mu(t)+\log \left(\theta_{t-1}\right)+\epsilon_{t}
$$

where $\epsilon_{t} \sim \mathcal{N}\left(-\frac{\sigma^{2}}{2}, \sigma^{2}\right)$.

Storesletten et al. (2004) have found a high estimate of the volatility $\sigma_{H}^{2}=$ 0.0161 and Heathcote et al. (2010) a low estimate of $\sigma_{L}^{2}=0.00625$. In this simulation, I choose an intermediate value of $\sigma_{M}^{2}=0.0095$, in line with Heathcote et al. (2005)'s estimate of a medium volatility. I calibrate $\mu(t)$ using empirical analogs from wage data from the American Community Survey (ACS) done by the U.S. Census Bureau, controlling for possible selection in the data. The method and calibrated values, presented in Appendix B, give an average per-period productivity growth of $+7 \%$ per year at age 25 and an average productivity decline of $-4 \%$ per year at age 79 .

Preferences during working years are

$$
\log \left(c_{t}\right)-\frac{\kappa}{1+\frac{1}{\varepsilon}}\left(\frac{y_{t}}{\theta_{t}}\right)^{1+\frac{1}{\varepsilon}}-\phi(t)
$$

with $\varepsilon=0.5$ and $\kappa=1$, consistent with the estimate of Chetty (2012). During retirement, per period utility is simply $\log \left(c_{t}\right)$. While many parameters are readily estimated from the literature, the fixed cost function $\phi(t)$ is an important parameter to calibrate in my model. I endogenously calibrate the fixed costs in a baseline U.S. economy.

Endogenously matched parameters in the Baseline Economy The baseline economy is the income fluctuation model in which agents, who experience idiosyncratic productivity shocks, can freely borrow, save in a risk-free asset, and choose their consumption, hours worked, and their retirement age. For simplicity, I assume that agents start claiming retirement benefits when they exit the labor force without loss of generality. ${ }^{24}$ The tax system is set to mimic the U.S. tax system. I follow Heathcote et al. (2014) and set the labor income tax equal to

\footnotetext{
${ }^{23}$ Farhi and Werning (2013) and Stantcheva (2017) consider productivity that is a geometric random walk without drift.

${ }^{24}$ Making the retirement age and claiming age different turns out not to matter quantitatively for my results in numerical tests. Because of $\log$ utility in consumption, workers never hit the natural borrowing limit. Therefore, the only case in which a worker would want to start claiming benefits while continuing to work is when a previously highly productive worker, with large expected SS benefits, becomes so unproductive that his current income and accumulated assets are not enough for him to sustain his high level of consumption. Because of the high persistence of the productivity process, the fraction of such workers is small.
} 
the approximation function

$$
T\left(y_{t}\right)=y_{t}-\lambda_{\operatorname{tax}} y_{t}^{1-\tau_{\text {tax }}}
$$

where the value of the progressivity parameter $\tau_{\operatorname{tax}}$ is 0.181 . The capital tax is set to a flat tax rate equal to $20 \%$ of capital gains, equivalently $1 \%$ of the capital stock.

The SS benefits system features three specific ages that are important for the availability and value of retirement benefits. The Normal Retirement Age (NRA), which I set at 66 for the present cohort, is the age at which a worker can claim the full amount of retirement benefits, the Primary Insurance Amount (PIA). The PIA is a function of the Average Indexed Monthly Earnings (AIME), which is the average monthly earnings of the 35 highest earning years. The PIA follows a progressive benefit schedule. ${ }^{25}$ Thus, I use the same method used for tax functions and approximate SS benefits using

$$
P I A(A I M E)=\lambda_{s s} A I M E^{1-\tau_{s s}} .
$$

I follow Heathcote et al. (2014) and estimate that $\tau_{s s}=0.33$ by running a regression on the $\log$ version of this equation, the details of which are in Appendix B. The left panel of Figure 2 shows the PIA as a function of AIME. The regression produces a $R^{2}$ of 0.94 and a good approximation of the SS benefits function that I use for analytical reasons. The Early Retirement Age $(\mathrm{ERA}=62)$ is the age at
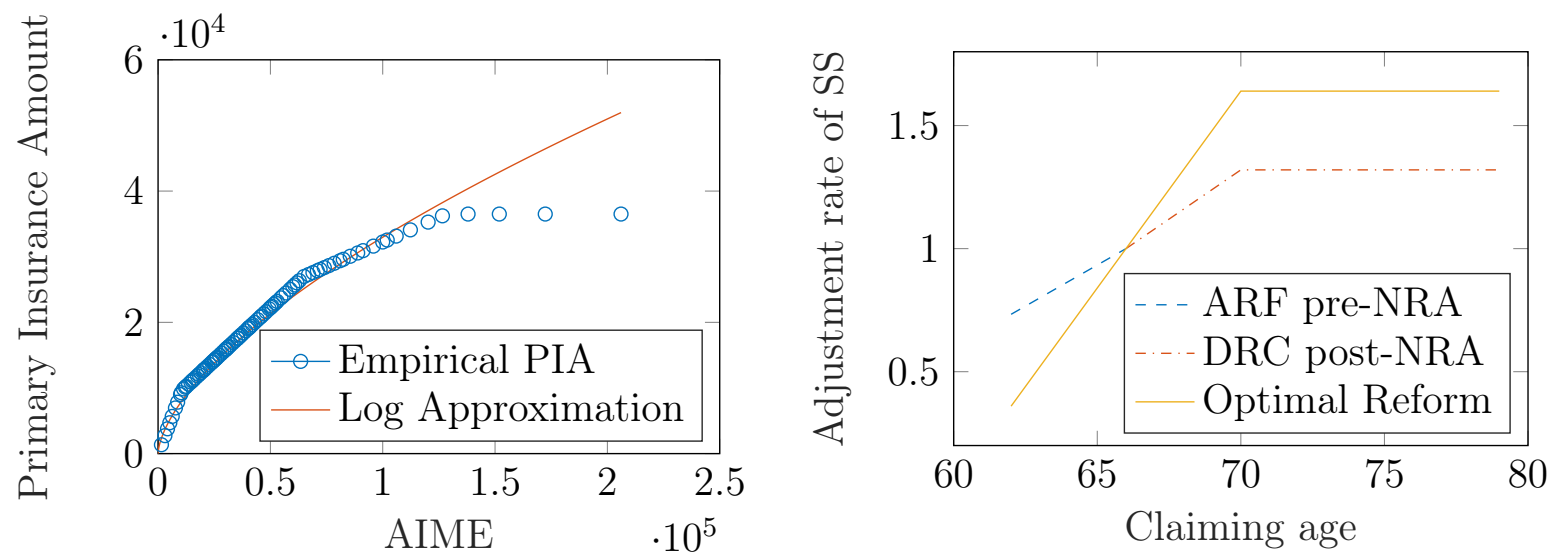

Figure 2: Left: PIA as a function of AIME, Right: SS benefits as a function of PIA and claiming age

\footnotetext{
${ }^{25}$ In the U.S. SS system, the PIA is a step function of the AIME. The first bracket gives a PIA with a replacement rate of $90 \%$ of the AIME until the AIME reaches $\$ 895$. The second bracket gives a replacement rate of $32 \%$ until it reaches $\$ 5,397$. Finally, the third bracket replaces $15 \%$ of the AIMEs over $\$ 5,397$ and below $\$ 127,200$.
} 
which an agent can start claiming retirement benefits. For each year between the ERA and the NRA, an individual who starts claiming benefits at that age loses $6.67 \%$ points of the PIA per early year (the Actuarial Reduction Factor, ARF). For instance, someone who retires at age 63 gets $80 \%$ of his PIA. The End of Eligibility Age $(\mathrm{EEA}=70)$ is the age at which an individual should start claiming benefits that would otherwise be lost. For each year between the NRA and the EEA, an individual who starts claiming benefits at that age gains $8 \%$ points of the PIA per year delayed (the Delayed Retirement Credit, DRC). For instance, someone who retires at age 70 , gets $132 \%$ of his PIA. These "actuarial" 26 adjustments to benefits stop at the EEA and are capped at $132 \%$ of the PIA. The SS benefits system of my calibration features all these adjustments that the dashed and dashed-dotted curves of the right panel of Figure 2 represent.

In this baseline economy, I calibrate the fixed costs as well as the parameters of the tax function $\lambda_{\operatorname{tax}}$ and the SS function $\lambda_{S S}$. To discipline the level of taxes $\lambda_{\text {tax }}$, I endogenously match the income-weighted average marginal tax that Barro and Redlick (2011) finds to be around 37\%. Another target for $\lambda_{S S}$ is to generate the average replacement rate of SS benefits at the NRA. Munnell and Soto (2005) report this value at $42 \%$.

I calibrate a specification of fixed costs that increase in age. In this specification, the fixed cost is constant until age 55 - when the first point of entry into retirement through the OASDI's disability program occurs in the U.S. - then increases linearly until age 79 as $\phi(t)=a+b(t-55)^{+}$. I calibrate $a$, the level, in order to generate the labor force participation rate for ages 65-69 in the U.S. population and $b$ the slope, in order to generate a measure of dynamic total elasticity of labor supply, as in French (2005), at age 65. In Toossi (2015), the Bureau of Labor and Statistics reports a labor force participation rate of individuals between ages 65 to 69 of $31.6 \%$ in 2014. I target a measure of dynamic total elasticity ${ }^{27}$ of labor supply of 1.05 consistent with Alpert and Powell (2013). I minimize the sum of square deviation from simulated moments to targets. ${ }^{28}$

Table 1 summarizes the calibrated values. I obtain a fixed cost equivalent to

\footnotetext{
${ }^{26}$ The standard term used for these adjustments does not necessarily imply that they are actuarially fair.

${ }^{27}$ I define the dynamic extensive elasticity of labor supply by computing the ratio of a $1 \%$ unexpected increase in income at age 65 on the percentage change in the average retirement age. The total elasticity is obtained by adding the intensive Frisch elasticity $\varepsilon=0.5$ with the dynamic extensive elasticity.

${ }^{28}$ Alpert and Powell (2013) report extensive elasticities with respect to after-tax labor income equal to 0.76 for women and 0.55 for men at age 65 . I choose a target of a dynamic extensive elasticity of 0.55 which is a lower bound of the elasticity of old workers in the general population.
} 
Table 1: Calibration

\begin{tabular}{|c|c|c|c|c|}
\hline concept & functional form & values & source/target & deviation \\
\hline \multicolumn{5}{|c|}{ Exogenously parametrized } \\
\hline \multirow{3}{*}{ productivity } & $\log \theta_{t}=\mu(t)+\rho \log \theta_{t-1}+\varepsilon_{t}$ & $\rho=1$ & Storesletten et al. (2004) & \\
\hline & $\sigma\left(\sigma^{2}-\sigma^{2}\right)$ & $\sigma_{M}^{2}=0.0095$ & Heathcote et al. (2005) & \\
\hline & $\varepsilon \sim N(-\overline{2}, O)$ & $\hat{\mu}: 7 \% \searrow-4 \%$ & Ruggles et al. (2018) & \\
\hline utility & $\log c-\frac{\kappa}{1+\frac{1}{\varepsilon}}\left(\frac{y}{\theta}\right)^{1+\frac{1}{\varepsilon}}$ & $\kappa=1, \varepsilon=0.5$ & Chetty (2012) & \\
\hline \multicolumn{5}{|c|}{ Endogenously calibrated in baseline U.S. economy } \\
\hline \multirow{2}{*}{ fixed cost } & \multirow{2}{*}{$\phi(t)=a+b(t-55)^{+}$} & $\hat{a}=5.25 \mathrm{~h} / \mathrm{d}$ & $\operatorname{lfp} 65 / 69=31.6 \%$ & $1.26 \%$ \\
\hline & & $\hat{b}=6 \mathrm{mn} / \mathrm{d} / \mathrm{y}$ & $\varepsilon_{65}=1.05$ & $0.94 \%$ \\
\hline tax function & $T(y)=y-\lambda_{\operatorname{tax}} y^{1-0.181_{\text {tax }}^{H S V}}$ & $\hat{\lambda}_{\operatorname{tax}}=0.83$ & $\overline{T^{\prime}(y)}=37 \%$ & $0.53 \%$ \\
\hline SS function & $P I A(A I M E)=\lambda_{S S} A I M E^{0.63_{S S}^{A C S}}$ & $\hat{\lambda}_{\mathrm{ss}}=0.53$ & $\overline{P I A}=42 \%$ & $0.05 \%$ \\
\hline
\end{tabular}

5.25 hours per day in terms of time cost at age 55 that increases by 6 minutes each year until attaining 7.75 hours per day at age $79 .{ }^{29}$ These estimates are within the range of estimates in Chang et al. (2014). Although the qualitative features of the model are unaffected for a wide range of parameters, the quantitative results are. Therefore, in Appendix I present the results for the specification of a $\phi(t)=\phi$ constant fixed cost. ${ }^{30}$

I compute the policy functions for the calibrated values above. From these policy functions, I perform a Monte Carlo simulation with $\mathrm{N}=1,000,000$ draws.

\footnotetext{
${ }^{29}$ To compute the time value of fixed utility costs, I follow Shourideh and Troshkin (2015) and use parameters from Chang et al. (2014) who estimates a model similar to this paper's baseline economy. I take the estimates of $\hat{\kappa}=82.70$ from Table 1 of Chang et al. (2014) for $\varepsilon=0.5$ and the lowest variance $\sigma_{x}$, which (annualized) is closest to the variance $\sigma_{M}$ in my model. I link the estimate of the fixed utility cost $\hat{\phi}$ to its time cost $\hat{l}$ by solving $\hat{\kappa} \frac{\hat{l}^{1+1 / \varepsilon}}{1+1 / \varepsilon}=\hat{\phi}$.

${ }^{30} \mathrm{~A}$ constant $\phi(t)=\phi$, in particular, can generate an average labor wedge that eventually declines with age as I show in Appendix B. However, to match the extensive elasticity of labor supply better, it is useful to have an increasing $\phi(t)$ as Table 1 shows. For the specification with a constant fixed cost, the estimated fixed cost is the utility equivalent of 6.6 hours per day. The estimated dynamic elasticity at age 65 is low (0.86), compared with the target of 1.05. The average retirement age in the baseline economy is 66.49 years old, while the optimal average retirement age is large and equal to 72.10 years old. The model does not match well the elasticity of old workers when $\phi$ is constant and features an unusually high optimal average retirement age. The intuition is that with a constant fixed cost, the only force for an extensive Frisch elasticity of labor supply that increases with age is the decreasing option value of staying in the labor market. With the medium instantaneous variance of productivity of $\sigma_{M}^{2}=0.0095$, this option value is low.
} 
I set the lump sum transfer to yield a zero present value resource cost for the allocations, $G=0$. This provides comparable allocations across simulations.

\subsection{Optimal Policies}

In this section, I describe the properties of the optimal policies obtained from the simulations of optimal allocations.

Optimal Labor Force Participation Rate The left panel of Figure 3 shows the optimal labor force participation rate as a function of age. The labor force participation rate decreases until age 75 , after which it is non-zero at each age but less than 1\%. The Average Retirement Age (ARA) is 69.63, and the labor force participation rate at ages $65-69$ is $77.86 \%$. These are larger than in the baseline economy, in which the ARA is 66.51 and the labor force participation rate at ages $65-69$ is the target of $31.6 \%$. This is consistent with the fact there are still considerable implicit disincentives to continued work between after the NRA in the U.S. tax and SS system as documented by Gruber and Wise (1998).
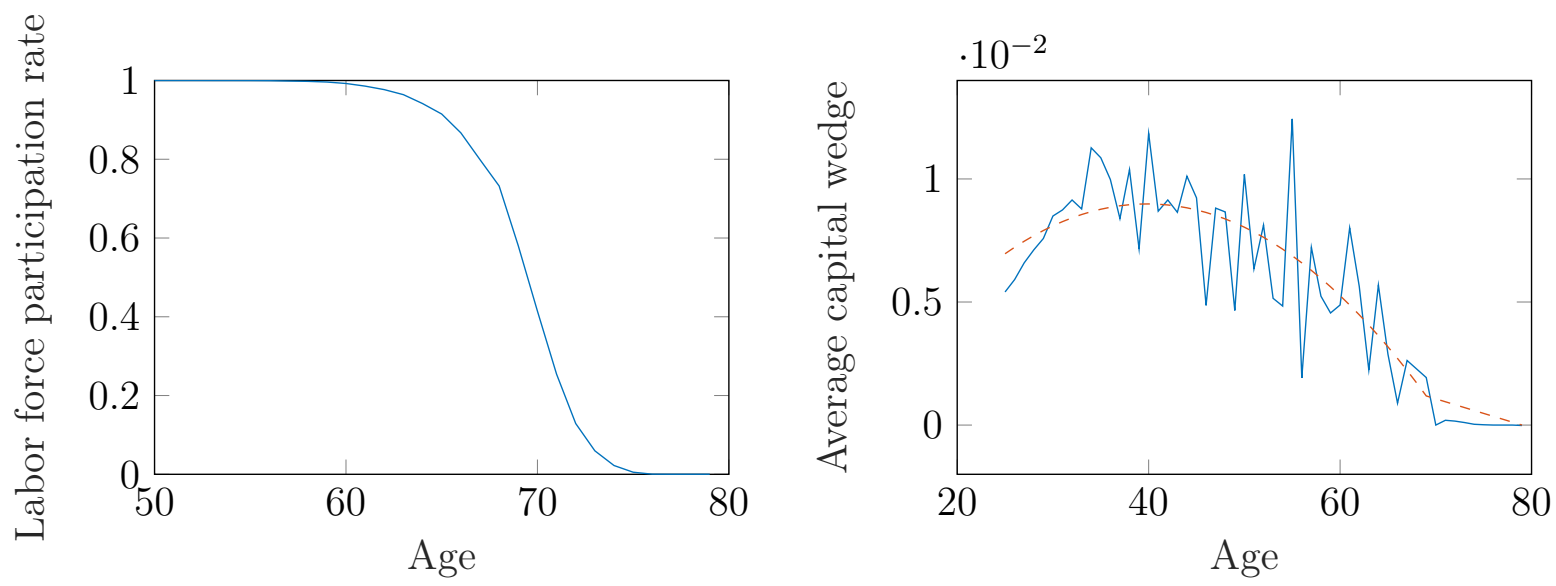

Figure 3: Left: Labor force participation rate as a function of age. Right: capital wedge with empirical $\hat{\mu}$ and its smoothed counterpart.

Optimal Capital Wedge The right panel of Figure 3 shows the cross-sectional average of the capital wedge as a function of age and its smoothed counterpart. ${ }^{31}$ On one hand, as shown in Section 3.3, the capital wedge is directly linked to the variance of consumption growth $\tau_{t}^{K}=\sigma_{c, t}^{2} \sigma_{t}^{2}$. At retirement, consumption is

\footnotetext{
31 The calibrated values of $\hat{\mu}(t)$ using wage date feature large oscillations; as a result, the capital wedge (solid curve) features these oscillations as well.
} 
constant and the capital wedge is zero. This force pushes for decreasing the capital wedge over time. On the other hand, the predictable component of the innovations to productivity, captured by $\mu(t)$, are insured through the capital wedge. The calibrated values $\hat{\mu}(t)$ generates productivity profiles that are hump-shaped in age. Therefore, the capital wedge is hump-shaped in age as a combination of its convergence to zero at retirement and the insurance of the drift $\mu(t)$. The average capital wedge is small in magnitude, going from a tax rate of $0.66 \%$ of the capital stock or equivalently $13 \%$ of capital gains to $0.91 \%$ of the capital stock ( $18 \%$ of capital gain) at age 43 to zero at age 79 .

Optimal Labor Wedge Figure 4 displays the average labor wedge as a function of age. The profile of the average labor wedge is hump-shaped in age. The solid line represents the average labor wedge over the whole population. The dashed curve and dashed-dotted curve represent the average labor wedge in a population of agents with a history of low and high productivity shocks, respectively. ${ }^{32}$ For incentive compatibility, the average over the population with low productivity shocks is higher than the average in the population with high productivity shocks. Since the dashed curve is above the dashed-dotted curve, once low-productivity agents start retiring, the solid curve comes closer to the dashed-dotted one. This is a manifestation of the composition effect. At age 75 , the solid curve and the dashed-dotted curve are indistinguishable as the remaining labor force is mainly composed of highly productive workers. Overall, the average labor wedge increases from $1.75 \%$ at age 25 to $45.71 \%$ at age 64 , then decreases up to $27.87 \%$ at age 79 . In contrast, Appendix B shows that when retirement occurs at an exogenous age, the average labor wedge is increasing-in-age.

Another way to look at the decreasing labor wedge in old age is to plot the average wedge for those workers retiring at a specific age. The left panel of Figure 5 plots the average wedge for workers retiring at age 60, 65, 70, and 75. Each subsequent curve is below the previous one. Thus, the average labor wedge over the cross-section of workers follows the solid curve, then after age 60 follows the dashed curve all the way down to the dotted curve after age 75 . The right panel of Figure 5 gives another look at the composition effect through the consumption and output of the working population. Average consumption (resp. output) of

\footnotetext{
${ }^{32}$ I define the population with a history of low productivity shocks as agents who receive at each period a shock lower than the mean shock plus a quarter of the standard deviation of instantaneous shocks, such that $\exp \left(\varepsilon_{t}^{L}\right) \leq 1+\sigma / 4$; and the population with a history of high productivity shocks as agents who receive at each period a shock higher than the mean shock minus a quarter of the standard deviation of instantaneous shocks, with $\exp \left(\varepsilon_{t}^{H}\right) \geq 1-\sigma / 4$.
} 


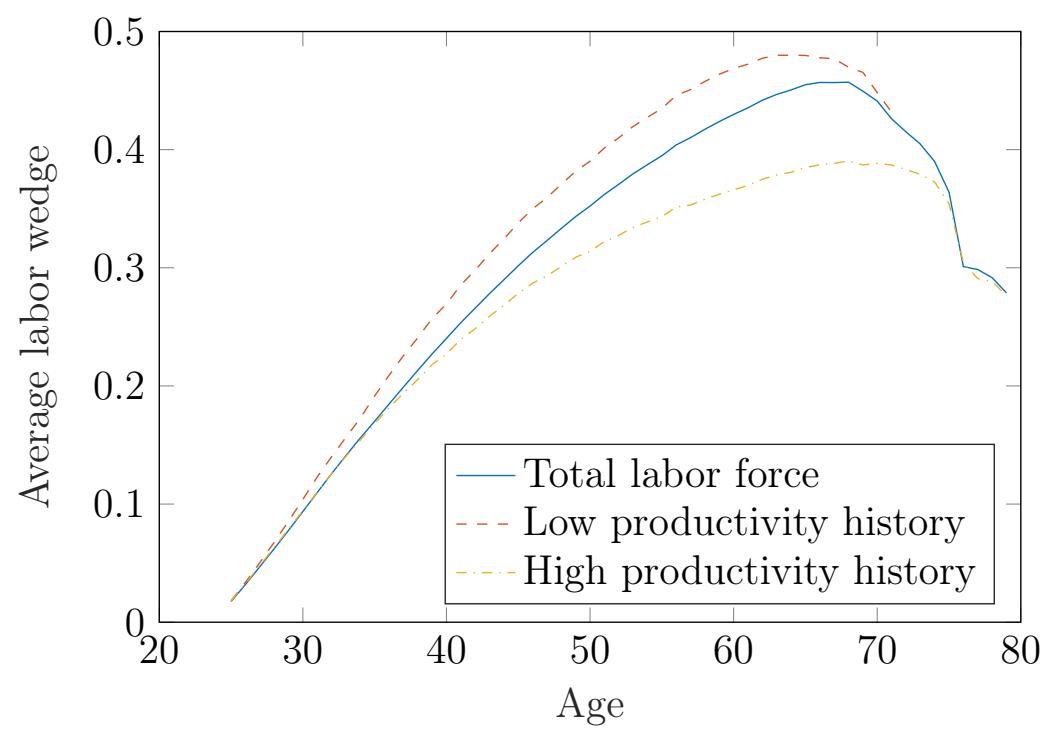

Figure 4: Cross-sectional averages of optimal labor wedge

workers is constant (resp. hump-shaped) before retirement, then increasing (resp. increasing) once some workers start retiring.
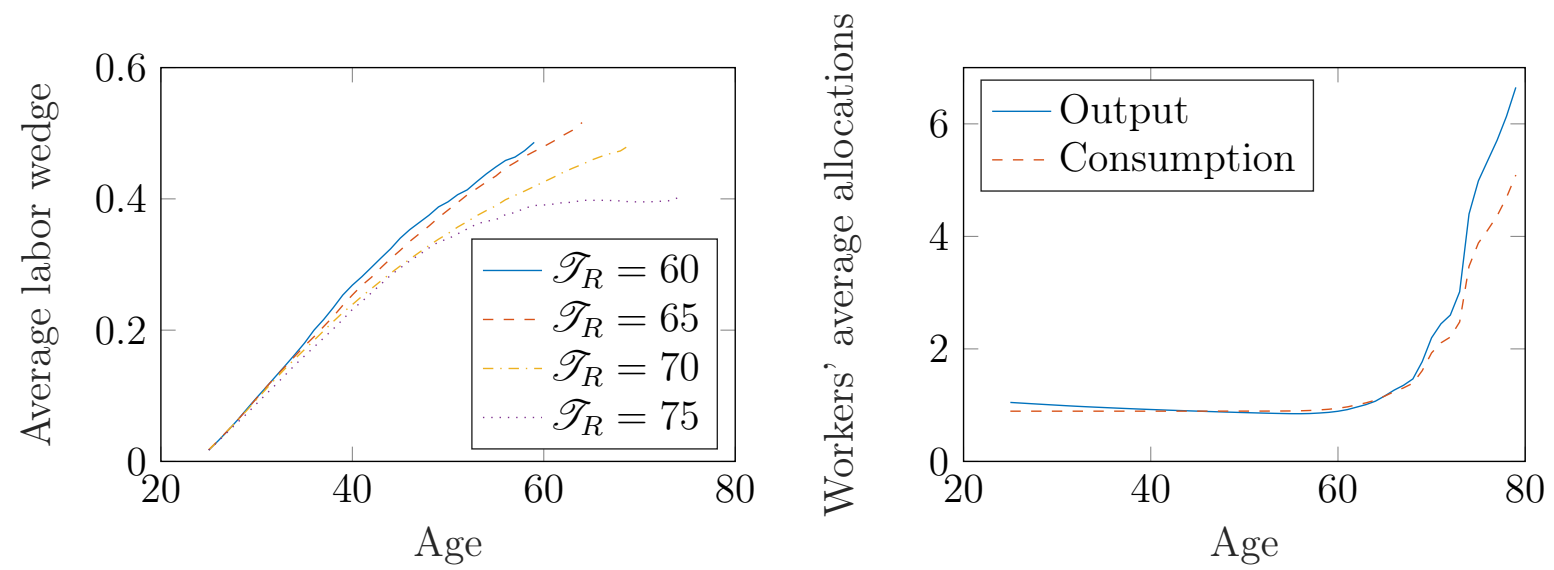

Figure 5: Left: Selection and labor wedge, Right: Mean allocations over working population

Retirement Consumption and Allocations The left panel of Figure 6 displays the allocations over the whole population. With log utility, the Inverse Euler equation implies that consumption is a martingale. Therefore, average consumption (dashed curve) is constant both before retirement and after retirement, while average output (solid) decreases slowly when most agents are working and decreases sharply once agents start retiring. The right panel of Figure 6 plots the mean consumption of retired agents. Over time, agents with higher consumption 
retire, which increases the average consumption of the retirees. The average consumption of retirees is increasing until almost all agents have retired, at which point it equals the average consumption of the whole population.
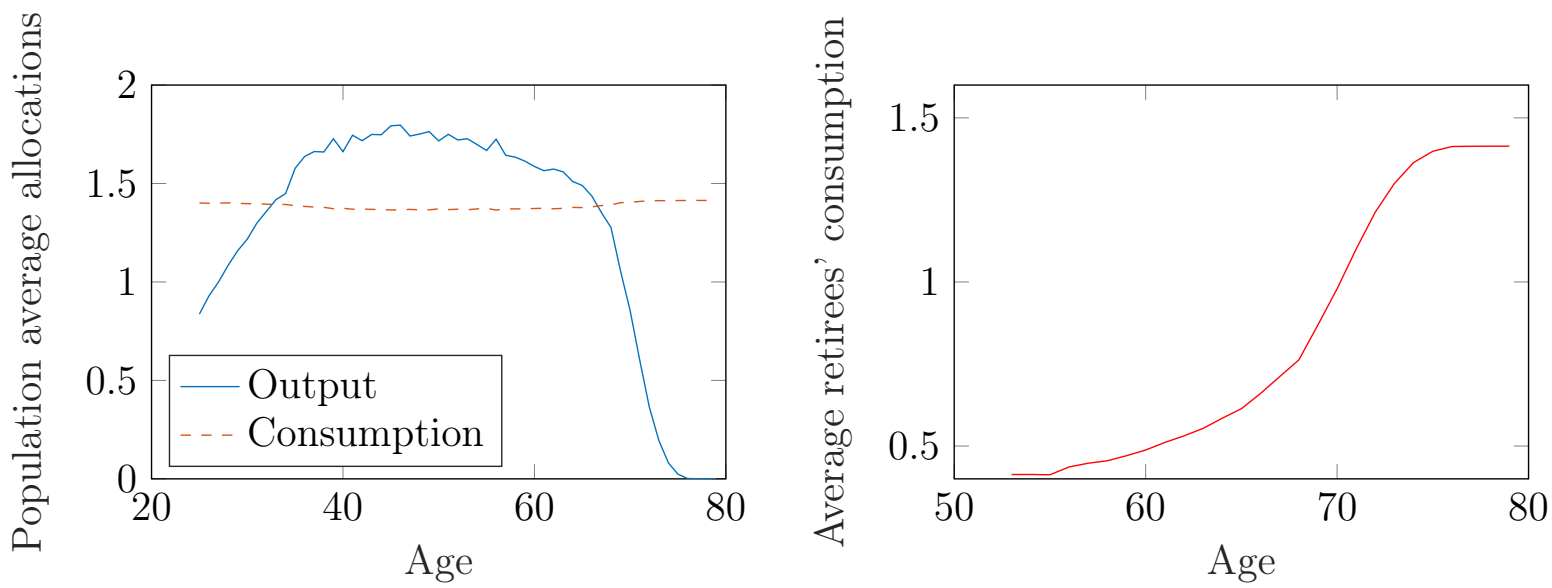

Figure 6: Left: Mean allocations over the whole population, Right: Mean consumption among retirees

\subsection{Welfare Analysis}

\subsubsection{Welfare Gains and Simple Policies}

I quantify the welfare gains compared with the baseline U.S. economy with a target labor force participation rate at ages 65-69 of 31.6\% and an Average Retirement Age (ARA) of $66.51 .{ }^{33}$ In the second-best, agents retire later on average compared with the baseline economy, with an ARA of 69.63 and a labor force participation rate at ages 65-69 of 77\%. The second-best improves welfare as much as an equivalent increase in consumption at all histories and periods of $1.75 \%$. These welfare gains are large and correspond to an upper bound on welfare gains from jointly reforming the U.S. tax system and SS system when productivity is unobservable.

From the optimal policies found above, I conduct several experiments. In all these experiments, I am interested in the welfare gains relative to the status quo U.S. tax code in the baseline economy. The simple policies I study are history independent but age-dependent. I consider linear taxes (marginal taxes that are flat in income) equal to the cross-sectional average of taxes from the simulations.

\footnotetext{
${ }^{33}$ The literature has usually compared the welfare from the second-best with the welfare achieved in a laissez-faire economy with no taxes or subsidies. Because of the importance of the SS benefits system, here the relevant economy to compare the second-best with is the baseline U.S. economy. In addition, such a direct comparison with a parametrization of the U.S. tax and SS system allows me to measure welfare gains of reforms.
} 
These experiments are motivated by the fact that they yield the bulk of the welfare gains in the optimal taxation literature that assumes a fixed retirement age (Farhi and Werning (2013), Golosov et al. (2016)). ${ }^{34}$ I qualify their results accounting for a flexible retirement age.

Table 2: Welfare Gains from Tax, SS, and Joint Tax and SS Reforms.

\begin{tabular}{ll}
\hline reforms & welfare gains as $\%$ of sb \\
\hline hump-shaped $\tau^{L}(t)$ average optimal wedge & 42.70 \\
\hline optimal $\left(\lambda_{s s}\left|\tau_{s s}\right|\right.$ age-dependent) SS reform & 34.44 \\
\hline hump-shaped $\tau^{L}(t)$ and Optimal age-dependent SS reform & 93.62 \\
hump-shaped $\tau^{L}(t)$ and Optimal $\lambda_{s s}$ SS reform & 62.46 \\
hump-shaped $\tau^{L}(t)$ and Optimal $\tau_{s s}$ SS reform & 46.87 \\
\hline
\end{tabular}

Note: Line 1 reports welfare gains from replacing the tax system with the hump-shaped in age linear labor tax over the cross-section of workers from the optimal policies. Line 2 reports welfare gains from optimal SS reforms (i) decrease $\lambda_{S S}$ or (ii) increase $\tau_{S S}$ while keeping the replacement rate of SS benefits fixed, or (iii) make SS benefits steeper in claiming age. Line 3 to 5 gives welfare gains from a joint combination of the humpshaped labor tax with its corresponding optimal SS reform (ii), (i) and (ii) respectively. A hump-shaped in age linear tax combined with steeper in claiming age SS benefits achieve the largest welfare gains as a fraction of the second-best gains.

In the reform of Line 1 of Table 2, the labor tax and capital tax in the baseline economy are replaced by the linear taxes (flat in income marginal tax) equal to the average labor wedge (hump-shaped in age) over the working population and the average capital wedge over the whole population, respectively. The goal of this experiment is to measure the welfare gains from a reform of the tax code alone. Replacing the tax code with the hump-shaped one brings modest welfare gains, with an increase in consumption at all histories and periods equivalent to $42.70 \%$ to that of the second-best. These welfare gains in consumption of $0.75 \%$ are high, but they are significantly lower than those under the second-best policies. While Farhi and Werning (2013) find that, with a fixed retirement age, simple age-dependent taxes achieve $95 \%$ of welfare gains from the second-best, I find that with flexible retirement, those welfare gains shrink to less than half the gains from the secondbest. A reform of the tax code alone, despite the increasing, then decreasing-in-age labor tax, induces agents to retire even earlier than in the baseline economy with an ARA of 61.32 and almost all agents retired by age 65 . The status quo SS system

\footnotetext{
${ }^{34}$ Optimizing over age-dependent taxes in this dynamic economy is computationally heavy because of the number of tax functions, one for each period, and the non-negligible time it takes for the income fluctuation algorithm to run for one set of parameter values.
} 
does not provide as strong incentives for delayed retirement as the optimal system does, and the wealth gains from age-dependent taxes induce agents to retire even earlier than in the baseline economy.

I investigate the benefits of reforming the SS system alone while keeping the tax system as in the status quo system in the baseline economy in the second line of Table 3. These reforms are within the one-dimensional class of those that either (i) uniformly decrease the level of benefits $\lambda_{S S}$ or (ii) increase the level of progressivity of benefits $\tau_{S S}$ while keeping the replacement rate of SS benefits fixed, or (iii) increase the absolute value of the "actuarial" adjustment rates of SS benefits (the Actuarial Reduction Factor before the NRA and the Delayed Retirement Credit after the NRA) and therefore make SS benefits steeper in claiming age. The optimal such reform is within the class that makes SS benefits steeper in claiming age, since, adjustment rates of SS benefits is the strongest margin that affects workers' decision to retire before or after the NRA. This reform requires setting a large uniform adjustment rate of $16 \%$ that is represented by the solid curve of the right panel of Figure 2. ${ }^{35}$ The welfare gains from such a claiming-age-dependent reform are $34.44 \%$ of those from the second-best, which is equivalent to a $0.6 \%$ increase in consumption in all histories and all periods. Therefore an optimal age-dependent reform of SS captures large welfare gains.

To capture more welfare gains, I augment the tax reform with the optimal claiming-age-dependent SS reform given the new tax system. The goal of this experiment is to measure the welfare gains from a joint reform of the tax code and SS system. The third line of Table 3 states that this reform achieves welfare gains equivalent to an increase of $1.64 \%$ consumption at all histories and periods or $93.62 \%$ of those from the second-best. Like French (2005) found, exit from the labor force before the NRA is mostly determined by the structure of SS benefits. By increasing adjustment rates of SS benefits in absolute value, one can induce agents to retire later. Because of the fixed cost that is incurred both by lowproductivity workers and high-productivity workers, most of the agents who delay retirement are highly productive. The decreasing-in-age labor tax after age 68 increases the efficiency of the intensive labor supply of these high-productivity workers, and we obtain the bulk of welfare gains from the age-dependent linear tax that is hump-shaped in age.

The fourth and fifth lines of Table 3 consider reforms that augment the tax

\footnotetext{
${ }^{35}$ Another reform would be to increase the NRA. The actuarial adjustment I found, that is the double of the status quo Delayed Retirement Credit and Actuarial Reduction Factor, is equivalent to a 14 months increase of the NRA for a 65 -year-old worker and 28 months increases of the NRA for a 64-year-old worker and so on.
} 
reform with an optimal SS that decreases the level of benefits $\lambda_{S S}$ and increases the level of progressivity of benefits $\tau_{S S}$ while keeping the replacement rate of SS benefits fixed, respectively. Like in the case of the the SS reform alone, these reforms capture less than the full optimal welfare gains, respectively, $62.46 \%$ and $46.87 \%$ of those from the second-best.

These experiments suggest that when accounting for flexible retirement, reforming the tax code alone is not enough and should be complemented with a SS reform. Within the class of the status quo SS system, reforms that make retirement benefits steeper in claiming age achieve the largest welfare gains.

\subsection{Counterfactual Analysis}

I consider a series of alternative reforms in order to determine: (i) how important the age-dependency of the tax system is in terms of welfare compared with an age-independent tax system, (ii) how important the hump-shaped profile of the labor tax is in terms of welfare compared with the family of increasing-in-age labor taxes, and (iii) how important a joint reform of the tax system and SS system is in terms of welfare compared with a reform of the tax code alone.

Table 3: Welfare gains from counterfactual policies as a \% of the second-best

\begin{tabular}{lll}
\hline scenarios & tax welfare gains & tax + SS welfare gains \\
\hline hump-shaped $\tau^{L}(t)$ average optimal policies & 42.70 & 93.62 \\
\hline optimal age-independent flat tax $\tau^{L}$ & 39.48 & 56.56 \\
\hline increasing-in-age $\tau^{L}(t)$ for fixed retirement age & 36.27 & 74.15 \\
increasing-in-age $\tau^{L}(t)$ for random retirement & 32.66 & 80.23 \\
increasing-in-age $\tau^{L}(t)$ approximation of opt wedge & 21.49 & 67.05 \\
\hline
\end{tabular}

Note: Left column gives welfare gains from tax reforms as \% of second-best gains. Right column gives welfare gains from joint tax and SS reform. Line 1 summarizes the welfare gains from policies derived from the second-best. Line 2 gives welfare gains from optimal age-independent flat tax. Lines 3 to 5 report welfare gains from counterfactual increasing-in-age taxes. Line 3 for linear labor taxes equal to the average labor wedge from the model with exogenous retirement at the optimal ARA, Line 4 for the linear labor taxes of a model with random retirement and finally Line 5 for the best increasingin-age approximation of optimal wedges. Hump-shaped in age taxes outperform ageindependent and increasing-in-age taxes when combined with claiming-age-dependent reform of SS benefits.

The first line of Table 3 summarizes the welfare gains from policies derived from the second-best, with the left column reporting the welfare gains from the 
tax reform alone (42.70\% of second-best gains), while the right column reports the welfare gains from a joint tax and SS reform (93.62\%).

Optimal Age-independent Taxes From second line of Table 3, the optimal age-independent flat tax $\left(\tau^{L}=22 \%\right.$ lower than the status quo income-weighted average marginal income tax of $37 \%$ ) achieves $39.48 \%$ of the welfare gains from the second-best, i.e., $0.69 \%$ more consumption per-period compared with the status quo. $^{36}$ Age-independent taxes perform as well as age-dependent taxes (42.70\%) under the status quo SS system. However, with an optimal SS reform given the optimal age-independent tax, the joint reform only capture $56.56 \%$ of the secondbest gains, while the same reform with age-dependent policies derived from the second-best achieves $93.62 \%$ of second-best gains. Therefore, under a joint reform of the tax and SS system, there is at least $37.06 \%$ of the gain from the second-best, i.e., $0.65 \%$ more consumption coming from age-dependency of the tax system.

To determine which type of age-dependency is needed in the tax system, I compare hump-shaped in age taxes with 3 counterfactual reforms that consider increasing-in-age labor income taxes in lines 3 to 5 of Table 3.

Counterfactual taxes from fixed retirement model The labor taxes (resp. capital taxes) in the baseline economy are replaced by taxes, respectively, equal to the increasing-in-age average labor wedge (resp. the average capital wedge) from the model with exogenous retirement at the age of 69.63 , which corresponds to the optimal ARA. ${ }^{37}$ Such taxes are increasing-in-age from $1.74 \%$ at age 25 to $43.79 \%$ at age 79 . The goal of this experiment is to see whether the standard result that an average labor wedge increasing in age achieves significant welfare holds once I account for a flexible retirement age.

The third line of Table 3 shows welfare achieved by such a reform. Changing the tax code with a counterfactual model and increasing-in-age linear labor tax actually achieves welfare comparable to the hump-shaped in age labor tax $(36.27 \%$ of the second-best for the former and $42.70 \%$ for the latter) but by significantly less than the second-best optimum. This is consistent with the finding in Farhi and Werning (2013) or Golosov et al. (2016) that with a fixed retirement age, an increasing-in-age linear labor tax is close to optimal. With a flexible retirement age, the increasing-in-age linear labor tax achieves similar welfare as the hump-

\footnotetext{
${ }^{36}$ In finding the optimal age-independent flat tax, I set an age-independent capital tax equal to the average capital wedge across ages and states. As in Farhi and Werning (2013), capital distortions do not play a major role for insurance in this framework.

${ }^{37}$ I perform the analysis for both fixed retirement ages 69 and 70.
} 
shaped in age labor tax, because they both induce agents to retire even earlier than in the baseline economy with an ARA of 61 so that almost all workers retire by age 65 . Therefore, the welfare gains from the decreasing portion of the humpshaped in age labor tax are not present without a reform of SS system. The welfare gains from a joint reform of the tax and SS system are $74.15 \%$ of the second-best. Compared with the first line, $93.62 \%$ of the second-best, the welfare gains from the increasing-in-age linear labor tax are significantly lower than the welfare gains from the hump-shaped in age labor tax once the SS system is reformed to correct for the retirement distribution. This suggests that decreasing the labor tax with age for old workers and reforming the SS system can be welfare improving by allowing high-productivity agents to work longer (over the extensive margin) and more efficiently (over the intensive margin).

Counterfactual taxes from random retirement model One might worry that the above comparison does not give justice to age-dependent taxes because the model with a fixed retirement age implicitly sets a linear labor tax of $100 \%$ after the second-best ARA. Therefore, I investigate the reforms that use the average labor wedges from a model where agents retirement randomly and at each point in time, the labor force participation rate is the same as in the model with endogenous retirement, i.e., $P\left(\mathscr{T}_{R}^{\text {random }}=t\right)=P\left(\mathscr{T}_{R}^{s b}=t\right)$ for all periods $t$. Such taxes are incrasing-in-age from $1.75 \%$ at age 25 to $50.19 \%$ at age 79 .

The fourth line of Table 3 gives the welfare gains from replacing the tax system with such taxes. This reform achieves slightly less welfare gains $(32.66 \%$ of the second-best) than the reform with the average wedges from the model with endogenous retirement under the status quo SS system. Once the SS system is reformed as well, it also achieves fewer welfare gains ( $80.23 \%$ of the second-best) than the hump-shaped in age linear labor tax (93.62\% of the second-best). Therefore, this reform suggests that the hump-shaped in age linear labor tax achieves at least $13.39 \%$ more welfare as a fraction of the second-best welfare gains, or $0.23 \%$ more consumption at all histories at all times, compared with the planner using a counterfactual model with increasing-in-age taxes while retirement is flexible.

Best increasing-in-age approximation of optimal wedges However, one can argue that the increasing-in-age linear labor tax from the model with random retirement in a context where retirement is flexible is expected to underperform compared with the hump-shaped one, because the model of the economy is the wrong model. To make the point about comparing the performance of hump- 
shaped in age linear labor taxes against the class of increasing-in-age linear labor taxes, I find the best flat in income and increasing-in-age approximation of optimal wedges by running a linear regression.

The best linear (in age) approximation of the hump-shaped in age average labor wedge gives a flat labor tax of $12.39 \%$ at age 25 that increases linearly in age until age 79 when it becomes $48.78 \%$. The last line from Table 3 shows that replacing the tax system with these increasing-in-age labor taxes brings $21.49 \%$ of the welfare gains from the second-best, which is comparatively low. In addition, since the increasing-in-age labor tax from the regression is lower than the humpshaped-in-age one at most ages before 68 , the ARA in the former reform (61.87) is higher than the ARA in the latter (61.32). Once the SS system is reformed as well, welfare gains are $67.05 \%$ of those from the second-best. These reforms suggest that a hump-shaped in age linear labor tax improves welfare more than an increasing-in-age linear labor tax, even when both taxes are set to mimic the optimal wedges of the right model with a flexible retirement age.

\section{Conclusion}

This paper studies optimal income taxes and retirement benefits in a life-cycle model with an intensive margin of labor supply and an endogenous retirement age. The planner insures individuals who privately observe persistent shocks to their productivity. In this environment, the optimal labor tax is hump-shaped in age, unlike in existing dynamic models with no endogenous retirement choice, in which the optimal tax is everywhere increasing. Because of the retirement margin, the total Frisch elasticity of labor supply increases with age. This elasticity effect flattens the labor tax for old workers relative to the model without an extensive margin. In addition, as high-productivity workers retire later than lowproductivity workers, the distribution of productivity in the labor force features, over time, a higher mean and lower variance than in the general population. This novel composition effect pushes for a labor tax that declines for old workers. Optimal policy balances these effects with the insurance benefits of taxation, yielding the hump-shape in tax rates. In numerical simulations, the optimum achieves sizable welfare gains that approximately optimal age-dependent taxes fail to capture under the status U.S. Social Security system. Nevertheless, an optimal combination of age-dependent linear taxes with steeper in claiming-age benefits generates welfare gains close to optimal.

As life expectancies have risen over the past century, accounting for retirement 
in social insurance policies is of first order importance. The theory proposed in this paper leads to two open empirical questions that are important in quantifying optimal policies. Empirical estimates of the time fixed costs and monetary fixed costs of work would improve the calibration of macro models to match micro evidence on extensive margin elasticities. Furthermore, an empirical estimate of the mean and variance of hourly wages among full-time workers age 60-75, would help quantify the strength of the novel composition effect highlighted in this paper.

\section{References}

Aguila, Emma, Attanasio, Orazio, And Meghir, Costas. 2011. Changes in consumption at retirement: evidence from panel data. Review of Economics and Statistics, 93(3), 1094-1099.

Albanesi, Stefania, And Sleet, Christopher. 2006. Dynamic optimal taxation with private information. The Review of Economic Studies, 73(1), 1-30.

Alpert, AbBy, And Powell, David. 2013. Estimating Intensive and Extensive Tax Responsiveness: Do Older Workers Respond to Income Taxes?

Atkinson, Anthony Barnes, and Stiglitz, Joseph E. 1976. The design of tax structure: direct versus indirect taxation. Journal of public Economics, 6(1-2), 55-75.

Banks, James, Blundell, Richard, And Tanner, Sarah. 1998. Is there a retirement-savings puzzle? American Economic Review, 769-788.

Barro, Robert J, And Redlick, Charles J. 2011. Macroeconomic effects from government purchases and taxes. The Quarterly Journal of Economics, 126(1), 51-102.

Bergemann, Dirk, And Strack, Philipp. 2015. Dynamic revenue maximization: A continuous time approach. Journal of Economic Theory, 159, 819-853.

Bismut, JeAn-Michel. 1973. Conjugate convex functions in optimal stochastic control. Journal of Mathematical Analysis and Applications, 44(2), 384-404.

Bureau, US Census. 2016. American community survey. Selected characteristics of the native and foreign-born populations: 2016 American Community Survey 1-year estimates.

Chang, Yongsung, Kim, Sun-Bin, Kwon, Kyooho, Rogerson, Richard, et al. . 2014. Individual and aggregate labor supply in a heterogeneous agent economy with intensive and extensive margins. Unpublished Manuscript.

Chetty, RAJ. 2012. Bounds on elasticities with optimization frictions: A synthesis of micro and macro evidence on labor supply. Econometrica, 80(3), 969-1018. 
Chetty, Raj, Guren, Adam, Manoli, Day, and Weber, Andrea. 2012. Does Indivisible Labor Explain the Difference between Micro and Macro Elasticities? A Meta-Analysis of Extensive Margin Elasticities. NBEr macroeconomics Annual.

Chetty, Raj, Stepner, Michael, Abraham, Sarah, lin, Shelby, Scuderi, Benjamin, Turner, Nicholas, Bergeron, Augustin, And Cutler, DAVID. 2016. The association between income and life expectancy in the United States, 2001-2014. Jama, 315(16), 1750-1766.

Choné, Philippe, and Laroque, Guy. 2014. Income tax and retirement schemes.

Conesa, Juan Carlos, Kitao, Sagiri, and Krueger, Dirk. 2009. Taxing capital? Not a bad idea after all! The American economic review, 99(1), 25-48.

Cremer, Helmuth, lozachmeur, Jean-Marie, and Pestieau, Pierre. 2004. Social security, retirement age and optimal income taxation. Journal of Public Economics, 88(11), 2259-2281.

De NARDi, MARIACRISTINA. 2004. Wealth inequality and intergenerational links. The Review of Economic Studies, 71(3), 743-768.

Deaton, Angus, And Paxson, Christina. 1994. Intertemporal choice and inequality. Journal of political economy, 102(3), 437-467.

Di Nunno, Giulia, Øksendal, Bernt Karsten, and Proske, Frank. 2009. Malliavin calculus for Lévy processes with applications to finance. Vol. 2. Springer.

Diamond, Peter Arthur, And Mirrlees, James A. 1978. A model of social insurance with variable retirement. Journal of Public Economics, 10(3), 295336.

Dixit, Avinash. 1993. Art of Smooth Pasting. Vol. 55. Fundamentals of Pure and Applied Economics.

Erosa, Andres, and Gervais, Martin. 2002. Optimal taxation in life-cycle economies. Journal of Economic Theory, 105(2), 338-369.

Farhi, Emmanuel, and Werning, Iván. 2013. Insurance and taxation over the life cycle. The Review of Economic Studies, 80(2), 596-635.

FrEnch, ERIC. 2005. The effects of health, wealth, and wages on labour supply and retirement behaviour. The Review of Economic Studies, 72(2), 395-427.

Golosov, Mikhail, And Tsyvinski, Aleh. 2006. Designing optimal disability insurance: A case for asset testing. Journal of Political Economy, 114(2), 257279 .

Golosov, Mikhail, And Tsyvinski, Aleh. 2015. Policy implications of dy- 
namic public finance. economics, 7(1), 147-171.

Golosov, Mikhail, Tsyvinski, Aleh, Werning, Ivan, Diamond, Peter, And Judd, Kenneth L. 2006. New Dynamic Public Finance: A User's Guide [with Comments and Discussion]. NBER macroeconomics annual, 21, 317-387. Golosov, Mikhail, Troshikin, Maxim, and Tsyvinski, Aleh. 2016. Redistribution and social insurance. The American Economic Review, 106(2), 359-386.

Gomes, Renato, Lozachmeur, Jean-Marie, and Pavan, Alessandro. 2017. Differential taxation and occupational choice. The Review of Economic Studies, rdx022.

Greenwood, Jeremy, Hercowitz, Zvi, and Huffman, Gregory W. 1988. Investment, capacity utilization, and the real business cycle. The American Economic Review, 402-417.

Grochulski, Borys, And Zhang, Yuzhe. 2016. Optimal Contracts with Reflection.

Gruber, Jonathan, And Wise, David. 1998. Social security and retirement: An international comparison. The American Economic Review, 88(2), 158-163.

Gruber, Jonathan, And Wise, David A. 2002 (December). Social Security Programs and Retirement Around the World: Micro Estimation. Working Paper 9407. National Bureau of Economic Research.

HAnsen, GARY D. 1993. The cyclical and secular behaviour of the labour input: Comparing efficiency units and hours worked. Journal of Applied Econometrics, 8(1), 71-80.

Hartman, Philip. 2002. Ordinary differential equations.

Heathcote, Jonathan, Storesletten, Kuetil, and Violante, GioVANNI L. 2005. Two views of inequality over the life cycle. Journal of the European Economic Association, 3(2-3), 765-775.

Heathcote, Jonathan, Perri, Fabrizio, and Violante, Giovanni L. 2010. Unequal we stand: An empirical analysis of economic inequality in the United States, 1967-2006. Review of Economic dynamics, 13(1), 15-51.

Heathcote, Jonathan, Storesletten, Kuetil, and Violante, GioVANNI L. 2014. Optimal tax progressivity: An analytical framework. Tech. rept. National Bureau of Economic Research.

Heathcote, Jonathan, Storesletten, Kjetil, Violante, Giovanni L, et al. . 2017. Optimal Progressivity with Age-Dependent Taxation. Tech. rept. Federal Reserve Bank of Minneapolis.

JACKA, SD, AND LynN, JR. 1992. Finite-horizon optimal stopping, obstacle 
problems and the shape of the continuation region. Stochastics Stochastics Rep, 39(25-42).

Jacquet, Laurence, Lehmann, Etienne, and Van der Linden, Bruno. 2013. Optimal redistributive taxation with both extensive and intensive responses. Journal of Economic Theory, 148(5), 1770-1805.

KAPIČKA, MAREK. 2013. Efficient allocations in dynamic private information economies with persistent shocks: A first-order approach. The Review of Economic Studies, rds045.

Karabarbounis, Marios. 2016. A road map for efficiently taxing heterogeneous agents. American Economic Journal: Macroeconomics, 8(2), 182-214.

Kushner, Harold, And Dupuis, Paul G. 2013. Numerical methods for stochastic control problems in continuous time. Vol. 24. Springer Science and Business Media.

Lazear, Edward P, And Moore, Robert L. 1988. Pensions and turnover. Pages 163-190 of: Pensions in the US Economy. University of Chicago Press.

Leland, Hayne E. 1994. Corporate debt value, bond covenants, and optimal capital structure. The journal of finance, 49(4), 1213-1252.

Makris, Miltiadis, And Pavan, Alessandro. 2017. Taxation under Learningby-Doing.

Michau, Jean-Baptiste. 2014. Optimal redistribution: A life-cycle perspective. Journal of Public Economics, 111, 1-16.

Mirrlees, James A. 1971. An exploration in the theory of optimum income taxation. The review of economic studies, 38(2), 175-208.

Munnell, Alicia H, And Soto, Mauricio. 2005. What replacement rates do households actually experience in retirement?

Pavan, Alessandro, Segal, Ilya, And Tolkka, Juuso. 2014. Dynamic mechanism design: A myersonian approach. Econometrica, 82(2), 601-653.

Peterman, William B. 2016. Reconciling micro and macro estimates of the Frisch labor supply elasticity. Economic Inquiry, 54(1), 100-120.

Prescott, Edward C, Rogerson, Richard, and Wallenius, Johanna. 2009. Lifetime aggregate labor supply with endogenous workweek length. Review of Economic Dynamics, 12(1), 23-36.

Reichling, Felix, and Whalen, Charles. 2012. Review of estimates of the Frisch elasticity of labor supply.

Rogerson, Richard, And Wallenius, Johanna. 2013. Nonconvexities, retirement, and the elasticity of labor supply. The American Economic Review, 103(4), 1445-1462. 
Rothschild, Casey, and Scheuer, Florian. 2013. Redistributive taxation in the roy model. The Quarterly Journal of Economics, 128(2), 623-668.

Ruggles, Steven, Flood, S, Goeken, R, Grover, J, Meyer, E, Pacas, J, And SobeK, M. 2018. IPUMS USA: Version 8.0 [dataset]. Minneapolis, MN: IPUMS.

Rust, John P. 1989. A dynamic programming model of retirement behavior. Pages 359-404 of: The economics of aging. University of Chicago Press.

Saez, Emmanuel. 2001. Using elasticities to derive optimal income tax rates. The review of economic studies, 68(1), 205-229.

Saez, Emmanuel. 2002. Optimal income transfer programs: intensive versus extensive labor supply responses. The Quarterly Journal of Economics, 117(3), 1039-1073.

Saez, Emmanuel, And Stantcheva, Stefanie. 2016. Generalized social marginal welfare weights for optimal tax theory. The American Economic Review, 106(1), 24-45.

SANNIKOV, YUliY. 2008. A continuous-time version of the principal-agent problem. The Review of Economic Studies, 75(3), 957-984.

SANNIKOV, YUliY. 2014. Moral hazard and long-run incentives. Unpublished working paper, Princeton University.

Shourideh, Ali, And Troshikin, Maxim. 2015. Incentives and efficiency of pension systems. Tech. rept. Mimeo.

Stantcheva, Stefanie. 2017. Optimal Taxation and Human Capital Policies over the Life Cycle. Journal of Political Economy, 125(6).

Stock, James H, And Wise, David A. 1988. Pensions, the option value of work, and retirement.

Storesletten, Kjetil, Telmer, Christopher I, and Yaron, Amir. 2004. Consumption and risk sharing over the life cycle. Journal of monetary Economics, 51(3), 609-633.

Strack, P, And Kruse, T. 2013. Optimal stopping with private information. Tech. rept. Mimeo.

Toossi, Mitra. 2015. Labor force projections to 2024: the labor force is growing, but slowly. Monthly Lab. Rev., 138, 1.

Weinzierl, Matthew. 2011. The surprising power of age-dependent taxes. The Review of Economic Studies, 78(4), 1490-1518.

Williams, NoAh. 2011. Persistent private information. Econometrica, 79(4), $1233-1275$. 


\section{A - Analytic Appendix}

\section{Proof of Propositions 1 and 5}

Proof. The planner's problem is

$$
\max _{\left\{\lambda, c_{t}, l_{t}, \mathscr{T}_{R}\right\}} \mathrm{E}\left\{\int_{0}^{T} e^{-\rho s}\left[u\left(c_{t}\right)-\lambda c_{t}\right] d t+\int_{0}^{\mathscr{T}_{R}} e^{-\rho s}\left[\lambda \theta_{t} l_{t}-\kappa \frac{\left(l_{t}\right)^{1+\frac{1}{\varepsilon}}}{1+\varepsilon}-\phi_{t}\left(\theta_{t}\right)\right] d t\right\}
$$

subject to the law of motion of productivity (1). From the optimal allocations $u^{\prime}(c)=\lambda$ and $\kappa l_{t}^{\frac{1}{\varepsilon}}=\lambda \theta_{t}$, denote $\mathrm{E}\left\{\int_{0}^{T} e^{-\rho s}\left[u\left(c_{t}\right)-\lambda c_{t}\right] d t\right\}=h(\lambda)$. Then the above objective rewrites as

$$
\max _{\left\{\lambda, \mathscr{T}_{R}\right\}} h(\lambda)+\mathrm{E}\left\{\int_{0}^{\mathscr{T}_{R}} e^{-\rho t}\left[\lambda^{1+\varepsilon} \frac{\left(\theta_{t}\right)^{1+\varepsilon}}{\kappa^{\varepsilon}(1+\varepsilon)}-\phi_{t}\left(\theta_{t}\right)\right] d t\right\} .
$$

Denote a maximizer by $\lambda^{*}$. By an envelope condition, the expected change in the payoff if retirement is delayed an infinitesimal short time is $\lambda^{* 1+\varepsilon} \frac{\left(\theta_{t}\right)^{1+\varepsilon}}{\kappa^{\varepsilon}(1+\varepsilon)}-\phi_{t}\left(\theta_{t}\right)$. Taking $\psi<\frac{\lambda^{* 1+\varepsilon}}{\kappa^{\varepsilon}}$ in the condition of growth bounded from above of $\phi_{t}(\theta)$ in Proposition 1 or assuming that $G$ is high enough such that marginal utility of consumption $\lambda^{* 1+\varepsilon}$ is high and the inequality holds, then the expected change in payoff is increasing in productivity. The dynamic single crossing condition in Strack and Kruse (2013) holds and Theorem 4.3 of Jacka and Lynn (1992) implies that the shape of the stopping region (retirement rule) is determined by a timevarying threshold.

Note that when $\phi_{t}$ is independent of productivity, or nonincreasing in productivity, the "bounded growth from above" condition in the Propositon holds, implying Proposition 1.

\section{Proof of Corollary 1}

Proof. Consider the infinite horizon model, $T=+\infty$. To ensure convergence of social welfare, I assume

$$
\rho>(1+\varepsilon)\left(\mu+\frac{1}{2} \sigma^{2} \varepsilon\right)
$$


Social welfare is now time-independent and replacing the HJB equation in this setting is

$$
\max \left\{0-w(\theta),-\rho w(\theta)+\mu \theta w_{\theta}+\frac{\sigma^{2} \theta^{2}}{2} w_{\theta \theta}+\frac{\theta^{1+\varepsilon}}{\kappa^{\varepsilon}(1+\varepsilon)}-\phi\right\} .
$$

I conjecture that the solution is of the following form: there is a threshold $\theta_{R}^{f b}$ such that an agent is retired if and only if his productivity falls below the threshold $\theta_{t} \leq \theta_{R}^{f b}$. This implies that $w(\theta)=0$ for all $\theta \leq \theta_{R}^{f b}$ and for $\theta>\theta_{R}^{f b}, w$ is a nonnegative solution to the equation

$$
-\rho w(\theta)+\mu \theta w_{\theta}+\frac{\sigma^{2} \theta^{2}}{2} w_{\theta \theta}=-\frac{\theta^{1+\varepsilon}}{\kappa^{\varepsilon}(1+\varepsilon)}+\phi
$$

Moreover, $w$ must be $C^{1}$ on its entire domain. This implies that $w\left(\theta_{R}^{f b}\right)=0$ a value matching condition and $w_{\theta}\left(\theta_{R}^{f b}\right)=0$, a smooth pasting condition. Finally, observe that, for $\theta \leq \theta_{R}^{f b}$, the second term in the right hand side of (27) implies that $\frac{\theta^{1+\varepsilon}}{\kappa^{\varepsilon}(1+\varepsilon)} \leq \phi$ i.e. at retirement and afterwards, the marginal social value of continued work is negative. In particular $\hat{\theta}_{R}^{f b} \leq \theta^{*}$.

Define the quadratic polynomial $P(x)=-\rho+\mu x+\frac{\sigma^{2}}{2} x(x-1)$. The homogeneous equation

$$
-\rho w(\theta)+\mu \theta w_{\theta}+\frac{\sigma^{2} \theta^{2}}{2} w_{\theta \theta}=0
$$

admits the general solution

$$
w(\theta)=C_{-} \theta^{x_{-}}+C_{+} \theta^{x_{+}}
$$

in which $x_{-}$and and $x_{+}$are the negative and positive roots of $P$. I find a particular solution for each non-homogenous term, respectively denoted $A \theta^{1+\varepsilon}$ and $B$ in which $A=-\frac{1}{\kappa^{\varepsilon}(1+\varepsilon) P(1+\varepsilon)}$ and $B=-\frac{\phi}{\rho}$. By the assumption in $(26), P(1+$ $\varepsilon)<0$. The sum of these particular solutions $A \theta^{1+\varepsilon}+B$ is the value of social welfare if agents never retire.

By the superposition principle of linear homogenous ODEs the solution takes the form

$$
w(\theta)=A \theta^{1+\varepsilon}+B+C_{-} \theta^{x_{-}}+C_{+} \theta^{x_{+}}
$$

for $\theta>\theta_{R}^{f b}$ and $w(\theta)=0$ for $\theta \leq \theta_{R}^{f b}$. From (26) I ensure that $x_{+}>1+\varepsilon$. Since $l^{f b}-\kappa \frac{\left(l^{f b}\right)^{1+\frac{1}{\varepsilon}}}{1+\frac{1}{\varepsilon}}=\frac{\theta^{1+\varepsilon}}{\kappa^{\varepsilon}(1+\varepsilon)}$ I can conjecture that $w(\theta)=_{\theta \rightarrow+\infty} \mathcal{O}\left(\theta^{1+\varepsilon}\right)$. Therefore $C_{+}=0$. 
By the value matching and smooth pasting conditions:

$$
\begin{gathered}
A\left(\theta_{R}^{f b}\right)^{1+\varepsilon}+B+C_{-}\left(\theta_{R}^{f b}\right)^{x_{-}}=0 \\
(1+\varepsilon) A \frac{\left(\theta_{R}^{f b}\right)^{1+\varepsilon}}{\theta_{R}^{f b}}+x_{-} C_{-} \frac{\left(\theta_{R}^{f b}\right)^{x_{-}}}{\theta_{R}^{f b}}=0 .
\end{gathered}
$$

Multiplying (32) by $x_{-}$and (33) by $\hat{\theta}_{R}^{f b}$ and subtracting the two yields

$$
\left(1+\varepsilon-x_{-}\right) A\left(\theta_{R}^{f b}\right)^{1+\varepsilon}=x_{-} B .
$$

Thus the expression of $\theta_{R}^{f b}$ and $w$ in Corollary 1 follow by replacing the values of $A$ and $B$.

Now in finite horizon, the problem is time dependent and thresholds are time dependent. When time goes to $T$, the value of waiting for productivity to improve decreases and thresholds converge to $\theta^{*}$. Only the dynamic single crossing property of the derivative operator is needed in finite horizon for this to hold. This is again an application of Jacka and Lynn (1992).

\section{The First Order Approach}

\subsection{First Order Approach under Risk Neutrality}

I first introduce the First Order Approach (FOA) in the simpler setting in which agents are risk neutral in consumption and productivity is a GBM. I relax incentive compatibility by considering a family of deviations that Bergemann and Strack (2015) call consistent deviations. The effect of these deviations on promised utility can be summarized by what Pavan et al. (2014) call the impulse response function. This FOA is standard in the dynamic contracting literature with persistent shocks.

The value of the agent's productivity if he reports his productivity truthfully is

$$
\theta_{t}=\theta_{0} \exp \left(\left(\mu-\frac{\sigma^{2}}{2}\right) t+\sigma B_{t}\right)
$$

I define $\Phi$ by $\theta_{t} \equiv \Phi\left(t, \theta_{0}, B_{t}\right)$ and set the following definition, which is motivated by Bergemann and Strack (2015).

Definition 2. (Consistent deviations). A deviation is called consistent if an agent, with real productivity $\theta_{t}=\Phi\left(t, \theta_{0}, B_{t}\right)$ and associated initial shock $\theta_{0}$, misreports his initial shock by announcing $\tilde{\theta}_{0} \in \Theta_{0}$ at $t=0$ and continues to misreport $\tilde{\theta}_{t}=\Phi\left(t, \tilde{\theta}_{0}, B_{t}\right)$ instead of his true productivity $\theta_{t}$ at all future dates $t \leq T$. 
With this definition, an agent who follows a consistent deviation misreports his true type in all future periods. An agent's reported productivity $\tilde{\theta}_{t}=\Phi\left(t, \tilde{\theta}_{0}, B_{t}\right)$ would be equal to the productivity he would have had if his initial shock had been $\tilde{\theta}_{0}$ instead of $\theta_{0}$. From these misreports, the planner can infer the true realized path of Brownian shocks $B_{t}$. However, since the allocations depend on the history of productivities instead of the Brownian shocks, the inference on the Brownian shocks is not of immediate use for the principal. Bergemann and Strack (2015) show that incentive compatibility with respect to consistent deviations - which is a one-dimensional class of deviations - is sufficient for full incentive compatibility in the risk-neutral and GBM case. This result allows me to derive the incentivecompatible optimal allocations and retirement distortions.

Consider the ex-ante utility at time 0 of an agent with initial productivity $\theta_{0}$ who announces $\tilde{\theta}_{0}$ and follows consistent deviations; denoting it $v\left(\theta_{0}, \tilde{\theta}_{0}\right)$. Then $v\left(\theta_{0}, \tilde{\theta}_{0}\right)=\mathrm{E}^{\{\tilde{\theta}\}}\left\{\int_{0}^{T} e^{-\rho t} c_{t}\left(\tilde{\theta}_{0}\right) d t-\int_{0}^{\mathscr{T}_{R}\left(\tilde{\theta}_{0}\right)} e^{-\rho t}\left[\kappa \frac{\left(\frac{y_{t}\left(\tilde{\theta}_{0}\right)}{\Phi\left(t, \theta_{0}, B_{t}\right)}\right)^{1+\frac{1}{\varepsilon}}}{1+\frac{1}{\varepsilon}}+\phi_{t}\left(\Phi\left(t, \theta_{0}, B_{t}\right)\right)\right] d t \mid \tilde{\theta}_{0}\right\}$.

Restricting attention to consistent deviations alone, the incentive problem turns into a static one. Truthful reports at time zero are necessary for incentive compatibility, i.e. $v\left(\theta_{0}\right)=\max _{\tilde{\theta}_{0}} v\left(\theta_{0}, \tilde{\theta}_{0}\right)$ and an envelope condition allows me to obtain the derivative of ex-ante utility. The sensitivity of ex-ante utility with respect to initial reports satisfies:

$$
v_{\theta}\left(\theta_{0}\right)=\mathrm{E}\left\{\int_{0}^{\mathscr{T}_{R}} e^{-\rho t}\left[\left(1+\frac{1}{\varepsilon}\right)\left(\frac{\Phi_{\theta}\left(t, \theta_{0}, B_{t}\right)}{\theta_{t}}\right) \kappa \frac{\left(\frac{y_{t}}{\theta_{t}}\right)^{1+\frac{1}{\varepsilon}}}{1+\frac{1}{\varepsilon}}-\Phi_{\theta}\left(t, \theta_{0}, B_{t}\right) \phi_{t}^{\prime}\left(\theta_{t}\right)\right] d t \mid \theta_{0}\right\} .
$$

$\Phi_{\theta}\left(t, \theta_{0}, B_{t}\right)$ is what Pavan et al. (2014) call the impulse response function and Bergemann and Strack (2015) call the stochastic flow in continuous-time. Here with GBM productivity the stochastic flow is the ratio of current productivity to initial productivity, that is,

$$
\Phi_{\theta}\left(t, \theta_{0}, B_{t}\right)=\exp \left(\left(\mu-\frac{\sigma^{2}}{2}\right) t+\sigma B_{t}\right)=\theta_{t} / \theta_{0}
$$

Then the incentive compatibility constraint simplifies to

$$
v_{\theta}\left(\theta_{0}\right)=\frac{1}{\theta_{0}} \mathrm{E}\left\{\int_{0}^{\mathscr{T}_{R}} e^{-\rho t}\left[\left(1+\frac{1}{\varepsilon}\right) \kappa \frac{\left(\frac{y_{t}}{\theta_{t}}\right)^{1+\frac{1}{\varepsilon}}}{1+\frac{1}{\varepsilon}}-\theta_{t} \phi_{t}^{\prime}\left(\theta_{t}\right)\right] d t \mid \theta_{0}\right\} .
$$




\subsection{First Order Approach under Risk Aversion}

Here, I relax incentive compatibility by considering specific types of deviations as in the risk neutral case. Suppose the agent has reported his type truthfully until time $t,\left\{\tilde{\theta}^{t}\right\}=\left\{\theta^{t}\right\}$ and then decides to misreport his type. Since the planner observes continuous reports from the agent, she can construct a process $B_{t}^{\tilde{\theta}}$ from the reports that evolves according to $d B_{t}^{\tilde{\theta}}=\frac{d \tilde{\theta}_{t}-\mu_{t} \tilde{\theta}_{t} d t}{\sigma_{t} \tilde{\theta}_{t}}$. Under truthtelling, $B_{t}^{\tilde{\theta}}=B_{t}$. Therefore, the agent is restricted to reports that make $B_{t}^{\tilde{\theta}}$ a Brownian motion. The Girsanov Theorem implies that there exist misreports $-\eta_{t}$ such that $d B_{t}=d B_{t}^{\tilde{\theta}}+\eta_{t} d t$ under the measure $\mathcal{Q}$ of the Brownian motion $B_{t}^{\tilde{\theta}}$ and gives the formula for the change of measure from $\mathcal{P}$ to $\mathcal{Q}$. An incentive compatible mechanism must be immune to these deviations.

Lemma 3. (Sensitivity of promised utility) IC $\subseteq$ FOA. Moreover, If an allocation $\{c, y, \nu\} \in F O A$ then there exists a process $\left\{\sigma_{\Delta, t}\right\}$ such that the sensitivity process $\left\{\Delta_{t}\right\}$ has the integral form:

$$
\Delta_{t}=\mathrm{E}\left\{\int_{t}^{\mathscr{T}_{\mathscr{R}}} e^{-\rho s}\left[\mu_{s} \Delta_{s}+u_{\theta}\left(c_{s}, \frac{y_{s}}{\theta_{s}}\right)-\phi_{s}^{\prime}\left(\theta_{s}\right)+\sigma_{\Delta, s} \sigma_{s}\right] d s \mid \mathcal{F}_{t}\right\}
$$

Proof. Denote $\{\tilde{\theta}\}$ the process reported by the agent. Let $\theta_{t}=\theta$ at time $t$. By Girsanov's theorem, there exists a process $\{\eta\}$ is adapted to $\mathcal{F}_{t}$ such that

$$
d \tilde{\theta}_{t}=d \theta_{t}+\eta_{t} d t=\left(\theta_{t} \mu_{t}+\eta_{t}\right) d t+\theta_{t} \sigma_{t} d B_{t}
$$

The agent's problem is to choose controls $\eta_{t}$ to maximize promised utility for given allocations $\{c, y\}$ and retirement rule $\mathscr{T}_{R}$. Denote $\left\{\theta^{\eta}\right\} \equiv\{\tilde{\theta}\}$ the misreports generated by $\{\eta\}$. Global incentive compatibility is equivalent to the fact that the optimal report is truth-telling i.e $\eta_{t}^{\star}=0 \forall t$. Now with the FOA, assume that all the controls $\eta_{s}, \forall s \in[0, t)$ have been equal to 0 so far. Promised utility at time $t$ given the control $\eta$ is

$w_{t}\left(\theta, \theta^{\eta}\right)=\sup _{\{\eta\}} E\left\{\int_{t}^{\mathscr{T}_{R}(\eta)} e^{-\rho(s-t)}\left[u\left(c_{s}(\eta), \frac{y_{s}(\eta)}{\theta_{s}}\right)-\phi_{s}\left(\theta_{s}\right)\right] d s+\int_{\mathscr{T}_{R}(\eta)}^{T} e^{-\rho(s-t)}\left[u\left(c_{s}(\eta), 0\right)\right] d s \mid \mathcal{F}_{t}^{\eta}\right\}$.

The expectation above is taken with respect to the realization of the process $\{\tilde{\theta}\}$, since it is reports that determines the allocation and the retirement rule. If the agent follows a process $\eta$ then

$$
d B_{t}^{\eta}=\frac{d \theta_{t}^{\eta}-\left(\left(\theta_{t}^{\eta}-\int_{0}^{t} \eta_{s} d s\right) \mu_{t}+\eta_{t}\right) d t}{\left(\theta_{t}^{\eta}-\int_{0}^{t} \eta_{s} d s\right) \sigma_{t}}
$$

forms a standard Brownian motion. Therefore, there is exists nonnegative process 
$\gamma^{\eta}$ and some sensitivity process $Y^{\prime} \eta$ such that

$$
d w_{t}\left(\theta_{t}, \theta_{t}^{\eta}\right)=\left(\rho w_{t}\left(\theta_{t}, \theta_{t}^{\eta}\right)-u\left(c_{t}, \frac{y_{t}}{\theta_{t}}\right)+\phi_{t}\left(\theta_{t}\right)\right) d t-\gamma_{t}^{\eta} d t+\sigma_{t} Y_{t}^{\prime \eta} d B_{t}^{\eta} .
$$

Then replacing the standard Brownian from (41) in this equation we have

$$
d w_{t}\left(\theta_{t}, \theta_{t}^{\eta}\right)=\left(\rho w_{t}\left(\theta_{t}, \theta_{t}^{\eta}\right)-u+\phi\right) d t-\gamma_{t}^{\eta} d t+\sigma_{t} Y_{t}^{\eta}\left[d \theta_{t}^{\eta}-\left(\left(\theta_{t}^{\eta}-\int_{0}^{t} \eta_{s} d s\right) \mu_{t}+\eta_{t}\right) d t\right]
$$

Since the dependence on past controls $\eta=0$ is completely captured by the current value of $\theta^{\eta}, v_{t}=w_{t}\left(\theta_{t}, \theta^{\eta=0}\right)$. Ito's formula implies that

$d w_{t}\left(\theta_{t}, \theta_{t}^{\eta}\right)=\partial_{t} w_{t}\left(\theta_{t}, \theta^{\eta}\right) d t+\partial_{\theta^{\eta}} w_{t}\left(\theta_{t}, \theta_{t}^{\eta}\right)\left(\theta_{t} \mu_{t}+\eta_{t}\right) d t+\partial_{\theta^{\eta}} w_{t}\left(\theta_{t}, \theta_{t}^{\eta}\right) \theta_{t} \sigma_{t} d B_{t}+\frac{1}{2} \partial_{\left(\theta^{\eta}\right)^{2}}^{2} w_{t}\left(\theta_{t}, \theta_{t}^{\eta}\right) \theta_{t}^{2} \sigma_{t}^{2} d t$

The equation (42) becomes with the FOA $\eta_{s}=0, \forall s \in[0, t)$ :

$$
d w_{t}\left(\theta_{t}, \theta_{t}^{\eta}\right)=\left(\rho w_{t}\left(\theta_{t}, \theta_{t}^{\eta}\right)-u\left(c_{t}, \frac{y_{t}}{\theta_{t}}\right)+\phi_{t}\left(\theta_{t}\right)\right) d t-\gamma_{t}^{\eta} d t+\theta_{t}^{\eta} \sigma_{t} Y_{t}^{\eta} d B_{t}
$$

Comparing equations (43) and (42) and equalizing their drifts yield:

$\partial_{t} w_{t}\left(\theta_{t}, \theta_{t}^{\eta}\right)+\partial_{\theta^{\eta}} w_{t}\left(\theta_{t}, \theta_{t}^{\eta}\right)\left(\theta_{t} \mu_{t}+\eta_{t}\right)+\frac{1}{2} \partial_{\left(\theta^{\eta}\right)^{2}}^{2} w_{t}\left(\theta_{t}, \theta_{t}^{\eta}\right) \theta_{t}^{2} \sigma_{t}^{2}=\left(\rho w_{t}\left(\theta_{t}, \theta_{t}^{\eta}\right)-u\left(c_{t}, \frac{y_{t}}{\theta_{t}}\right)+\phi_{t}\left(\theta_{t}\right)\right) d t-\gamma_{t}^{\eta} d t$.

Now I obtain the Hamilton-Jacobi-Bellman equation for $w_{t}$

$\rho w_{t}\left(\theta_{t}, \theta_{t}^{\eta}\right)=\sup _{\eta_{t}}\left\{\partial_{t} w_{t}\left(\theta_{t}, \theta^{\eta}\right)+\partial_{\theta^{\eta}} w_{t}\left(\theta_{t}, \theta_{t}^{\eta}\right)\left(\theta_{t} \mu_{t}+\eta_{t}\right)+\frac{1}{2} \partial_{\left(\theta^{\eta}\right)^{2}}^{2} w_{t}\left(\theta_{t}, \theta_{t}^{\eta}\right) \theta_{t}^{2} \sigma_{t}^{2}+u\left(c_{t}, \frac{y_{t}}{\theta_{t}}\right)-\phi_{t}\left(\theta_{t}\right)\right\}$.

Therefore following Theorem 3.1, p. 95 in Hartman (2002), The envelope theorem implies $^{38}$

$$
\begin{gathered}
\rho \partial_{\theta} w_{t}\left(\theta_{t}, \theta_{t}^{\eta}\right)=\partial_{t, \theta} w_{t}\left(\theta_{t}, \theta^{\eta}\right)+\partial_{\theta^{\eta}, \theta}^{2} w_{t}\left(\theta_{t}, \theta_{t}^{\eta}\right)\left(\theta_{t} \mu_{t}+\eta_{t}\right)+\partial_{\theta^{\eta}} w_{t}\left(\theta_{t}, \theta_{t}^{\eta}\right) \mu_{t}+\frac{1}{2} \partial_{\left(\theta^{\eta}\right)^{2}, \theta}^{3} w_{t}\left(\theta_{t}, \theta_{t}^{\eta}\right) \theta_{t}^{2} \sigma_{t}^{2} \\
+\partial_{\left(\theta^{\eta}\right)^{2}}^{2} w_{t}\left(\theta_{t}, \theta_{t}^{\eta}\right) \theta_{t} \sigma_{t}^{2}+u_{\theta}\left(c_{t}, \frac{y_{t}}{\theta_{t}}\right)-\phi_{t}^{\prime}\left(\theta_{t}\right) .
\end{gathered}
$$

This expression can be evaluated at $\eta_{t}=0$, writing $\frac{\partial w_{t}(x, \theta)}{\partial \theta}=\Delta_{t}(x, \theta)$ and considering the fact that when $\eta_{t}=0$ we have $\partial w_{\theta^{\eta}}\left(\theta, \theta^{\eta}\right)=\Delta_{t}$, so that

$$
\rho \Delta_{t}=\partial_{t} \Delta_{t}+\partial_{\theta} \Delta_{t}\left(\theta_{t} \mu_{t}+0\right)+\Delta_{t} \mu_{t}+\frac{1}{2} \partial_{(\theta)^{2}}^{2}\left(\Delta_{t}\right) \theta_{t}^{2} \sigma_{t}^{2}+\partial_{\theta} \Delta_{t} \theta_{t} \sigma_{t}^{2}+u_{\theta}\left(c_{t}, \frac{y_{t}}{\theta_{t}}\right)-\phi_{t}^{\prime}\left(\theta_{t}\right) .
$$

The Feynman-Kac formula applies to this differential equation and I deduce that

$$
\Delta_{t}=\mathrm{E}\left\{\int_{t}^{\mathscr{T}_{R}} e^{-\rho s}\left[\Delta_{s} \mu_{s}-u_{\theta}\left(c_{s}, \frac{y_{s}}{\theta_{s}}\right)+\phi_{s}^{\prime}\left(\theta_{s}\right)+\partial_{\theta} \Delta_{s} \theta_{s} \sigma_{s}^{2}\right] d s+\Delta_{\mathscr{T}_{R}} \mid \mathcal{F}_{\mathrm{t}}\right\} .
$$

\footnotetext{
${ }^{38}$ For a fully rigorous argument, one needs to make regularity assumptions on $\mathscr{T}_{R}$ and use Malliavin calculus to differentiate with respect to stochastic processes. See Di Nunno et al. (2009).
} 
After retirement, an optimal allocation must give constant consumption. Therefore the sensitivity is zero at retirement. This with $\partial_{\theta} \Delta_{s} \theta_{s}=\sigma_{\Delta, s}$, implies the result:

$$
\Delta_{t}=\mathrm{E}\left\{\int_{t}^{\mathscr{T}_{R}} e^{-\rho s}\left[\Delta_{s} \mu_{s}-u_{\theta}\left(c_{s}, \frac{y_{s}}{\theta_{s}}\right)+\phi_{s}^{\prime}\left(\theta_{s}\right)+\sigma_{\Delta, s} \sigma_{s}^{2}\right] d s \mid \mathcal{F}_{\mathrm{t}}\right\}
$$

Hamilton-Jacobi-Bellman Equation First, for the sake of legibility I drop the state 4-tuple $(v, \Delta, \theta, t)$ from the notation. The associated Hamilton-JacobiBellman equation to this problem is then:

$$
0=\max _{c_{t}, y_{t}, \sigma_{\Delta, t}}\left\{-K+g(t) u_{l=0}^{-1}\left(\frac{v}{g(t)}\right) \quad, \quad-\rho K+\left(c_{t}-y_{t}\right)+\mathcal{L}(v, \Delta, \theta, t) \circ K\right\}
$$

in which $\mathcal{L}(v, \Delta, \theta, t)$ is the derivative operator with respect to state variables:

$$
\begin{aligned}
\mathcal{L}(v, \Delta, \theta, t) \circ K & =K_{v}\left[\rho v_{t}-u+\phi_{t}\right]+K_{\Delta}\left[(\rho-\mu) \Delta_{t}-u_{\theta}+\phi_{t}^{\prime}-\sigma_{\Delta, t} \sigma\right]+K_{t}+K_{\theta} \theta_{t} \mu \\
& +\frac{1}{2} K_{v v} \theta_{t}^{2} \Delta_{t}^{2} \sigma^{2}+\frac{1}{2} K_{\Delta \Delta} \sigma_{\Delta, t}^{2} \sigma^{2}+\frac{1}{2} K_{\theta \theta} \theta_{t}^{2} \sigma^{2} \\
& +K_{v \Delta} \theta_{t} \Delta_{t} \sigma_{\Delta, t} \sigma^{2}+K_{v \theta} \theta_{t}^{2} \Delta_{t} \sigma^{2}+K_{\Delta \theta} \theta_{t} \sigma_{\Delta, t} \sigma^{2}
\end{aligned}
$$

The first component of the right-hand side of this dynamic equation captures that once an agent is retired with promised utility $v$, the cost of providing such utility is the discounted value of the flow consumption $u_{l=0}^{-1}\left(\frac{v}{g(t)}\right)$. The second component captures the fact that before retirement, the flow cost over an infinitesimal time $d t$ is the discounted cost $-\rho K d t$, flow consumption minus output, and the derivatives of the cost function with respect to state variables. By optimality, these should sum up to zero in the working region.

\section{Proof of Lemma 2}

Proof. For given consumption, output, $\{c, y\}$ and retirement rule $\mathscr{T}_{R}$, the expected utility of an agent is at time $t$ is:

$$
v_{t}=\mathrm{E}\left\{\int_{t}^{\mathscr{T}_{R}} e^{-\rho(s-t)} u\left(c_{s}, \frac{y_{s}}{\theta_{s}}\right) d s+\int_{\mathscr{T}_{R}}^{T} e^{-\rho(s-t)} u\left(c_{s}, 0\right) d s \mid \mathcal{F}_{t}\right\}
$$


Then

$e^{-\rho t} v_{t}+\int_{0}^{t} e^{-\rho s} u\left(c_{s}, \frac{y_{s}}{\theta_{s}}\right) d s=\mathrm{E}\{\underbrace{\int_{0}^{\mathscr{T}_{R}} e^{-\rho s} u\left(c_{s}, \frac{y_{s}}{\theta_{s}}\right) d s+\int_{\mathscr{T}_{R}}^{T} e^{-\rho s} u\left(c_{s}, 0\right) d s}_{W} \mid \mathcal{F}_{t}\} \equiv W_{t}$.

By iterated expectation, $W_{t}$ is a martingale. By the Martingale Representation Theorem, there exists a square integrable process such that $W_{t}=\mathrm{E}[W]+$ $\int_{0}^{t} \sigma_{s}^{\prime} v d B s$. This implies that $e^{-\rho t} v_{t}=\mathrm{E}[Y]-\int_{0}^{t} e^{-\rho s} u\left(c_{s}, \frac{y_{s}}{\theta_{s}}\right) d s+\int_{0}^{t} \sigma_{s}^{\prime} d B s$. Therefore $e^{-\rho t} v_{t}$ is an Ito process. Applying Ito's lemma,

$$
d v_{t}=\left(\rho v_{t}-u+h\right) d t+\sigma_{t}^{v} d B_{t}
$$

in which $\sigma_{t}^{v}=e^{r t} \sigma_{t}^{\prime v}$. By Feynman-Kac, $\sigma_{t}^{v}=\theta_{t} \Delta_{t} \sigma_{t}$ and

$$
d v_{t}=\left(\rho v_{t}-u+h\right) d t+\theta_{t} \Delta_{t} \sigma_{t} d B_{t}
$$

with the initial value condition

$$
v_{0}=v
$$

The law of motion of the sensitivity process is a direct application of this idea to Lemma (3).

\section{Proof of Proposition 2}

Proof. Applying Ito's lemma to $\lambda_{t}=K_{v}\left(v_{t}, \Delta_{t}, \theta_{t}, t\right)$ yields

$$
d \lambda_{t}=\mathcal{L}\left(v_{t}, \Delta_{t}, \theta_{t}, t\right) \circ K_{v} d t+\left(K_{v v} \theta_{t} \Delta_{t}+K_{v \Delta} \sigma_{\Delta, t}+K_{v \theta} \theta_{t}\right) \sigma_{t} d B_{t} .
$$

Using the envelope theorem, differentiate HJB with respect to $v$ to get $-\rho K_{v}-$ $\mathcal{L}\left(v_{t}, \Delta_{t}, \theta_{t}, t\right) \circ K_{v}+\rho K_{v}=0$, i.e $\mathcal{L}\left(v_{t}, \Delta_{t}, \theta_{t}, t\right) \circ K_{v}=0$. Therefore, the drift of $d \lambda_{t}$ is zero and $\lambda_{t}$ is a martingale. The volatility process is determined by $\sigma_{c, t}=K_{v v} \theta_{t} \Delta_{t}+K_{v \Delta} \sigma_{\Delta, t}+K_{v \theta} \theta_{t}$.

\section{Proof of Proposition 3}

Proof. Applying Ito's lemma to $y_{t}=K_{\Delta}\left(v_{t}, \Delta_{t}, \theta_{t}, t\right)$ yields

$$
d \gamma_{t}=\mathcal{L}\left(v_{t}, \Delta_{t}, \theta_{t}, t\right) \circ K_{\Delta} d t+\left(K_{\Delta v} \theta_{t} \Delta_{t}+K_{\Delta \Delta} \sigma_{\Delta, t}+K_{\Delta \theta} \theta_{t}\right) \sigma_{t} d B_{t} .
$$

Using the envelope theorem, differentiate HJB with respect to $\Delta$ to get

$$
-\rho K_{\Delta}-\mathcal{L}\left(v_{t}, \Delta_{t}, \theta_{t}, t\right) \circ K_{v}+\left(\rho-\mu_{t}\right) K_{\Delta}+K_{v v} \theta_{t}^{2} \Delta_{t} \sigma_{t}^{2}+K_{v \Delta} \theta_{t} \sigma_{\Delta, t} \sigma_{t}^{2}=0
$$


using this equation, the first order condition for $\sigma_{\Delta, t}$ and the expression for $\sigma_{c, t}$, the drift of $\gamma_{t}$ is $\left(-\theta_{t} \lambda_{t} \sigma_{c, t} \sigma_{t}^{2} d t+\mu_{t} \gamma_{t}\right) d t$ and the drift is $\gamma_{t} \sigma_{t} d B_{t}$. Hence the result.

\section{$7 \quad$ Extensions}

In this section, I present the extensions of my results to the case of non-separable utility in consumption and labor, agents with stochastic lifetimes and productivitydependent fixed costs.

\subsection{Non-Separable Utility}

In this section, I relax the assumption of separable intensive preferences in consumption and labor. In particular, I allow for non-separabilities between consumption and leisure. Saez (2002) argues that this non-separability is important to study optimal income taxation. Non-separability between consumption and leisure brings difficulties in that the Inverse Euler equation does not hold. It is well known that with nonseparable preferences, the no capital tax result of Atkinson and Stiglitz (1976) does not hold. The reason is that income and productivity now directly affect the intertemporal rate of substitution for consumption. Intertemporal distortions allow to separate types and relax incentive constraints.

Denote the consumption function $C(y, u, \theta)$ the inverse of $u\left(\cdot, \frac{y}{\theta}\right)$. Define

$$
\eta(y, u, \theta) \equiv \frac{-\theta C_{y \theta}(y, u, \theta)}{C_{y}(y, u, \theta)}
$$

By differentiation of the implicit function $C, C_{y}=-u_{y} / u_{c}=\left|M R S_{t}\right|=1-\tau_{t}^{L}$ is the marginal rate of substitution between consumption and leisure. Therefore $\eta$ represents the elasticity $-\frac{d \log \left|M R S_{t}\right|}{d \log \theta_{t}}$ and plays an important role in this section. In the separable isoelastic utility case above, this elasticity is $\eta(y, u, \theta)=1+\frac{1}{\varepsilon}$. Define the co-state $\lambda_{t}=K_{v}$ as in the separable utility case. With non-separable utility, $\lambda$ is still a martingale $d \lambda_{t}=\sigma_{\lambda, t} \sigma_{t} d B_{t}$ but is not the inverse of the marginal utility of consumption since the Inverse Euler equation does not hold. The labor wedge satisfies

$$
d\left(\frac{1}{u_{c}} \frac{1}{\eta} \frac{\tau_{t}^{L}}{1-\tau_{t}^{L}}\right)=\left[\lambda_{t} \sigma_{\lambda, t} \sigma_{t}^{2}\right] d t .
$$

The no-volatility result generalizes: the stochastic process $\frac{1}{u_{c}} \frac{1}{\eta} \frac{\tau_{t}^{L}}{1-\tau_{t}^{L}}$ has zero instantaneous volatility so that its realized paths vary much less than those for productivity, in the sense that they are of bounded variation. To qualify the 
wedges further, I consider the Greenwood et al. (1988) preferences

$$
u(c, l)=\frac{1}{1-\nu}\left(c-\frac{l^{1+\frac{1}{\varepsilon}}}{1+\frac{1}{\varepsilon}}\right)^{1-\nu}
$$

for $\nu>0$. Then $\eta=1+\frac{1}{\varepsilon}$ and the labor wedge satisfies

$$
d\left(\frac{\tau_{t}^{L}}{1-\tau_{t}^{L}} \frac{1}{u_{c}}\right)=\left[\left(1+\frac{1}{\varepsilon}\right) \lambda_{t} \sigma_{\lambda, t}\right] \sigma_{t}^{2} d t .
$$

as well as

$$
d\left(\frac{\tau_{t}^{L}}{1-\tau_{t}^{L}}\right)=\left[\left(1+\frac{1}{\varepsilon}\right)\left(\lambda_{t} u_{c}\right) \sigma_{\lambda, t}\right] \sigma_{t}^{2} d t+\frac{\tau_{t}^{L}}{1-\tau_{t}^{L}} \frac{1}{u_{c}} d\left(u_{c}\right) .
$$

The dynamics of the labor wedge depend on the covariance between growth in $\lambda$ and log-productivity, the inverse intensive Frisch elasticity of labor supply, $\lambda_{t} u_{c}$ (which is one in the separable utility case) and the innovations in marginal of consumption. The first term of labor wedge is positive and pushes the labor wedge up as in the Exogenous Retirement model. The term that mirrors the marginal utility of consumption is responsible for the composition effect. Therefore as long as high-productivity agents retire earlier than low-productivity agents, the composition effect is active and the average labor wedge is hump-shaped in age. The following lemma shows that it is the case in the first-best problem.

Lemma 4. Suppose $u$ is a Greenwood et al. (1988)-type utility function. The optimal retirement rule in the first-best is a cut-off rule $\mathscr{T}_{R}^{f b}=\inf \left\{t ; \theta_{t} \leq \theta_{R}^{f b}(t)\right\}$.

Proof. Denote $\lambda$ the Lagrangian on the government's resource constraint. The first order condition on $c_{t}$ when an agent works is $\left(c_{t}-\frac{l_{t}^{1+\frac{1}{\varepsilon}}}{1+\frac{1}{\varepsilon}}\right)^{-\nu}=\lambda$ and $c_{t}^{-\nu}=\lambda$ when an agent is retired. The first order condition for the labor supply of workers is $l_{t}^{\frac{1}{\varepsilon}} \lambda=\lambda \theta_{t}$ so that $l_{t}=\theta_{t}^{\varepsilon}$. After rearranging and simplifying, the terms in $\lambda$ cancel out and the planner's retirement problem is rewritten as:

$$
\max _{\left\{\lambda, \mathscr{T}_{R}\right\}} \mathrm{E}\left\{\int_{0}^{\mathscr{T}_{R}} e^{-\rho t}\left[\lambda \frac{\left(\theta_{t}\right)^{1+\varepsilon}}{(1+\varepsilon)}-\phi_{t}\left(\theta_{t}\right)\right] d t\right\} .
$$

The proof ends as in the proof of Propositon 1 applying Theorem 4.3 in Jacka and Lynn (1992).

The conjecture could be made from this lemma that in the second-best as well, agents with a history of low productivity shocks retire earlier than agents with a history of high productivity. Hence the composition effect would push for a hump-shaped in age labor wedge in the non-separable utility case as well. 
As for retirement consumption, it is constant after retirement as in the separable utility case. However, because the Inverse Euler does not hold, little is known about consumption before retirement and about whether such consumption drops at retirement in the second-best. In the first-best though, the smooth pasting condition implies that marginal utility of consumption is continuous at retirement and consumption drops at retirement $c_{\mathscr{T}_{R}^{+}}=c_{\mathscr{T}_{R}^{-}}+\frac{\theta_{R}^{f b}(t)^{1+\varepsilon}}{1+1 / \varepsilon}$ to counter the discrete fall in labor.

\subsection{Stochastic Lifetime}

There is empirical evidence that life expectancy is positively correlated with income. ${ }^{39}$ Chetty et al. (2016) find that in the United States, between 2001-2014, the gap in life expectancy between the richest $1 \%$ and poorest $1 \%$ of individuals is 14.6 years.

To model this positive correlation, I assume that there exist an exogenous productivity threshold $\theta_{D}$ such that $T=\mathscr{T}_{D}=\inf \left\{t \in \mathbb{R}, \theta_{t} \leq \theta_{D}\right\}$. Then the discounting function after retirement with productivity $\theta \geq \theta_{D}$ is $g(\theta)=$ $\frac{1}{\rho}\left(1-\left(\frac{\theta}{\theta_{D}}\right)^{\gamma-}\right)$ (increasing in current productivity $\theta$ ) in which $\gamma-$ is the negative solution of $\rho=\mu \gamma+\frac{\sigma^{2}}{2} \gamma(\gamma-1)$. This modeling choice has the convenience that, if productivity is a GBM, time is not a state variable of the planner's problem anymore while each agent have a finite expected lifetime. ${ }^{40}$ Since the problem is time homogenous, I focus on retirement consumption rather than the life-cycle pattern of the wedges. The HJB equation becomes

$$
0=\max _{c_{t}, y_{t}, \mathscr{T}_{R}, \sigma_{\Delta, t}}\left\{-K+g(\theta) u_{l=0}^{-1}\left(\frac{v}{g(\theta)}\right) \quad, \quad-\rho K+\left(c_{t}-y_{t}\right)+\mathcal{L}(v, \Delta, \theta) \circ K\right\}
$$

where the derivatives operator over state variables $\mathcal{L}$ is defined in Appendix A. For a given promised utility $v$, retirement consumption $u_{l=0}^{-1}\left(\frac{v}{g(\theta)}\right)$ is decreasing in current productivity. In addition, the net present value of retirement benefits are $g(\theta) u_{l=0}^{-1}\left(\frac{v}{g(\theta)}\right)$ and for a given promised utility $v$ they are lower for highproductivity agents compared to low-productivity agents. ${ }^{41}$ Other things equal, with stochastic lifetime correlated with income, the planner can take advantage of the fact that high-productivity agents have longer life expectancy than the general population in order to give them lower retirement consumption and lower net

\footnotetext{
39 Not necessarily causal in one direction or the other.

${ }^{40}$ This allows me in work in progress to have an in-depth look at optimal policies for human capital acquisition in a setting in which life expectancy is positively correlated with income and human capital.

${ }^{41}$ For a concave utility function $u$, the function $g \mapsto g u^{-1}(v / g)$ is decreasing.
} 
present value of consumption compared to a model in which the end of the horizon is the average life expectancy $T=\mathrm{E}\left[\mathscr{T}_{D}\right]$.

\subsection{Productivity-Dependent Fixed Costs}

In this section, I consider the case when the fixed cost depends on current productivity and age $\phi_{t}\left(\theta_{t}\right)$. Proof of results on wedges in Appendix A have been done so far under this general case, so that results on wedges are unaffected by this assumption. Only the retirement decisions are left to be determined. The retirement decision depends on $\phi_{t}^{\prime}$, i.e. how fast the fixed cost increases in productivity. I consider two subcases.

\subsubsection{Slow-Increasing Fixed Costs}

Proposition 5. (First-best retirement decision) Suppose that for some $\psi>0$, $\forall(\theta, t), \phi_{t}^{\prime}(\theta) \leq \psi \theta^{\varepsilon}$. There exists a time-dependent deterministic productivity threshold $\theta_{R}^{f b}(t)$ such that, in the first-best, retirement occurs if and only if productivity falls below it: $\mathscr{T}_{R}^{f b}=\inf \left\{t ; \theta_{t} \leq \theta_{R}^{f b}(t)\right\}$.

The proof is similar as in Proposition 1 and is presented in the corresponding section. Proposition 1 generalizes to productivity-dependent fixed costs as long as the fixed cost of staying in the labor market for high-productivity workers is not too high compared to that of low-productivity workers

Risk Neutrality and Pareto Optimal Retirement To understand how the retirement decision is affected by the dependence of the fixed utility cost in productivity, and compare the first-best retirement decision to the second-best one, I consider the case where agents are risk neutral that is more tractable than the risk averse agents case.

Consider the case of agents who are risk neutral in consumption and productivity is a GBM. Risk neutrality in consumption implies that consumption need not be distorted. Because of the strict concavity of $u(c)$ in the case of risk-averse agents with a utilitarian planner, the equivalent generalized social marginal welfare weights (as in Saez and Stantcheva (2016)) reflect decreasing marginal utility of consumption. Low-productivity agents have lower consumption and higher marginal utility and therefore higher social welfare weights. To ensure comparability between the risk-averse utilitarian and the risk neutral cases, I assume that the planner puts Pareto welfare weights $\alpha\left(\theta_{0}\right)$ on each agent with initial type $\theta_{0}$. Since with concave utility, marginal utility of consumption is non-increasing, 
I assume the function $\alpha: \Theta_{0} \mapsto(0 ;+\infty)$ is non-increasing. I normalize the sum of Pareto weights to one $\int_{0}^{\infty} \alpha\left(\theta_{0}\right) d F\left(\theta_{0}\right)=1$ and call the summand of weights $\Lambda(\theta)=\int_{0}^{\theta} \alpha\left(\theta_{0}\right) d F\left(\theta_{0}\right)$

The following lemma formulates the retirement decision problem by subtituting optimal allocations in the planner's problem.

Lemma 5. (Allocations and wedges) The labor wedges are time invariant and depend only on initial heterogeneity and the welfare weights

$$
\frac{\tau_{t}^{L}}{1-\tau_{t}^{L}}=\frac{\tau\left(\theta_{0}\right)}{1-\tau\left(\theta_{0}\right)}=\left(1+\frac{1}{\varepsilon}\right) \frac{1}{\theta_{0}} \frac{\Lambda\left(\theta_{0}\right)-F\left(\theta_{0}\right)}{f\left(\theta_{0}\right)}
$$

In addition, the planner's problem is to choose the retirement rule so as to solve:

$$
\max _{\mathscr{T}_{R}} \int_{0}^{\infty} \mathrm{E}\left\{\int_{0}^{\mathscr{T}_{R}} e^{-\rho t}\left[\left(1-\tau\left(\theta_{0}\right)\right)^{\varepsilon}\left[y_{t}^{f b}-\kappa \frac{\left(\frac{y_{t}^{f b}}{\theta_{t}}\right)^{1+\frac{1}{\varepsilon}}}{1+\frac{1}{\varepsilon}}\right]-\left[\phi_{t}-\frac{\tau\left(\theta_{0}\right)}{1-\tau\left(\theta_{0}\right)} \frac{\varepsilon}{1+\varepsilon} \theta_{t} \phi_{t}^{\prime}\left(\theta_{t}\right)\right] d t\right\} d F\left(\theta_{0}\right)\right.
$$

Proof. The problem of the planner is to choose allocations $\{c, y\}$ and a retirement rule $\mathscr{T}_{R}$ to maximize social welfare subject to the definition of ex-ante utility, the resource constraint (4), the relaxed incentive compatibility constraint (37) and the law of motion of productivity (1). I rewrite the problem below for reading convenience.

$$
\begin{aligned}
& \max _{\left\{c, y, v, \mathscr{T}_{R}\right\}} \int_{0}^{\infty} \alpha\left(\theta_{0}\right) v\left(\theta_{0}\right) d F\left(\theta_{0}\right) \\
& \text { s.to } \frac{d \theta_{t}}{\theta_{t}}=\mu d t+\sigma d B_{t} \\
& \quad v\left(\theta_{0}\right)=\mathrm{E}_{0}\left\{\int_{0}^{T} e^{-\rho t} c_{t} d t-\int_{0}^{\mathscr{T}_{R}} e^{-\rho t}\left[\kappa \frac{\left(\frac{y t}{\theta_{t}}\right)^{1+\frac{1}{\varepsilon}}}{1+\frac{1}{\varepsilon}}+\phi_{t}\right] d t \mid \theta_{0}\right\} \\
& \quad 0 \leq \mathrm{E}\left\{\int_{0}^{\mathscr{T}_{R}} e^{-\rho t} y_{t} d t\right\}-\mathrm{E}\left\{\int_{0}^{T} e^{-\rho t} c_{t} d t\right\} \\
& v_{\theta}\left(\theta_{0}\right)=\frac{1}{\theta_{0}} \mathrm{E}_{0}\left\{\int_{0}^{\mathscr{T}_{R}} e^{-\rho t}\left[\left(1+\frac{1}{\varepsilon}\right) \kappa \frac{\left(\frac{y t}{\theta_{t}}\right)^{1+\frac{1}{\varepsilon}}}{1+\frac{1}{\varepsilon}}-\theta_{t} \phi_{t}^{\prime}\left(\theta_{t}\right)\right] d t \mid \theta_{0}\right\}
\end{aligned}
$$

Eliminate consumption from the problem by plugging the definition of ex-ante utility at time zero into the feasibility constraint (4). The feasibility constraint then becomes:

$$
\int_{0}^{\infty}\left(v\left(\theta_{0}\right)+\mathrm{E}_{0}\left\{\int_{0}^{\mathscr{T}_{R}} e^{-\rho t}\left[\kappa \frac{\left(\frac{y_{t}}{\theta_{t}}\right)^{1+\frac{1}{\varepsilon}}}{1+\frac{1}{\varepsilon}}+\phi_{t}\right] d t \mid \theta_{0}\right\}\right) d F\left(\theta_{0}\right) \leq \int_{0}^{\infty} \mathrm{E}_{0}\left\{\int_{0}^{\mathscr{T}_{R}} e^{-\rho t} y_{t} d t \mid \theta_{0}\right\} d F\left(\theta_{0}\right) .
$$

Denote by $\lambda$ the multiplier on the new feasibility constraint (51). If $v\left(\theta_{0}\right)$ is interior, the first order conditions on $v: \alpha\left(\theta_{0}\right) f\left(\theta_{0}\right)-\lambda f\left(\theta_{0}\right)=0$ integrated over 
$\Theta_{0}$ yields $\lambda=1$. The problem is then to maximize the Lagrangian

$$
\begin{aligned}
\int_{0}^{\infty} \alpha\left(\theta_{0}\right) v\left(\theta_{0}\right) d F\left(\theta_{0}\right)- & {\left[\int_{0}^{\infty}\left(v\left(\theta_{0}\right)+\mathrm{E}_{0}\left\{\int_{0}^{\mathscr{T}_{R}} e^{-\rho t}\left[\kappa \frac{\left(\frac{y_{t}}{\theta_{t}}\right)^{1+\frac{1}{\varepsilon}}}{1+\frac{1}{\varepsilon}}+\phi_{t}\right] d t \mid \theta_{0}\right\}\right) d F\left(\theta_{0}\right)\right.} \\
& \left.-\int_{0}^{\infty} \mathrm{E}_{0}\left\{\int_{0}^{\nu} e^{-\rho t} y_{t} d t \mid \theta_{0}\right\} d F\left(\theta_{0}\right)\right]
\end{aligned}
$$

subject to the incentive constraints from the FOA (37)and the law of motion of productivity (1). By partial integration

$$
\begin{gathered}
\int_{0}^{\infty} v\left(\theta_{0}\right) d F\left(\theta_{0}\right)=\int_{0}^{\infty} \frac{1-F\left(\theta_{0}\right)}{f\left(\theta_{0}\right)} v_{\theta}\left(\theta_{0}\right) d F\left(\theta_{0}\right)+\lim _{\theta \rightarrow 0} v(\theta) \\
\int_{0}^{\infty} \alpha\left(\theta_{0}\right) v\left(\theta_{0}\right) d F\left(\theta_{0}\right)=\int_{0}^{\infty} \frac{1-\Lambda\left(\theta_{0}\right)}{f\left(\theta_{0}\right)} v_{\theta}\left(\theta_{0}\right) d F\left(\theta_{0}\right)+\lim _{\theta \rightarrow 0} v(\theta) .
\end{gathered}
$$

Eliminating $v$ from the Lagrangian using partial integration and the expression of $v_{\theta}$ from in the incentive compatibility constraint, the planner's problem becomes

$$
\left.\int_{0}^{\infty} \mathrm{E}_{0}\left\{\int_{0}^{\mathscr{T}_{R}} e^{-\rho t}\left[y_{t}-\kappa \frac{\left(\frac{y_{t}}{\theta_{t}}\right)^{1+\frac{1}{\varepsilon}}}{1+\frac{1}{\varepsilon}}\left[1+\left(1+\frac{1}{\varepsilon}\right) \frac{\Lambda\left(\theta_{0}\right)-F\left(\theta_{0}\right)}{f\left(\theta_{0}\right)} \frac{1}{\theta_{0}}\right]-\left[\phi_{t}-\frac{\Lambda\left(\theta_{0}\right)-F\left(\theta_{0}\right)}{f\left(\theta_{0}\right)} \frac{\theta_{t}}{\theta_{0}} \phi_{t}^{\prime}\left(\theta_{t}\right)\right]\right] d t \mid \theta_{0}\right\}\right\} c
$$

The first order condition for $y_{t}$ implies that the labor wedge is time invariant and depends only on initial heterogeneity and the welfare weights.

$$
\frac{\tau_{t}^{L}}{1-\tau_{t}^{L}}=\frac{\tau\left(\theta_{0}\right)}{1-\tau\left(\theta_{0}\right)}=\left(1+\frac{1}{\varepsilon}\right) \frac{1}{\theta_{0}} \frac{\Lambda\left(\theta_{0}\right)-F\left(\theta_{0}\right)}{f\left(\theta_{0}\right)} .
$$

Since $y_{t}^{f b}-\kappa \frac{\left(\frac{y_{t}^{f b}}{\theta_{t}}\right)^{1+\frac{1}{\varepsilon}}}{1+\frac{1}{\varepsilon}}=\frac{\theta_{t}^{1+\varepsilon}}{\kappa^{\varepsilon}(1+\varepsilon)}$ and $y_{t}^{s b}-\kappa \frac{\left(\frac{y_{t}^{s b}}{\theta_{t}}\right)^{1+\frac{1}{\varepsilon}}}{1+\frac{1}{\varepsilon}}\left[1+\left(1+\frac{1}{\varepsilon}\right) \frac{\Lambda\left(\theta_{0}\right)-F\left(\theta_{0}\right)}{f\left(\theta_{0}\right)} \frac{1}{\theta_{0}}\right]=$ $\left(1-\tau\left(\theta_{0}\right)\right)^{\varepsilon} \frac{\theta_{t}^{1+\varepsilon}}{\kappa^{\varepsilon}(1+\varepsilon)}$ then I can replace $y^{s b}$ in the planner's objective (52) to obtain $\max _{\nu} \int_{\underline{\theta}}^{\infty} \mathrm{E}\left\{\int_{0}^{\mathscr{T}_{R}} e^{-\rho t}\left[\left(1-\tau\left(\theta_{0}\right)\right)^{\varepsilon}\left[y_{t}^{f b}-\kappa \frac{\left(\frac{y_{t}^{f b}}{\theta_{t}}\right)^{1+\frac{1}{\varepsilon}}}{1+\frac{1}{\varepsilon}}\right]-\left[\phi_{t}-\frac{\tau\left(\theta_{0}\right)}{1-\tau\left(\theta_{0}\right)} \frac{\varepsilon}{1+\varepsilon} \theta_{t} \phi_{t}^{\prime}\left(\theta_{t}\right)\right] d t\right\} d F\left(\theta_{0}\right)\right.$.

The normalization of Pareto weights and the assumption of non-increasing weights implies that $\Lambda\left(\theta_{0}\right)-F\left(\theta_{0}\right)$ is always non-negative. The labor wedges are therefore non-negative. In the risk neutral case, with GBM productivity, the labor wedges only depend on the inverse intensive Frisch elasticity of labor supply, initial heterogeneity, and the welfare weights of the planner. Because there is no income effect, consumption can be allocated freely over time without distorting the labor margin.

In the context of private information, labor distortions are such that the flow utility of consumption and disutility of labor is lower than it is in the first-best. 
This is captured by the factor $\left(1-\tau\left(\theta_{0}\right)\right)^{\varepsilon}<1$ in front of $\left[y_{t}^{f b}-\kappa \frac{\left(y_{t}^{f b} / \theta_{t}\right)^{1+1 / \varepsilon}}{1+1 / \varepsilon}\right]$ in the planner's objective. These labor distortions create incentives for the agents to retire early. However, the virtual fixed cost either increases or decreases depending on the sign of $\phi_{t}^{\prime}\left(\theta_{t}\right)$.

If $\phi_{t}^{\prime}$ is negative, the virtual fixed cost increases compared to the first-best. Its effect goes in the same direction as the decrease in output $y$ and agents retire earlier than in the first-best. Therefore, if $\phi_{t}^{\prime}$ is negative, all agents retire earlier in the second-best compared to the first-best. In addition, retirement is a cut-off rule. If $\phi_{t}^{\prime}$ is positive, the virtual fixed cost decreases compared to the first-best and depends negatively on the intensive Frisch elasticity of labor and the labor wedge. Its effect goes in the opposite direction as the decrease in $y$. Therefore, the distortion on the retirement rule is ambiguous. Suppose there exists $\psi>0$ such that $\phi_{t}\left(\theta_{t}\right)=\psi \theta_{t}$. Having solved the retirement decision problem in the first-best case, the derivation of the analogous rule for the second-best scenario is relatively simple. Dividing the planner's objective by $\left(1-\tau\left(\theta_{0}\right)\right)^{\varepsilon}$, one can observe that the choice of the retirement rule in the second-best is equivalent to the choice of the retirement rule in the first-best when the fixed utility cost is replaced by a virtual cost $\tilde{\phi}$ defined as $\tilde{\phi}\left(t, \theta_{t}\right)=\frac{\phi\left(t, \theta_{t}\right)}{\left(1-\tau\left(\theta_{0}\right)\right)^{\varepsilon}}\left(1-\frac{\tau\left(\theta_{0}\right)}{1-\tau\left(\theta_{0}\right)} \frac{\varepsilon}{1+\varepsilon}\right)$. In contrast to the first-best case, the retirement rule depends on initial productivity. Defining $S\left(\tau\left(\theta_{0}\right)\right) \equiv \tilde{\phi}\left(t, \theta_{t}\right) / \phi\left(t, \theta_{t}\right)$, the following proposition summarizes the results on retirement distortions.

\section{Proposition 6. (Retirement distortions)}

1. There exists a time-dependent and initial productivity dependent deterministic retirement threshold $\theta_{R}^{s b}\left(t, \theta_{0}\right)$ such that $\mathscr{T}_{R}^{s b}=\inf \left\{t ; \theta_{t} \leq \theta_{R}^{s b}\left(t, \theta_{0}\right)\right\}$.

2. Suppose $\phi_{t}\left(\theta_{t}\right)=\psi \theta_{t}$ with $\psi \in \mathbb{R}$, at the infinite horizon limit, $T=+\infty$ the retirement thresholds are time-invariant $\hat{\theta}_{R}^{s b}: \Theta_{0} \mapsto \mathbb{R}^{+*}, \mathscr{T}_{R}^{s b}=\inf \left\{t ; \theta_{t} \leq\right.$ $\left.\theta_{R}^{s b}\left(\theta_{0}\right)\right\}$ and

$$
\theta_{R}^{s b}\left(\theta_{0}\right)=\theta_{R}^{f b} S\left(\tau\left(\theta_{0}\right)\right)^{\frac{1}{\varepsilon}}
$$

3. If $\psi \leq 0$, retirement occurs earlier in the second-best compared to the firstbest for all agents $\theta_{R}^{s b}\left(t, \theta_{0}\right) \geq \theta_{R}^{f b}(t)$. If $\psi>0$, a criterion for whether retirement happens early or is delayed compared to the first-best is

$$
S\left(\theta_{0}\right)=\frac{1}{\left(1-\tau\left(\theta_{0}\right)\right)^{\varepsilon}}\left(1-\frac{\tau\left(\theta_{0}\right)}{1-\tau\left(\theta_{0}\right)} \frac{\varepsilon}{1+\varepsilon}\right) .
$$


For a given $T<+\infty$, retirement occurs earlier in the second-best compared to the first-best: $\theta_{R}^{s b}\left(t, \theta_{0}\right) \geq \theta_{R}^{f b}(t)$ for all $t \leq T$ if and only if $S\left(\theta_{0}\right) \geq 1$.

Point 1 of the proposition highlights that retirement thresholds depend on the initial productivity of the agents. Again, the option of continued work compared to retiring is negative at retirement. The second point gives an explicit formula for the optimal retirement threshold at infinite horizon as in the discussion after Corollary $1 .^{42}$ Point 2 gives an explicit expression for the retirement thresholds at infinite horizon.

Point 3 of the proposition states that if the fixed utility cost is increasing in productivity, there is a force that pushes for delayed retirement. High types have a high fixed cost and lower information rents than in the case when the fixed cost is independent of productivity. This creates an effect that goes in the opposite direction of the income tax. Depending on the strength of this effect retirement may occur early or be delayed compared to the first-best. The proposition shows that the relative weight of the two forces depends on the criterion $S$ that in turn depends on the intensive Frisch elasticity of labor and the welfare weights of the planner. This criterion allows one to determine what productivity types should be induced to retire before $S\left(\theta_{0}\right) \geq 1$ or after the first-best $S\left(\theta_{0}\right)<1$.
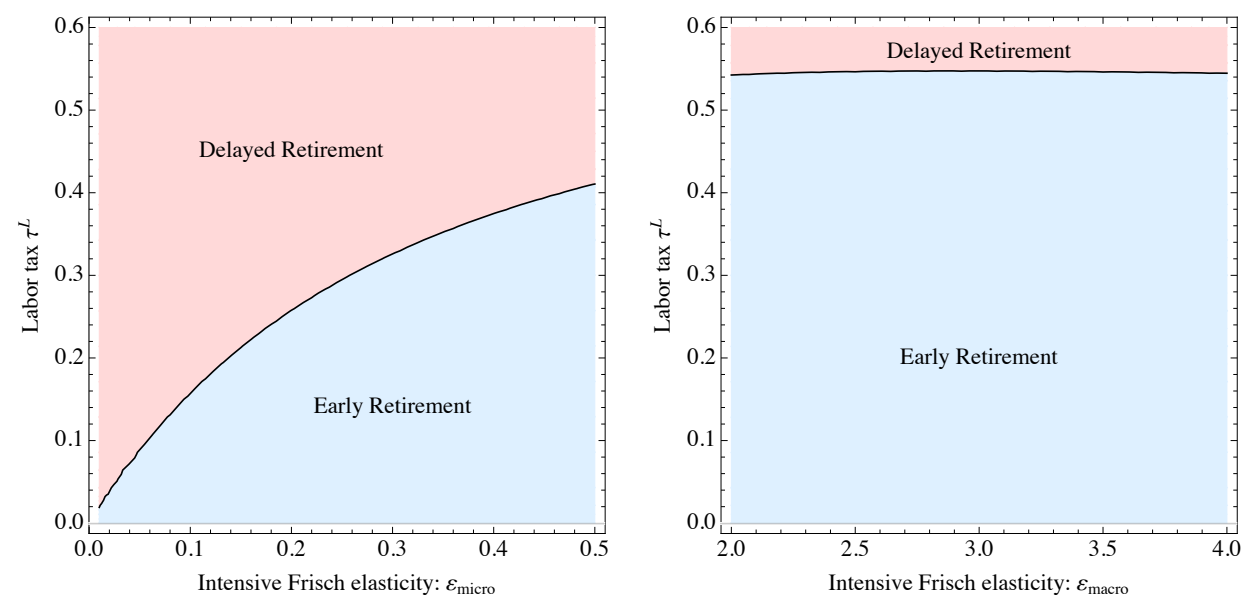

Figure 7: $\{\tau: S(\tau) \geq 1\}$ as a function of $\varepsilon$. On the vertical axis $\tau\left(\theta_{0}\right)$ and on the horizontal axis $\varepsilon_{\text {micro }} \in[0 ; 0.5]$ on the left and $\varepsilon_{\text {macro }} \in[2 ; 4]$ on the right. Early retirement at the bottom, delayed retirement on top.

Figure 7 shows that the size of the intensive Frisch elasticity of labor is important in determining the individual retirement decisions and therefore the optimal

\footnotetext{
${ }^{42}$ There is no concern for immiseration at infinite horizon here since, with risk neutrality in consumption, consumption is not pinned down by first order conditions.
} 
hazard rate and labor force participation rate of the elderly. The larger the intensive Frisch elasticity, the more agents there are who delay retirement compared to the first-best. Reichling and Whalen (2012) and Peterman (2016) provide a survey of the estimates of the Frisch elasticity of labor supply in the micro and in the macro literature.

Figure 7's left panel illustrates the optimal deviations of retirement compared to the first-best for typical values of the intensive Frisch elasticity of labor supply from the micro literature, with $\varepsilon_{\text {micro }} \in[0 ; 0.5]$. When $\varepsilon$ is small, agents' labor is inelastic and the incentive effect of labor distortions is small. The effect of distortions through rents induced by the fixed cost dominates once an agent faces labor distortions that lie in the upper region. There is a large disparity in optimal retirement behavior. For instance, for a an intensive Frisch elasticity of labor supply of $\varepsilon=0.2$, agents facing a marginal labor income tax rate ${ }^{43}$ below $26 \%$ retire early while agents facing a marginal tax rate above $26 \%$ delay retirement optimally.

Figure 7's right panel illustrates the optimal deviations of retirement compared to first-best for typical values of the Frisch elasticity of labor from the macro literature, with $\varepsilon_{\text {macro }} \in[2 ; 4]$. When $\varepsilon$ is large, agents' labor is elastic and the incentive effect of labor distortions is large. Therefore, most agents retire earlier than in the first-best. One need a high optimal tax rate, above $54 \%$, for the distortions through rents induced by the fixed costs increasing in productivity for the agents to delay retirement compared to first-best. The curve $\{S(\tau)=1\}$ asymptotes to around $\tau^{L}=54 \%$ for large values of $\varepsilon$ up to infinity.

This discussion highlights that an accurate estimate of the intensive Frisch elasticity of labor supply and the variations in the extensive elasticity through $\phi^{\prime}(\theta)$ are important in determining individual retirement decisions and therefore the optimal hazard rate and labor force participation rate of the elderly.

\subsubsection{Fast-Increasing Fixed Costs}

I assumed that the fixed utility cost of staying in the labor market grows slowly in productivity i.e there exists $\psi>0$, such that $\forall(\theta, t), \phi_{t}^{\prime}(\theta) \leq \psi \theta^{\varepsilon}$. This section relaxes this assumption and shows that if the fixed utility cost of staying in the labor market grows fast in productivity, when agents promised utility becomes high, they become too costly to incentivize to work and they retire.

\footnotetext{
${ }^{43}$ In this setting, allocations can be implemented by non-linear labor income taxes equal to the wedges.
} 
Lemma 6. Suppose there exists $\psi>0$ such that $\phi_{t}\left(\theta_{t}\right) \geq \psi \theta_{t}^{1+\varepsilon}$. Then, for each $t$ there exists a promised utility $v_{t}^{*}$ such that if $v_{t} \geq v_{t}^{*}$, the planner collects more revenue from retiring the agent than from making him work.

Proof. For a fixed $\theta$, the function $y \mapsto \frac{h\left(\frac{y}{\theta}\right)+\phi_{t}\left(\theta_{t}\right)}{y}$ is minimized at a $y$ that satisfies $\frac{1}{\theta} h^{\prime}\left(\frac{y}{\theta}\right)=\frac{h\left(\frac{y}{\theta}\right)+\phi_{t}\left(\theta_{t}\right)}{y}($ marginal utility cost equals average utility cost). This yields $\frac{y_{\min }}{\theta}=\left(\frac{\phi_{t}(\theta)(1+\varepsilon)}{\kappa}\right)^{\frac{\varepsilon}{1+\varepsilon}}$ and the minimum value of average cost is $\frac{1}{\theta} h^{\prime}\left(\frac{y_{\min }}{\theta}\right)=$ $\kappa^{\frac{\varepsilon}{1+\varepsilon}} \frac{\left((1+\varepsilon) \phi_{t}\left(\theta_{t}\right)\right)^{\frac{1}{1+\varepsilon}}}{\theta_{t}}$. With the assumption on $\phi_{t}$ I have uniformly on $\theta$ and $t$, $h\left(\frac{y_{t}}{\theta_{t}}\right)+\phi_{t}\left(\theta_{t}\right) \geq K y_{t}$ in which $K=\kappa^{\frac{\varepsilon}{1+\varepsilon}}((1+\varepsilon) \psi)^{\frac{1}{1+\varepsilon}}$.

For any $v_{t}$ and $t$ define $\bar{c}$ the constant consumption level which, given continually to the agent after $t$, gives him an expected utility of $v_{t}: g(t) u\left(\bar{c}\left(t, v_{t}\right)\right)=v_{t}$. Also define $v_{t}^{*}$ by $u^{\prime}\left(\bar{c}\left(t, v_{t}^{*}\right)\right)=K$. Such a level exists provided that $u^{\prime}(0)>K$, a condition without which the agent would never work even in the full information solution (and which is true by definition for $\log$ utility). Then for $v_{t} \geq v_{t}^{*}$ the agent does not work and the optimal contract is $c_{t^{\prime}}=\bar{c}\left(t, v_{t}\right)$ for all $t^{\prime} \geq t$. To see this, let $v_{t} \geq v_{t}^{*}$, then $u^{\prime}\left(\bar{c}\left(t, v_{t}\right)\right) \leq K$. From concavity of $u$ and inequality on $h$,

$$
\begin{aligned}
v_{t}=\mathrm{E}\left(\int_{t}^{T} e^{-r(s-t)}\left(u\left(c_{s}\right)-1_{s \leq \mathscr{T}_{R}}\left[h\left(\frac{y_{s}}{\theta_{s}}\right)+\phi_{s}\left(\theta_{s}\right)\right]\right) d s\right) \leq \mathrm{E}\left(\int _ { t } ^ { T } e ^ { - r ( s - t ) } \left(u\left(\bar{c}\left(t, v_{t}\right)\right)\right.\right. \\
\left.\left.+\left(c_{s}-\bar{c}\left(t, v_{t}\right)\right) u^{\prime}\left(\bar{c}\left(t, v_{t}\right)\right)-1_{s \leq \mathscr{T}_{R}} K y_{s}\right) d s\right) \\
\leq g(t) u\left(\bar{c}\left(t, v_{t}\right)\right)-u^{\prime}\left(\bar{c}\left(t, v_{t}\right)\right) \mathrm{E}\left(\int_{t}^{T} e^{-r(s-t)}\left(1_{s \leq \mathscr{T}_{R}} y_{s}-c_{s}\right) d s+g(t) \bar{c}\left(t, v_{t}\right)\right) .
\end{aligned}
$$

Since $v_{t}=g(t) u\left(\bar{c}\left(t, v_{t}\right)\right)$ and $u^{\prime} \geq 0$, the revenue from any allocation $(c, y)$ is less than $-g(t) \bar{c}\left(t, v_{t}\right)$ which is the revenue from retiring the agent with constant consumption $\bar{c}\left(t, v_{t}\right)$. It follows that for $v_{t} \geq v_{t}^{*}$ the agent does not work.

The argument of the proof is mechanical and comes directly from the fast growth in $\phi_{t}\left(\theta_{t}\right)$. The lemma applies to any allocations, even non-incentive compatible ones.

Note that the lemma does not imply directly that under the conditions specified there is an upper retirement boundary since promised utility is an endogenous state variable of the problem. The existence of such a boundary depends on how big the government exogenous revenue $-G$ is to achieve high promised utility. Indeed, if $\psi$ is high it becomes more and more costly to incentivize high types who need to be retired whenever they have accumulated a high promised utility. ${ }^{44}$

\footnotetext{
${ }^{44}$ For instance, following the notation in the proof in Appendix A, for log utility the highest
} 
Under these conditions, both agents with a history of low productivity shocks and agents with a history of high productivity shocks retire earlier than agents with a history of average productivity. Therefore the composition effect is less strong than when $\phi_{t}\left(\theta_{t}\right)$ is constant or slowly growing in productivity. If ever high-productivity agents experience fixed costs of staying in the labor market much higher than lowproductivity agents, or equivalently when the extra benefit of retirement leisure is much higher for the former than the latter, the composition effect pushes for increasing ever more the labor wedge for old workers.

\section{B - Computational Appendix}

\section{Dynamic Mirrlees Model Numerical Algorithm}

\subsection{Planning Problem}

I do a numerical simulation of a discrete time version of the model. I present the discrete time model and the algorithm of the numerical simulation below. An agent working until time $t$, reports a productivity history $\theta^{t}$ and the planner recommends $\left\{c\left(\theta^{t}\right), y\left(\theta^{t}\right), v\left(\theta^{t}\right), \Delta\left(\theta^{t}\right), s\left(\theta^{t}\right)\right\}$. A retirement decision $s$ equal to zero means the agent works work in period $t+1$ and equal to one means the agents retires forever independently of $\theta_{t+1}$.

Define $u(c, y ; \theta)=u\left(c, \frac{y}{\theta}\right)$ and $f^{t}\left(\theta_{t} \mid \theta_{t-1}\right)$ the conditional density of $\theta_{t}$. With the savings rate denoted $q^{-1}$, the planner's problem is to minimize the cost $K$ such that, for a working agent $s=0$ :

$K\left(v, \Delta, \theta_{-}, t, 0\right)=\min \left[\int\left\{c(\theta)-y(\theta)+q K(v(\theta), \Delta(\theta), \theta, t+1, \tau(\theta)) f^{t}\left(\theta_{t} \mid \theta_{-}\right) d \theta\right]\right.$

subject to for all $\theta \in \Theta$

$$
\begin{gathered}
w(\theta)=u(c(\theta), y(\theta) ; \theta)-\phi_{t}(\theta)+\beta v(\theta) \\
\dot{w}(\theta)=u_{\theta}(c(\theta), y(\theta) ; \theta)-\phi_{\theta}(\theta)+\beta \Delta(\theta)
\end{gathered}
$$

promised fixed consumption before retirement occurs is $\bar{c}\left(t, v_{t}^{*}\right)=1 / K$. This quantity decreases with $\psi$; therefore when $\psi$ is high the likelihood of an upper retirement boundary being endogenously hit is higher. 
And

$$
\begin{gathered}
v=\int w(\theta) f^{t}\left(\theta \mid \theta_{-}\right) d \theta \\
\Delta=\int w\left(\theta^{t}\right) \partial_{\theta_{-}} f^{t}\left(\theta \mid \theta_{-}\right) d \theta .
\end{gathered}
$$

Define

$$
\beta_{\text {fact }}^{t}=\frac{1-\beta^{T+1-t}}{1-\beta}
$$

For a retired agent $s=1$ and $\Delta=0$ :

$$
K(v, 0, \theta, t+1,1)=\beta_{\text {fact }}^{t+1} u^{-1}\left(\frac{v}{\beta_{\text {fact }}^{t+1}}\right) .
$$

The relaxed planning problem can be recovered by setting $t=1$ and treating $\Delta$ a as control variable:

$$
K(v)=\min _{\Delta} K\left(v, \Delta, \theta_{0}, 1,0\right)
$$

\subsection{Normalization}

The process for productivity is a geometric random walk: $\theta_{t}=\theta_{t-1} \varepsilon_{t}$ in which $\varepsilon_{t}$ is $\log$-normal $\log \varepsilon_{t} \sim N\left(-\frac{\sigma^{2}}{2}, \sigma^{2}\right)$. Preferences are separable in consumption and labor and $u\left(c_{t}\right)=\log \left(c_{t}\right)$ and I denote $h\left(y_{t} / \theta_{t}\right)$ the disutility of labor. The fixed cost of staying in the labor market is a funtion of age $\phi(t)$. To reduce the number of state variables I re-normalize $\tilde{y}_{t} \equiv y_{t} / \theta_{t-1}, \tilde{c}_{t} \equiv c_{t} / \theta_{t-1}, h\left(y_{t} / \theta_{t}\right)=h\left(\tilde{y}_{t} / \varepsilon_{t}\right)$.

Denote $g$ the density of $\varepsilon_{t}$. The densities of $\theta_{t}$ and $\varepsilon_{t}$ are linked by $f\left(\theta_{t} \mid \theta_{t-1}\right) d \theta_{t}=$ $g\left(\varepsilon_{t}\right) d \varepsilon_{t}$ and $\partial_{\theta_{t-1}} f\left(\theta_{t} \mid \theta_{t-1}\right) d \theta_{t}=\frac{1}{\theta_{t-1}}\left(g\left(\varepsilon_{t}\right)+\varepsilon_{t} g^{\prime}\left(\varepsilon_{t}\right)\right) d \varepsilon_{t}$ (See derivation in Stantcheva (2017)). Denote $\tilde{g}\left(\varepsilon_{t}\right)=g\left(\varepsilon_{t}\right)+\varepsilon_{t} g^{\prime}\left(\varepsilon_{t}\right)$.

Normalized continuation variables are defined as:

$$
\begin{aligned}
\tilde{v}_{t} & \equiv \mathrm{E}\left(\sum_{s=t+1}^{\mathscr{T}_{R}\left(\theta^{t}\right)} \beta^{s-t-1}\left(\log \left(c_{s} / \theta_{t}\right)-h\left(y_{s} / \theta_{s}\right)-\phi(s)\right)+\sum_{s=\tau\left(\theta^{t}\right)+1}^{T} \beta^{s-t-1} \log \left(c_{s} / \theta_{t}\right)\right) \\
& =v_{t}-\beta_{t+1}^{f a c t} \log \left(\theta_{t}\right),
\end{aligned}
$$




$$
\begin{aligned}
\tilde{w}_{t}\left(\theta^{t}\right) \equiv & u\left(\tilde{c}_{t}\right)-h\left(\tilde{y}_{t} / \varepsilon_{t}\right)-\phi(t)+\beta\left(\sum_{s=t+1}^{\tau\left(\theta^{t}\right)} \beta^{s-t-1}\left(\log \left(c_{s} / \theta_{t-1}\right)-h\left(\left(y_{s} / \theta_{t-1}\right) /\left(\theta_{s} / \theta_{t-1}\right)\right)-\phi(s)\right)\right. \\
& \left.+\sum_{s=\tau\left(\theta^{t}\right)+1}^{T} \beta^{s-t-1} \log \left(c_{s} / \theta_{t-1}\right)\right) \\
= & u\left(\tilde{c}_{t}\right)-h\left(\tilde{y}_{t} / \varepsilon_{t}\right)-\phi(t)+\beta \tilde{v}_{t}+\beta_{t}^{f a c t} \log \left(\varepsilon_{t}\right) \\
= & w_{t}-\beta_{t}^{\text {fact }} \log \left(\theta_{t-1}\right),
\end{aligned}
$$

$$
\tilde{\Delta}_{t-1} \equiv \Delta_{t-1} / \theta_{t-1}
$$

Renormalized constraints The promise-keeping constraint

$$
v_{t-1}=\int w_{t}\left(\theta_{t}\right) f^{t}\left(\theta_{t} \mid \theta_{t-1}\right) d \theta_{t}
$$

implies

$$
\tilde{v}_{t-1}+\beta_{t}^{\text {fact }} \log \left(\theta_{t-1}\right)=\int\left[\tilde{w}_{t}\left(\theta_{t}\right)+\beta_{t}^{\text {fact }} \log \left(\theta_{t-1}\right)\right] f^{t}\left(\theta_{t} \mid \theta_{t-1}\right) d \theta_{t} .
$$

Therefore

$$
\tilde{v}_{t-1}=\int \tilde{w}_{t}\left(\varepsilon_{t}\right) g_{\epsilon}\left(\varepsilon_{t}\right) d \varepsilon_{t}
$$

Sensitivity of promised utility

$$
\Delta_{t-1}=\int w_{t}\left(\theta_{t}\right) \partial_{\theta_{t-1}} f^{t}\left(\theta_{t} \mid \theta_{t-1}\right) d \theta_{t}
$$

becomes

$$
\Delta_{t-1}=\int\left[\tilde{w}_{t}\left(\varepsilon_{t}\right)+\beta_{t}^{\text {fact }} \log \left(\theta_{t-1}\right)\right] g^{t}\left(\theta_{t} \mid \theta_{t-1}\right) d \theta_{t} .
$$

The integral in log is zero because it's the derivative of the expectation of a constant. Therefore

$$
\Delta_{t-1}=\int \tilde{w}_{t}\left(\varepsilon_{t}\right) \frac{\tilde{g}\left(\varepsilon_{t}\right)}{\theta_{t-1}} d \varepsilon_{t}
$$

and

$$
\tilde{\Delta}_{t-1}=\int \tilde{w}_{t}\left(\varepsilon_{t}\right) \tilde{g}\left(\varepsilon_{t}\right) d \varepsilon_{t}
$$


In addition

$$
\frac{\partial \tilde{w}\left(\varepsilon_{t}\right)}{\partial \varepsilon_{t}}=\frac{\tilde{y}_{t}}{\varepsilon_{t}^{2}} h^{\prime}\left(\frac{\tilde{y}_{t}}{\varepsilon_{t}}\right)+\beta \frac{\tilde{\Delta}_{t}}{\varepsilon_{t}} .
$$

\subsection{Normalized Planning Problem}

Let $\tilde{K}=K / \theta_{t-1}$. The planner's problem is then

$$
\tilde{K}(\tilde{v}, \tilde{\Delta}, t, 0)=\min \left[\int\left\{\tilde{c}(\varepsilon)-\tilde{y}(\varepsilon)+q \varepsilon \tilde{K}(\tilde{v}(\varepsilon), \tilde{\Delta}(\varepsilon), t+1, \tilde{s}(\varepsilon)) g\left(\varepsilon_{t}\right) d \varepsilon_{t}\right]\right.
$$

Subject to

$$
\begin{gathered}
\tilde{w}_{t}\left(\varepsilon_{t}\right)=u\left(\tilde{c}_{t}\right)-h\left(\tilde{y}_{t} / \varepsilon_{t}\right)-\phi(t)+\beta \tilde{v}_{t}+\beta_{t}^{f a c t} \log \left(\varepsilon_{t}\right) \\
\frac{\partial \tilde{w}\left(\varepsilon_{t}\right)}{\partial \varepsilon_{t}}=\frac{\tilde{y}_{t}}{\varepsilon_{t}^{2}} h^{\prime}\left(\frac{\tilde{y}_{t}}{\varepsilon_{t}}\right)+\beta \frac{\tilde{\Delta}_{t}}{\varepsilon_{t}} \\
\tilde{v}_{t-1}=\int \tilde{w}_{t}\left(\varepsilon_{t}\right) g\left(\varepsilon_{t}\right) d \varepsilon_{t} \\
\tilde{\Delta}_{t-1}=\int \tilde{w}_{t}\left(\varepsilon_{t}\right) \tilde{g}\left(\varepsilon_{t}\right) d \varepsilon_{t}
\end{gathered}
$$

and for retired agents:

$$
\tilde{K}(\tilde{v}, 0, t, 1)=\min \left[\int\left\{\tilde{c}(\varepsilon)+q \varepsilon \tilde{K}(\tilde{v}(\varepsilon), 0, t+1,1) g\left(\varepsilon_{t}\right) d \varepsilon_{t}\right]\right.
$$

Subject to

$$
\begin{gathered}
\tilde{w}_{t}\left(\varepsilon_{t}\right)=u\left(\tilde{c}_{t}\right)+\beta \tilde{v}_{t}+\beta_{t}^{f a c t} \log \left(\varepsilon_{t}\right) \\
\tilde{v}_{t-1}=\int \tilde{w}_{t}\left(\varepsilon_{t}\right) g\left(\varepsilon_{t}\right) d \varepsilon_{t}
\end{gathered}
$$

\subsection{Hamiltonian and First Order Conditions}

Dropping the tildes, the Hamiltonian of the normalized problem is, while working: 


$$
\begin{array}{r}
{\left[C^{t}(y(\varepsilon), w(\varepsilon)-\beta v(\varepsilon), \varepsilon)-y(\varepsilon)\right] g(\varepsilon)} \\
+q[K(v(\varepsilon), \Delta(\varepsilon), \varepsilon, t+1, s(\varepsilon))] g(\varepsilon) \\
+\lambda[v-w(\varepsilon) g(\varepsilon)]+\gamma[\Delta-w(\varepsilon) \tilde{g}(\varepsilon)] \\
+p(\varepsilon)\left[u_{\theta}^{t}\left(C^{t}(y(\varepsilon), w(\varepsilon)-\beta v(\varepsilon), \varepsilon), y(\varepsilon), \varepsilon\right)+\beta \Delta(\varepsilon)\right]
\end{array}
$$

And the limits of the co-state $p(\varepsilon)$ are zero at zero and infinity. The co-state satisfies:

$$
\frac{d p(\varepsilon)}{d \varepsilon}=-\left[\frac{1}{u^{\prime}(c(\varepsilon))}-\lambda-\gamma \frac{\tilde{g}\left(\varepsilon_{t}\right)}{g\left(\varepsilon_{t}\right)}\right] g\left(\varepsilon_{t}\right)
$$

The FOCs for $\Delta(\varepsilon), v(\varepsilon)$ and $y(\varepsilon)$ are:

$$
\begin{array}{r}
\frac{p(\varepsilon)}{\varepsilon^{2} g\left(\varepsilon_{t}\right)}=-\frac{q}{\beta} \gamma(\varepsilon) \\
\frac{1}{u^{\prime}(c(\varepsilon))}=\frac{q}{\beta} \varepsilon \lambda(\varepsilon) \\
1-\frac{1}{\varepsilon} \frac{h^{\prime}\left(\frac{\tilde{y}(\varepsilon)}{\varepsilon}\right)}{u^{\prime}(c(\varepsilon))}=\frac{p(\varepsilon)}{\varepsilon^{2} g\left(\varepsilon_{t}\right)} h^{\prime}\left(\frac{\tilde{y}(\varepsilon)}{\varepsilon}\right)\left[1+\frac{\tilde{y}(\varepsilon)}{\varepsilon} \frac{h^{\prime \prime}\left(\frac{\tilde{y}(\varepsilon)}{\varepsilon}\right)}{h^{\prime}\left(\frac{\tilde{y}(\varepsilon)}{\varepsilon}\right)}\right] .
\end{array}
$$

In these equations, I denote the extensions of $\lambda$ and $\gamma$ to retired states with the same notation.

\subsection{Algorithm}

Since the model is in finite horizon, the algorithm solves policy functions backwards from $t=T, v_{T}(\varepsilon)=0, \Delta_{T}(\varepsilon)=0, s_{T}(\varepsilon)=1$.

The algorithm takes as state space the dual $\left(\lambda_{-} \gamma_{-}, \varepsilon, s_{-}\right)$. I truncate $\varepsilon$ between the first percentile and the $99 \%$ percentile. The algorithm goes in the following steps:

- If in working state at time $t: s_{-}=0$

1. Start with a guess for the promised utility of the lowest type in a given period: $w_{t}\left(\varepsilon_{\text {low }}\right)$

(a) Solve for $y_{t}\left(\lambda_{t}, s_{t}, \varepsilon_{t}, p_{t}, w_{t}\left(\varepsilon_{\text {low }}\right)\right)$ using (56) and (55).

(b) Solve for $\lambda_{t}\left(s_{t}, \varepsilon_{t}, p_{t}, w_{t}\left(\varepsilon_{\text {low }}\right)\right)$ from (55), replacing $c$ as a function of $w$ and $v$ using the solution for $y_{t}\left(\lambda_{t}, s_{t}, \varepsilon_{t}, p_{t}, w_{t}\left(\varepsilon_{\text {low }}\right)\right)$ computed in $1(\mathrm{a})$. 
(c) Solve for $\gamma_{t}\left(s_{t}, \varepsilon_{t}, p_{t}, w_{t}\left(\varepsilon_{\text {low }}\right)\right)$.

(d) Replace $1 / u^{\prime}(c)$ using (55) in the ODE (54) satisfied by the co-state $p$ and solve the ODE.

i. While solving the ODE compare $K_{t+1}\left(\lambda_{t}\left(s_{t}=0\right), \gamma_{t}\left(s_{t}=0\right), \varepsilon, 0\right)$ to $K_{t+1}\left(\lambda_{t}\left(s_{t}=1\right), \gamma_{t}\left(s_{t}=1\right), \varepsilon, 1\right)$ and set $s_{t}$ equal to the work status with lowest cost.

2. Check the boundary condition $p\left(\varepsilon_{\text {high }}\right)$.

(a) If the boundary condition is not met within the tolerance level change $w_{t}\left(\varepsilon_{\text {low }}\right)$ and go to 1 .

3. Once the boundary condition is met, follow 1 . in reverse order to compute policy functions.

(a) Compute $\tilde{w}_{t}, \tilde{v}_{-}, \tilde{\Delta}_{-}$using their integral definitions.

- If in retired state at time $t: s_{-}=0$

- Set $\lambda_{t}=\lambda_{-} / \varepsilon, \gamma_{t}=0, s_{t}=1, \tilde{c}_{t}=\lambda_{-}, \tilde{y}_{t}=0$.

\section{Social Security Function}

In 2018 the PIA has 3 brackets $^{45}$; the first PIA bracket is $90 \%$ of the AIME from $\$ 0$ to $\$ 895$. The second is $32 \%$ of the AIME above $\$ 895$ up to $\$ 5,397$, and the third is $15 \%$ of the AIME above $\$ 5,397$ up to $\$ 10,700$ which corresponds to one twelfth of maximum taxable earnings in $2018^{46}$. The AIME is calculated using the mean of the highest 35 years of income in a person's life, after scaling by an index factor to account for inflation.

I use the same variables and survey data (Bureau (2016) 5\%) I used when calibrating productivity. I again narrow to those age 25 to 79 , employed (empstat $=1$ ), and use the person weights perwt which indicate how many people in the general population an observation should represent. To approximate the AIME I

\footnotetext{
${ }^{45}$ Calculation methodology for 2018 can be found at https://www.ssa.gov/pubs/EN05-10070.pdf. Historical cutoff points can be found at https://www.ssa.gov/oact/cola/bendpoints.html

${ }^{46}$ Note this calculation this yields maximum benefits of $\$ 3,041.59$, even though according to the SSA if you were to maximize your AIME in all 35 years your PIA would be $\$ 2,788$. This is because the maximum taxable earnings in past years scaled by indexing factors comes often comes out to less than $\$ 128,400$ the maximum taxable in 2018. For example, the 2015 maximum taxable is $\$ 118,500$ with an indexing factor 1.0113001 yielding $\$ 119,839.06$. A list of past maximum taxable earnings can be seen at https://www.ssa.gov/OACT/quickcalc/ and a list of indexing factors is at https://www.ssa.gov/cgi-bin/awiFactors.cgi
} 
simply use their reported income incwage that year, since reliable and complete data on lifetime earnings is very difficult to obtain. Like I did for the income function, I replicate the method in Heathcote et al. (2014) but for Social Security; I calculate the PIA based on the rules above and estimate the equation

$$
\log [P I A(A I M E)]=\log \left[\lambda_{s s}\right]+\tau_{s s} \log [A I M E]
$$

using OLS on 5.9 million observations (increases to 121.2 million when including frequency weights), which yielded $\tau_{s s}=0.63, R^{2}$ of 0.94 . Excluding weights or including those employed but with positive income did not change results significantly. Those without income were by default excluded.

\section{Efficiency Profile}

I calibrate $\mu_{t}$ using empirical analogs from wage data. In the calibration, $\left\{\mu_{t}\right\}_{t=25}^{79}$ is interpreted as a deterministic baseline trajectory for productivity, from which individuals may deviate. We can take the exponential of both sides and take the expectation, which yields

$$
E\left[\theta_{t}\right]=E\left[\theta_{t-1} e^{\epsilon_{t}} \mu_{t}\right]=E\left[\theta_{t-1}\right] E\left[e^{\epsilon_{t}}\right] \mu_{t}=E\left[\theta_{t-1}\right] \mu_{t}
$$

since $\mu_{t}$ is deterministic and $e^{\epsilon_{t}}$ is an independent log-normal variable with mean 1. This reduces the problem of calibrating $\mu_{t}$ to finding $E\left[\theta_{t}\right]$ and $E\left[\theta_{t-1}\right]$. Like De Nardi (2004), I follow the same method as Hansen (1993), which uses approximate hourly wages, calculated from total annual earnings, as a proxy for individual productivity, which I denote $w_{i}$ and $\theta_{i}$ respectively. The mean of hourly wage $\overline{w_{t}}$ for individuals of the same age would be a proxy for mean productivity $\overline{\theta_{t}}$ of the sample. But instead of using the smaller Current Population Survey (CPS) from the U.S. Bureau of Labor Statistics (BLS), I use the larger and more detailed American Community Survey (ACS) from the U.S. Census Bureau. I specifically use the most recent $20165 \%$ dataset which combines and normalizes the $1 \%$ datasets of 5 years. Given the framework of the model, I narrow the sample to those aged 25 and 79 and those indicated to be currently employed, and then calculate approximate mean hourly wages $\overline{w_{t}}$ for each age $t$

$$
\overline{\theta_{t}}=\overline{w_{t}}=\frac{1}{\sum_{i: \text { Age }_{i}=t} \text { weight }_{i}} \sum_{i: \text { Age }_{i}=t} \theta_{i} \mathbf{1}_{\text {employed }}\{i\} \text { weight }_{i}
$$


where $\theta_{i}$ individual productivity is

$$
\theta_{i}=w_{i}=\frac{1}{52} \frac{\text { AnnualIncome }_{i}}{\text { WeeklyHours }}
$$

More specifically, AnnualIncome ${ }_{i}$ is annual wage and salary income earned from an employer, WeeklyHour $s_{i}$ is usual weekly hours, and weight $t_{i}$ is the number of people in the U.S. person $i$ in the sample should represent in the population. I use 52 to obtain approximate annual hours since weeks worked is not available in the 2016 dataset. Table 4 lists variable names and descriptions used.

Table 4: Calibration of productivity efficiency profile

\begin{tabular}{llll}
\hline Variable & IPUMS name & description & value \\
\hline AnnualIncome $_{i}$ & incwage & annual salary and wages from an employer & $0-714,000$ \\
\hline \multirow{2}{*}{ WeeklyHours $_{i}$} & uhrswork & usual hours per week if employed last year & $0=\mathrm{N} / \mathrm{A}$ \\
& & & $99=99+$ \\
\hline \multirow{2}{*}{$i$} & empstat & employment status & $1=$ employed \\
& & & $2=$ unemployed \\
$\mathbf{1}_{\text {employed }}\left\{\begin{array}{l}\text { weight } \\
\text { w }\end{array}\right.$ & perwt & number of people represented by $i$ & $3=$ not in labor force \\
\hline
\end{tabular}

However, there are two issues I encounter if I were to directly use $\frac{\overline{w_{t}}}{\overline{w_{t-1}}}$ as my $\mu_{t}$ values; first, as age increases, representation in the sample and working share both decrease, leading to volatility in mean wage. Second, ACS is cross-sectional and cannot account for the theoretical prediction that those with lower wages retire earlier. To address these issues I instead use a regression approximation of $\mu_{t}$ while labor force participation is high and replace later years with extrapolations. First, I collapse the data set by age so there is one representative observation for each age, where all variables are the weighted averages across individuals of that age. Next I calculate $\frac{\overline{w_{t}}}{\bar{w}_{t-1}}$ and denote this $\tilde{w}_{t}$ and estimate the equation

$$
\tilde{w}=\beta_{0}+\beta_{1} a g e+\beta_{2} a g e^{2}+\beta_{3} a g e^{3}
$$

for ages where labor force participation is greater than or equal to $20 \%$ given the sample issues above, which turns out to be 70 and under. To obtain the empirical labor force participation rate and in particular the age when labor force participation reach 20\%, I use PSID data. I exclude those who report having retired then unretired to make it comparable with the permanent decision in the model and for simplicity. Figure 8 shows the empirical labor force participation 
rate and $20 \%$ cut-off

Labor Force Participation by Age

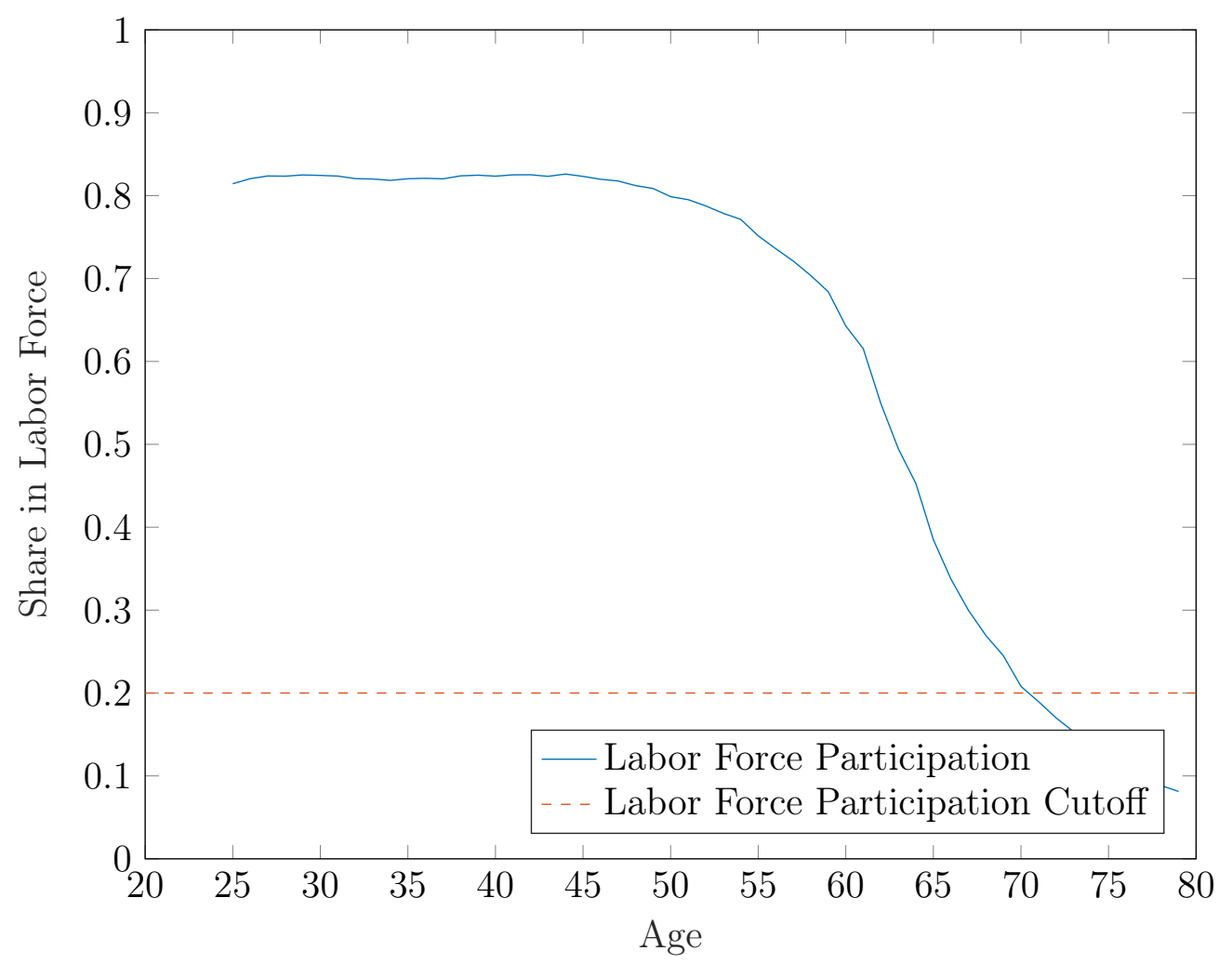

Figure 8: Empirical Labor Force Participation rate and 20\% cut-off.

Using the $\hat{\beta}$ coefficients I then calculate the fitted values $\hat{\mu}_{t}$ and use these fitted values for ages 71 to 79 and use the original calculated $\mu_{t}$ values for all earlier years. I run this regression without weights because $\mu_{t}$, not $\theta_{t}$ is the main parameter of interest. Also, I am solely interested in finding a baseline trend line with for productivity with respect to age instead of finding the best fit line for the entire population, which would weigh the middle of the distribution more. I use up to a cubic term because the path of $\tilde{w}_{t}$ has an inflection point. Using these, I use value $\overline{w_{25}}$ as a baseline and sequentially calculate the predicted values of $\overline{w_{t}}$ and plot these with the observed $w_{t}$ values below. Figure 9 shows the empirical and predicted efficiency profiles.

\section{Baseline Economy Numerical Algorithm}

I present the income fluctuation model in the baseline U.S. economy. In this economy, agents who face idiosyncratic productivity shocks, consume and save 
Mean Hourly Wage by Age, Empirical and Predicted

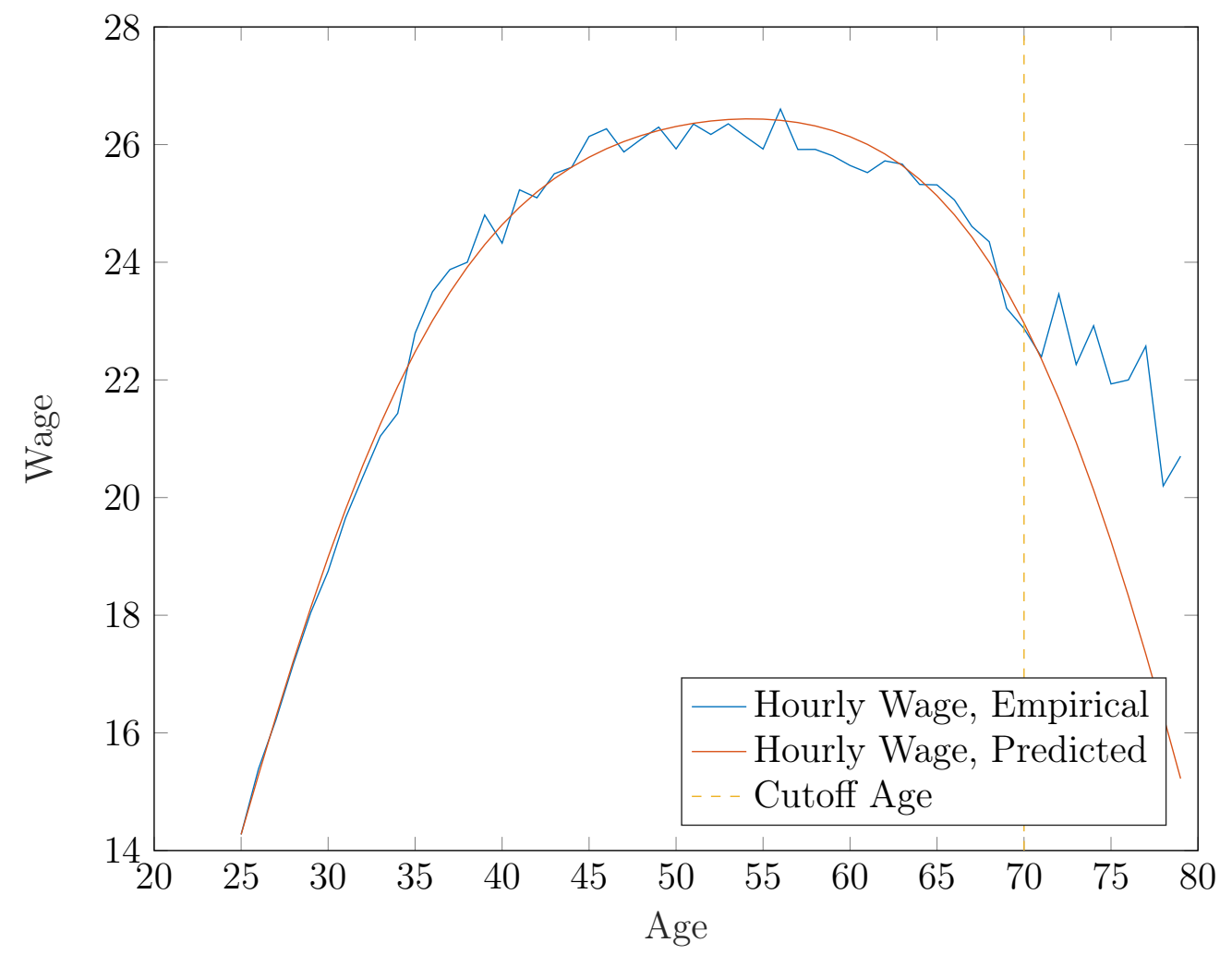

Figure 9: Efficiency Profile 
in a risk-free asset, choose their working hours and the age at which they retire. I define retirement as an irreversible exit of the labor force. I assume that the retirement age and the SS benefits claiming age are the same. Denote $s$ the last working period of an agent, i.e $s=t$ if the agent works at time $t$ and $s<t$ if the agent retired before $t$. The productivity $\theta_{t}$ represents current productivity if $s=t$ and last working productivity if $s<t, \theta_{t}=\theta_{s}$. With log utility, agents never hit their borrowing constraints because they consume at each period a constant fraction of their net worth. Denote $T\left(y_{t}\right)$ the Heathcote et al. (2014) income tax function and $b\left(\left\{y_{t^{\prime}}\right\}_{t^{\prime} \in[0, s]}, s\right)$ the SS benefits as a function of the history of earning and the retirement age. I make a Tauchen approximation of the productivity process $\theta_{t}=\theta_{t-1}^{\rho} \varepsilon_{t}$ where $\rho=0.999$ and denote the transition matrix $\pi$.

For a given asset level $a_{t}$ and productivity $\theta_{t}$, a working agent's continuation utility is

$$
\begin{gathered}
v_{t}\left(a_{t}, \theta_{t}, t\right)=\max _{c_{t}, y_{t}, a_{t+1}, s_{t+1}}\left\{\ln \left(c_{t}\right)-\frac{\kappa}{1+\frac{1}{\varepsilon}}\left(\frac{y_{t}}{\theta_{t}}\right)^{1+\frac{1}{\varepsilon}}-\phi(t)+\beta \sum_{\theta_{t+1} \mid \theta_{t}} V_{t+1}\left(a_{t+1}, \theta_{t+1}, s_{t+1}\right) \pi\left(\theta_{t+1} \mid \theta_{t}\right)\right\} \\
\text { s.t. } \quad c_{t}+\frac{q}{1-\tau^{K}} a_{t+1}=a_{t}+y_{t}-T\left(y_{t}\right) .
\end{gathered}
$$

For $s<t$, a retired agent's continuation utility is:

$$
\begin{aligned}
v\left(a_{t}, \theta_{t}, s\right) & =\max _{c_{t}, y_{t}, a_{t+1}}\left\{\ln \left(c_{t}\right)+\beta V_{t+1}\left(a_{t+1}, \theta_{t+1}, s\right)\right\} \\
\text { s.t. } \quad & c_{t}+\frac{q}{1-\tau^{K}} a_{t+1}=a_{t}+b\left(\left\{y_{t^{\prime}}\right\}_{t^{\prime} \in[0, s]}, s\right) .
\end{aligned}
$$

Then the intertemporal Euler equation holds, $\frac{1}{c_{t}}=\frac{\beta q}{1-\tau^{K}} \mathrm{E}\left[\frac{1}{c_{t+1}}\right]$ and for workers, the intratemporal equation holds $\kappa \frac{y_{t}^{1 / \varepsilon}}{\theta_{t}^{1+1 / \varepsilon}}=\frac{1}{c_{t}}\left(1-T^{\prime}\left(y_{t}\right)\right)$.

The algorithm follows these steps.

- Set $a_{T+1}=0, s_{T+1}=T$.

- For each $t$, if $s=t$ :

1. For given $a_{t+1}$ and $s_{t+1} \in\{t, t+1\}$ solve for $c_{t}$ using the Euler equation

2. Solve for $y_{t}$ using the intratemporal equation

3. Set $s_{t+1}$ to the work status that yields higher $v_{t}$

4. Solve for $a_{t}$ using the budget constraint of the workers, $c_{t}\left(a_{t+1}, s_{t+1}\right)$ and $y_{t}\left(a_{t+1}, s_{t+1}\right)$

5. Interpolate the policy functions for the missing values $a_{t}$ 
- For each $t$, if $s<t$ :

1. For given $a_{t+1}$ and $s_{t+1}=s$ solve for $c_{t}$ and $c_{s}$ using the Euler equation

2. Solve for $y_{s}$ using the intratemporal equation at time sand comput $b\left(\left\{y_{t^{\prime}}\right\}_{t^{\prime} \in[0, s]}, s\right)$ taking $\left\{y_{t^{\prime}}\right\}_{t^{\prime} \in[0, s]}=\left\{y_{s}\right\}$

3. Solve for $a_{t}$ using the budget constraint of the retired $c_{t}\left(a_{t+1}, s\right)$ and $y_{t}\left(a_{t+1}, s\right)$

4. Interpolate the policy functions for the missing values $a_{t}$

At the end of the algorithm I check that $\left|y\left(a_{t}, \theta_{t}, t\right)-y\left(a^{\prime}\left(a_{t}, \theta_{t}, t\right), \theta_{t+1}, t+1\right)\right|<\eta$ for some tolerance level $\eta$ to make sure that agents do not overwork just before retirement to validate the assumption in Step 2, when $s<t$.

\section{Alternative Calibration}

\subsection{Constant Fixed Cost}

For the specification with a constant fixed cost $\phi(t)=\phi$ over the life-cycle, the estimated fixed cost is the utility equivalent of 6.6 hours per day. The estimated dynamic elasticity at age 65 is very low (0.86) compared to the target of 1.05 . The left panel of Figure 10 plots the labor force participation rate as a function of age. For this specification, the average retirement age in the baseline economy is 66.49 years old while the optimal average retirement age is large and equal to 72.10 years old.

The model does not match well the elasticity of old workers when $\phi$ is constant and features an unusually high optimal average retirement age. The intuition is that with a constant fixed cost, the only force for an extensive Frisch elasticity of labor supply that increases with age is the decreasing option value of staying in the labor market. With the medium instantaneous variance of productivity of $\sigma_{M}^{2}=0.0095$, this option value is low and retirement region doe not evolve much over time.

The right panel of Figure 10 plots the average labor wedge for the general population and subpopulations of workers with a history of low productivity shocks and high productivity shocks respectively. The average labor wedge is humpshaped, increasing from $1.68 \%$ at age 25 to $46.97 \%$ at age 68 then decreasing to $33.80 \%$ at age 79 . 

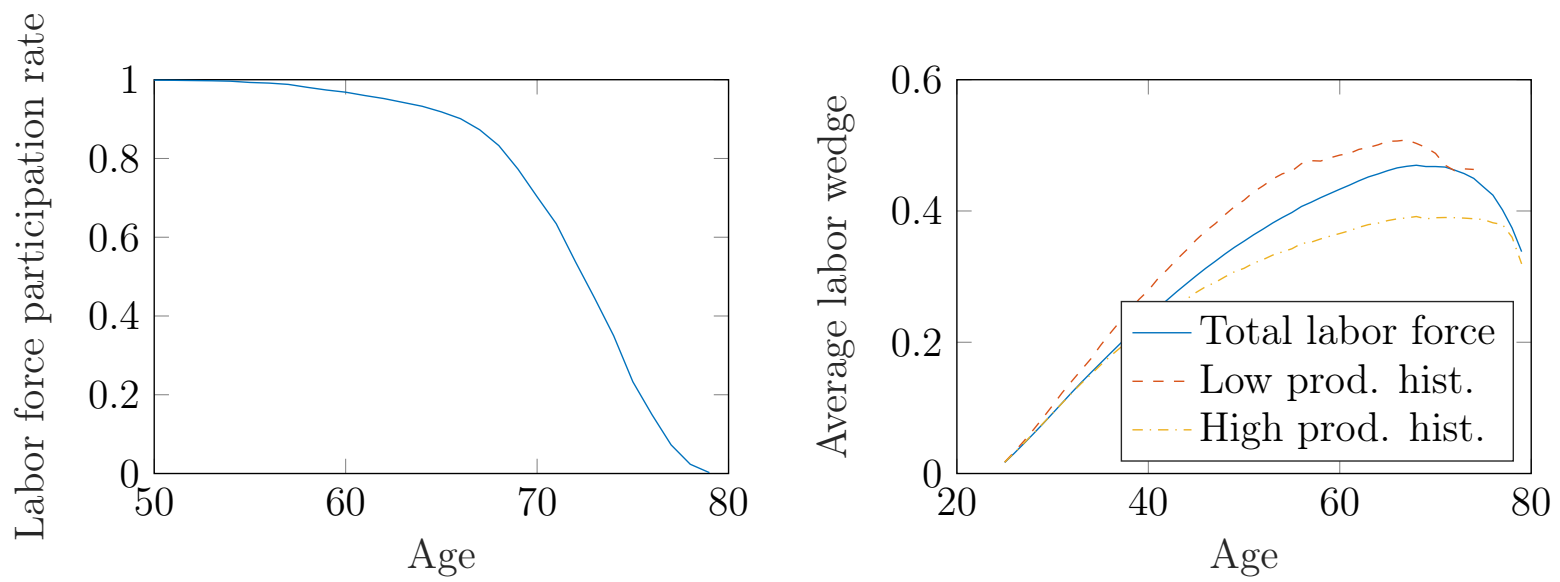

Figure 10: Left: Labor force participation rate as a function of age. Right: Average labor wedge as a function of age.

\subsection{Exogenous retirement}

Figure 11 plots the average labor in a model with exogenous retirement at $T=79$. With exogenous retirement, the average labor wedge is increasing-in-age despite the productivity profile being hump-shaped with age. The average labor wedge increases from $1.68 \%$ at age 25 to $48.35 \%$ at age 79 . This increasing profile reflects the fact that planner provides insurance against non-predictable shocks $\sigma d B_{t}$ to productivity through the labor wedge and the predictable shocks $\mu(t) d t$ through the capital wedge.

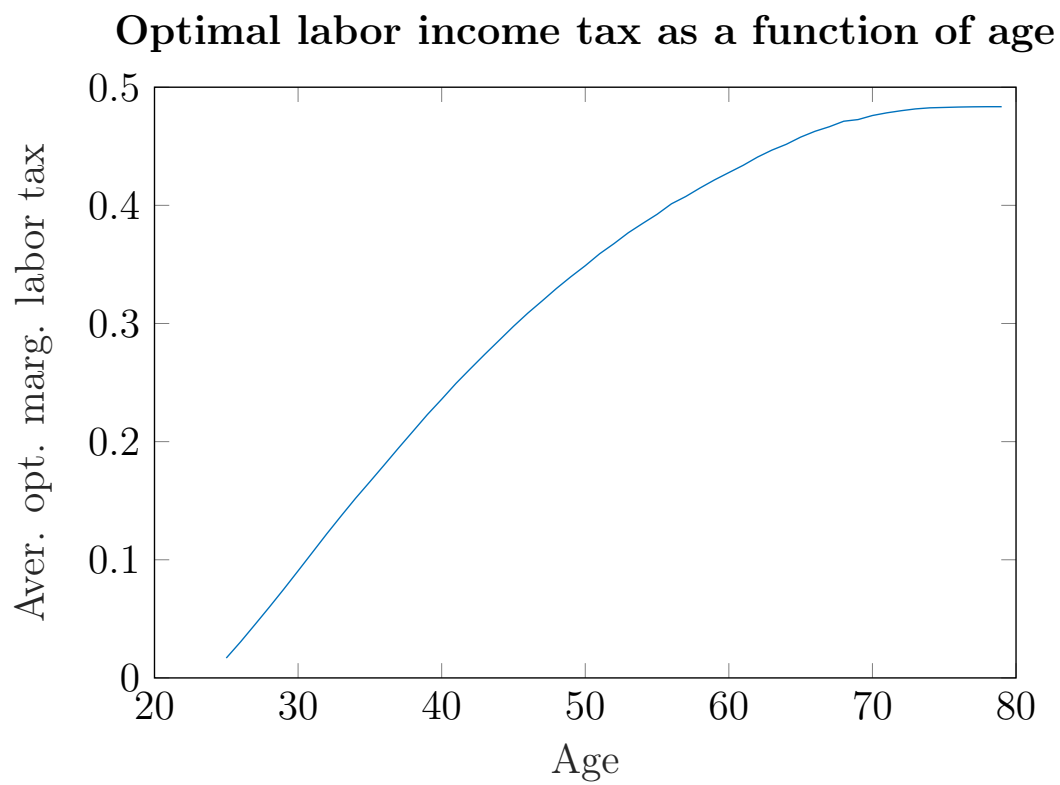

Figure 11: Labor wedge with exogenous retirement. 